\title{
Status of Thermal Imaging Technology as Applied to Conservation - Update 1
}

July 1980

Prepared for:

U.S. Department of Energy

Assistant Secretary for

Conservation and Solar Applications

Division of Buildings and Community Systems

Under Contract No. AC-01-78-CS-20413 


\section{DISCLAIMER}

This report was prepared as an account of work sponsored by an agency of the United States Government. Neither the United States Government nor any agency Thereof, nor any of their employees, makes any warranty, express or implied, or assumes any legal liability or responsibility for the accuracy, completeness, or usefulness of any information, apparatus, product, or process disclosed, or represents that its use would not infringe privately owned rights. Reference herein to any specific commercial product, process, or service by trade name, trademark, manufacturer, or otherwise does not necessarily constitute or imply its endorsement, recommendation, or favoring by the United States Government or any agency thereof. The views and opinions of authors expressed herein do not necessarily state or reflect those of the United States Government or any agency thereof. 


\section{DISCLAIMER}

Portions of this document may be illegible in electronic image products. Images are produced from the best available original document. 


\section{NOTICE}

This report was prepared as an account of work sponsored by the United States Government. Neither the United States nor the United States Department of Energy, nor any of their employees, makes any warranty, express or implied, or assumes any legal liability or responsibility for the accuracy, completeness, or usefulness of any information, apparatus, product, or process disclosed, or represents that its use would not infringe privately owned rights. Reference herein to any specific commercial product, process, or service by trade name, mark, manufacturer, or otherwise, does not necessarily constitute or imply its endorsement, recommendation, or favoring by the United States Government or any agency thereof. The views and opinions of authors expressed herein do not necessarily state or reflect those of the United States Government or any agency thereof. 
DOE/CS/20413-01

Dist. Category UC-95d

\section{Status of Thermal Imaging \\ Technology as Applied to \\ Conservation - Update 1}

July 1980

Prepared by:

DCS Corporation, Arlington, Va.

Frank J. Snow, JamesT. Wood,

Robert C. Barthle

Under Contract No. AC-01-78-CS-20413

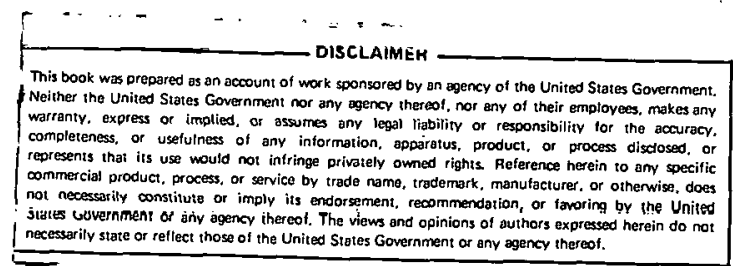

Prepared for:

\section{U.S. Department of Energy}

Assistant Secretary for

Conservation and Solar Applications

Division of Buildings and Community Systems

Washington,D.C. 20585 


\section{ACKNOWLEDGEMENT}

This document was developed for the U.S. Department of Energy. Its objective is to update the 1978 report on the status of thermal imaging technology as applied to conservation. The sponsor was Dr. Kurt W. Riegel, Chief, Technology and Consumer Products Branch of the Division of Buildings and Community Systems, Office of the Assistant Secretary for Conservation and Solar Applications. The study director was John J. Cuttica, Program Manager, Building Diagnostics Program. DCS Corporation wishes to express its appreciation to Dr. Kurt Riegel, Mr. Tohn Cuttica and Dr. George Courville of the same D.O.E. Office for their support and guidanie.

DCS also expresses its appreciation to Mr. Robert L. Boyd, Chairman of the ASHRAE Standard Project Committee (SPC $101 \mathrm{P}$ ) which is currently preparing a draft standard for the application of infrared sensing devices to building heat loss assessment, for permitting DCS to share in the valued judgments of his committee.

Information on the various equipments herein was obtained from manufacturers' standard product literature. Performance and cost data are intended to be representative only. Manufacturers should always be contacted for specific information. Endorsement of specific manufacturers is neither implied nor intended. Aerial and ground thermal survey services information and responses from aerial survey program sponsors are gratefully appreciated since some of it might have been withheld for proprietary or other reasons.

As might be expected with any new technology application area, there can be as much difficulty in finding the market as there can be in finding out if a needed product exists and who supplies it. Any omissions in this report should be attributed only to the above difficulty. A base of data beyond that received in time for incorporation in this report continues to develop and will be available for subsequent updates. 
SECTION

INTRODUCTION

$1 \quad$ AIRBORNE SURVEYS 3

b. Index and Description of Programs 6

c. Overview of Conducted Programs . 54

d. Companies That Provide Surveys r 61

e. Index of Available Equipment $\quad 67$

2 GROUND SURVEYS (THERMAL IMAGING/LINE SCANNERS) 69

a. Demonstrated Capabilities $\quad 70$

b. Companies That Provide Surveys , 71

c. Index of Available Equipment 144

3 GROUND SURVEYS (SPOT RADIOMETERS) 157

a. Demonstrated Capabilities 158

b. Companies That Provide Surveys 159

c. Index of Available Equipment '. 159

4 APPLICATION NEEDS 167

a. Standards - ASHRAE/ASTM 168

b. Environmental Effects on Data Collection 171

c. Building Material Characteristics 171

d. Concensus on Heat Loss Models 173

e. Inexpensive Instrumentation 173

f. Quantitative Measurements - "R" values 174

g. Public Awareness 175

5 INFRARED PROJECTS OF THE DOE BUILDING DIAGNOSTICS PROGRAM 
INDEX OF TABULATED DATA AND FIGURES

TITLE

PAGE

Cross Index of Aerial Survey Programs 9

- Control Number List of Survey Programs . 11

- Alphabetical List of Survey Program Sponsors 12

- Cross Reference by State _ . 13

- Cross Reference by Survey Category 14

- C.ross Reference by Aerial Survey Firm 14

Survcy Programs Summary List 15

Aerial Survey Program Descriptions $\quad 21$

Ground Thermographic Survey Firms $\quad 75$

Cross Index of Ground Thermographic Survey Firms $\quad 79$

- Control Number List of Ground Survey Firms 80

- Alphabetical List of Ground Survey Firms 81

- Cross Reference by State 82

Ground Survey Firm Data $\quad 83$

$\underline{\text { TABLES }}$

1 Residential Aerial Survey Sponsors 56

$2 \quad$ Industrial Aerial Survey Sponșors 57

3 Aerial Thermographic Survey Firms 62

4 Aerial Thermographic Scanner Systems 68

5 Portable Ground Thermal Survey Equipment 145

6. Spot Radiometers 160

FIGURE

Residential and Industrial Thermographic Surveys j5

$2 \quad$ Ground Thermal Survey Firms . 76 
This is the first update of the original thermal imaging applications assessment which covered the period ending December, 1978, and was published in May 1979. It is completely self contained in that it includes the material from the first report which emphasized aerial surveys. The new material includes an extensive presentation of information on the performance of ground infrared surveys as obtained from firms engaged in this relatively new area of energy audit service.

One of the major goals indicated in the National Energy Plan is to "bring 90 percent of existing American homes and all new buildings up to minimum energy efficiency standards" by 1985. While such standards are as yet undefined, it is nevertheless essential that all buildings be adequately insulated and sealed against air infiltration. The ability to determine the effectiveness of existing insulation, or to pinpoint areas where existing weather stripping, caulking and insulation is either totally lacking or insufficient in quantity, is an implicit requirement of this goal. Thermal imaging systems offer the potential for being a significant tool for making such thermal envelope measurements because of features which include non-destructive, non-contact and, in the case of aerial equipments, remote sensing over a substantial number of buildings at relatively low unit cost. This assessment report covers the application of both imaging and non-imaging infrared equipments in the performance of thermal surveys. The. purpose of this report is to provide a concise up-to-date status of the commercial availability and performance of infrared surveys for the detection of heat-loss in buildings.

This report update addresses, as previously, four areas of importance to thermal imaging technology as applied to conservation. These are the areas of:

- Airborne Surveys

- Ground Surveys (Thermal Imaging/Line Scanners)

- Ground Surveys (Spot Radiometers)

- Application Needs

Section 1, on Airborne Surveys, presents the results of the experiences of sponsors of aerial infrared residential programs which were conducted primarily by utilities and local governments. The primary goal of these programs was to develop an energy conservation consciousness on the part of homeowners. Goals of industrial 
aerial survey program sponsors were to locate and identify thermal fault conditions. This section also summarizes the capabilities of aerial infrared equipments currently used in such surveys and the firms providing services. The intent of this section is to provide a background of experience which can be useful to the planning and conducting of such energy conservation programs.

Section 2, on Ground Surveys, is a major expansion of the area of applying thermal imaging and line scanner equipments to provide thermal survey services to homeowners and industrial plant operators. Whereas the earlier assessment was limited to technical equipment features and improvement needs, this update incorporates the results of 30 survey firm responses. The larger number of responses obtained and the broader scope of information provided on the nature and extent of services results in a more complete insight into the present status of this new service industry. Section 3 is primarily a summary of the technical capabilities of spot radiometers used to supplement a thermal imager or line scanner in the conduct of a thermal survey or to provide a quality control device for checking local insulation.

The application needs of this new technology relative to energy conservation are summarized in Section 4. Applcation needs are the additional areas of research, analysis of standards development which directly effect the technology surrounding the use of IR as an effective tool in building heat loss diagnosis. First, they include the development of standards indicating minimum performance requirements for infrared equipments used for conducting thermal surveys and standards for acceptable survey procedures. Second, they include the further analytical and experimental work on the effect of the environment and the building structural details on the interpretation of thermal measurements. Finally, they include the determination of which of the many heat loss mathematical models available are best suited for economic energy conservation application. The above areas also include, as supporting efforts, the development of inexpensive instrumentation and the implementation of measures directed towards informing the public about this technology.

A brief summary of the activities of the Department of Energy Building Diagnostics Program relative to the application of infrared is included as Section 5. 
SECTION 1

AIRBORNE SURVEYS 
THIS PAGE

WAS INTENTIONALLY

LEFT BLANK 


\section{1 - AIRBORNE SUR VEYS}

Aerial thermographic surveys offer the potential of rapid large-area coverage, with resulting low per-building costs. Included in this section are a summary of the capabilities of equipments in current use, a compilation of responses obtained from organizations which have sponsored surveys and an index of available infrared équipment.

\section{a. Demonstrated Capabilities}

Airborne thermographic surveys are used to map variations in the apparent radiance of individual building rooftop surfaces. This is accomplished by flying a thermal imaging unit over the buildings in accordance with specified conditions. Hard copy thermograms are produced which, when correctly interpreted, enable the assessment of relative roof surface heat loss due to insulation defects or other causes. Aerial surveys are typically conducted using thermal infrared imaging line scanners. As the aircraft moves in straight line horizontal. flight, the scanner produces a one-dimensional repetitive scan line prependicular to the flight path, which in combination with the forward motion of the aircraft, generates the data needed to produce a two-dimensional image of the thermal radiation detected from the ground level scene. Operating at typical aircraft altitudes of 400 to 500 meters, aerial scanners have demonstrated a capability to provide thermal resolutions in the range of $0.1^{\circ} \mathrm{C}$ to $0.5^{\circ} \mathrm{C}$, with spatial resolutions of 2 milliradians or better. This corresponds to a ground spatial resolution of less than 3 feet. The techniques. which are currently employed in collecting and processing aerial thermal survey data are limited to the production of essentially qualitative results. Such results enable the Identification of apparent excessive heat loss through building rooftops but not the determination of actual insulation R-values. Residential building aerial surveys are generally conducted for the purpose of creating interest on the part of homeowners to correct gross deficiencies as well as establishing community conservation awareness. Industrial building surveys have the potential for providing more accurate results than residential surveys as there is generally a greater opportunity for ground truth cooperative measurement and recording of the building's interior and local environment. 


\section{b. Index and Description of Programs}

The compilation of programs which follows was taken from responses to a survey questionnaire sent to organizations identified as program sponsors by firms performing surveys and other sources. A particular program is categorized by the principal target of the sponsor and the survey data presentation.

This 1979 update incorporates the result of follow-up responses obtained from 7 of the 25 aerial survey sponsors originally (1978) responding and responses from 7 organizations whose experiences are reported here for the first time.

Since sponsor organizations generally have no previous experience with interpretation of thermograms or the quality of thermographlc data necessary to permlt some assessment of rooftop thermal loss conditions, they are dependent upon aerial survey firms for such guidance. Although this dependence is not causing problems in most cases, two of the survey sponsors did have some difficulty. One encountered a substantial delay in total program schedule and additional cost due to thermograms which the sponsor ultimately concluded were unsatisfactory. Circumstances did not permit reflying the survey in the necessary winter period for that year. Another sponsor, working with a different aerial survey firm, reporting having received too limited a period of training in thermographic data interpretation. This sponsor subsequently encountered difficulties in providing the needed skills to volunteer personnel who were to interpret thermograms for homeowners at the information dissemination centers. These experiences suggest the continued need for information on how to properly contract with aerial survey firms, and, if they are separate organizations, data interpretation firms.

All aerial surveys had several features in common, regardless of the surveying firm. Data was collected with an infrared line scanner at aircraft altitudes of approximately $400 \mathrm{~m}$ to $500 \mathrm{~m}$ above ground level. This seems to provide the best compromise between the thermal resolution, spatial resolution, and $\mathrm{V} / \mathrm{H}$ (aircraft velocity-to-height ratio) range of the scanner. Survey sponsors typically learned of the existence of aerial IR surveys and their potential from publications attendant to or descriptive of previous aerial surveys. As part of this assessment, the sponsors were asked to indicate two survey program cost factors, l.e., the cost-perbuilding, determined by dividing the cost of obtaining the aerial survey data by the 
number of buildings 'in the surveyed area; and the cost-per-thermogram viewer, obtained by dividing the cost of the total effort (aerial data acquisition and information dissemination program costs) by the number of homeowners who came to view thermograms. In those cases where sponsors had only aerial data cost available to arrive at a cost-per-viewer figure, this has been reported in the particular, survey program description. Costs for residential aerial surveys averaged approximately $\$ 0.41$ per home, with an average of $29.8 \%$ of surveyed homeowners viewing their thermograms during the data dissemination phase. Central distribution centers were utilized by all residential survey sponsors responding; but in major metropolitan areas, supplementing of these centers with community group meetings, mobile viewing vans, energy fairs and similar activities was necessary to maintain high viewing percentages. Opinions as to the usefulness of a "sponsor's manual" were equally divided. Ninety-four percent of residential survey sponsors had their thermogram interpreters trained by the surveying firm. Thirty-five percent indicated plans for a follow-up flyover of their areas.

All of the sponsors indicated general satisfaction with the thermal data obtained as far as contributing to their overall goals. One company indicated that data was sufficient for their steamline survey, but rooftop information was inadequate. Three of the sponsors of the larger survey programs which required multiple dissemination centers for area coverage indicated that the turnout of viewers was to some extent dependent on the quality of thermograms obtained. This would indicate that some minimum data quality level exists for successful programs.

A recurring problem with aerial survey programs conducted has been the lack of continuing interest in thermogram .viewing. All have reported an initial spurt of viewing which later quickly declined. Greater emphasis on effective dissemination programs in the planning stages could probably extend the attention span of the community.

Program sponsor response information is presented in the following sequence:

- Cross Index of Aerial Survey Programs

- Survey Programs Summary List

- Survey Program Descriptions 


\section{THIS PAGE}

\section{WAS INTENTIONALLY \\ LEFT BLANK}




\section{CROSS INDEX OF AERIAL SURVEY PROGRAMS}




\section{THIS PAGE \\ WAS INTENTIONALLY \\ LEFT BLANK}


1. Cedar Falls Utilities

2. Iowa Public Service Company

3. Iowa Utility Association

4. University of Iowa

5. Quaker Oats Company

6. Lafayette Utilities System

7. Great Falls Gas Company

8. Cengas Division of Minnesota Gas Company

9. Kansas-Nebraska Natural Gas Company

10. Metropolitan Utilities District

11. Minnesota Energy Agency

12. Consolidated Edison of New York

13. Brookhaven National Laboratory

14. Cornell University

15. State University of New York

16. Tompkins Cortland Community College

17. Grand River Dam Authority

18. Northwestern Public Service Company

19. Tennessee Energy Agency

20. City of Garland

21. Seattle City Light

22. Washington Water Power Company

23. Northern States Power Company

24. Northern Utility Incorporated

25. Arizona Department of Revenue

26. Hotchkiss School

27. St. Clair County

28. City of Texarkana

29. National Naval Medical Center (U.S. Navy)

30. Naval Research Laboratory (U.S. Navy)

31. Washington Navy Yard

32. New Mexico State Energy and Minerals Department 


\section{ALPHABETICAL LIST OF SURVEY PROGRAM SPONSORS}

Program Sponsor

Control Number

Arizona Department of Revenue

Brookhaven National Laboratory

Cedar Falls Utility

Cengas Division of Minnesota Gas Company · 8

City of Garland $\quad 20$

City of Texarkana $\quad 28$

Consolidated Edison of New York 12

Cornell University 14

Grand River Dam Authority 17

Great Falls gas Company $\quad$ ?

Hotchkiss School $\quad 26$

Iowa Public Service Company 2

Iowa Utility Association 3

Kansas - Nebraska Natural Gas Company 9

Lafayette Utilities System $\quad$. $\quad 6$

Metropolitan Utilities System $\quad \cdot 10$

Minnesota Energy Agency 11

National Naval Medical Center $\quad 29$

Naval Research Laboratory $\quad 30$

New Mexico Stated Energy and Minerals Department 32

Northern States Power Company $\quad 23$

Northern Utilities Incorporated $\quad 24$

Northwestern Public Service Company . 18

Quaker Oats Company . 5

Seattle City Lights $\quad 21$

St. Clair County $\quad 27$

State University of New York 15

Tennessee Energy Agency _ . . $\quad 19$

Tompkins Cortlandt Community College 16

University of lowa 4

Washington Navy Yard , 31

Washington Water Power Company 22, 


\section{CROSS REFERENCE BY STATE}

STATE

Arizona

Connecticut

Illinois

lowa

Louisiana

Montana

Nebraska

Maryland

Minnesota

New Mexico

New York

Oklahoma

South Dakota

Tennessee

Texas

Washington

Washington, D.C.

Wisconsin

Wyoming
CONTROL NUMBER

25

26

27

$1,2,3,4,5$

6

7

$8,9,10$

29

11

32

$12,13,14,15,16$

17

18

19

20,28

21,22

30,31

23

24 


\section{CROSS REFERENCE BY SUR VEY CATEGORY}

\section{SURVEY CATEGORY}

Residential

Industrial

Institutional

\section{CONTROL NUMBER}

$1,2,3,6,7,8,9,10,11,12,17,18,19,20$,

$21,22,23,24,25,27,28,32$

5,31

$4,13,14,15,16,26,29,30$

\section{CROSS REFERENCE BY AERIAL SURVEY FIRM}

\section{AERIAL SURVEY FIRM}

Ames Research Center

Bendix Aerospace System

Daedalus Enterprises

Earth Satellite Corporation

Mead Technology Laboratory

Remote Sensing Institute

Texas Instruments

\section{CONTROL NUMBER}

32

25

$4,5,13,14,15,16,26,29,31$

30

11

$1,7,8,9,18,22,23,24$

$2,3,6,10,12,17,19,20,21,27,28$ 
SUR VEY PROGRAMS SUMMARY LIST

, 


\section{SUR VEY PROGRAMS SUMMARY LIST}

\section{CTL\# TYPE}

$1 \quad$ Cedar Falls Utilities w/Iowa Public Service Cedar Falls, IA

Iowa Public Service Company Sioux City, IA

3 Iowa Utility Association

All incorpo:ated areas in

State $(900 \pm$ communities $)$

University of Iowa

Iowa City, IA

450 acres

5 Quaker Oats Company

Cedar Rapids, IA

๘

$100 \pm$ acres

6 Department of Utilities

Lafayette, LA

7

Great Falls Gas Company

8

Cengas Division of Minnesota

Gas Company

Lincoln, NE

5 Communities

9

Kansas-Nebraska Natural

Gas Company

Hastings, NE

30 square miles

10
SURVEY

Residential

Residential

Residential

Institutional

Industrial

Residential

Residential

Residential

Residential

Residential
Daedulus

\section{FIRM}

Remote Sensing

Texas Instruments

Texas Instruments

Daedulus

Texas Instruments

Remote Sensing

Remote Sensing

Remote Sensing

Texas Instruments

\section{$\underline{\cos T}$}

$\$ 0.58$ per house

$\$ 0.55$ per house

$\$ 0.50-\$ 0.55$ per house

$\$ 6,000$ total cost

$\$ 39$ per acre

$\$ 0.29$ per house $(\$ 8,200$ total cost)

$\$ 0.50$ per house

$\$ 0.21$ per house

$\$ 1.00$ per customer

$\$ 0.48$ per customer \$10K TI, \$47K labor) 


\section{SURVEY PROGRAMS SUMMARY LIST}

\section{CTL \# TYPE}

11 Minnesota Energy Agency

State of Minnesota

12

Con Edison

New York, NY

13

Brookhaven National Laboratory

Ur:ton, NY

465 acres

230 buildings

14

Cornell University

Ithaca, NY

4 square miles ( 2560 acres)

400 buildings

15 State University of New York

Albany, NY

for 10 campuses ( 150 acres)

16

Tompkins-Cortland Community

College

Dryden, NY

6 acres

Grand River Dam Authority

60 square miles

NE Oklahoma

(13 municipalities)

\section{SUR VEY}

Residential

Residential

Institutional

(w/follow-on

ground survey)

Institutional

(w/follow-on

building side-

wall survey)

Institutional

Institutional

Residential

Residential

Brookings, SD

4 square miles

\section{FIRM}

Mead Tech

(Honeywell prototype equipment)

Texas Instruments

Daedulus

Daedulus

Daedulus

Daedulus

Texas Instruments

$\$ 0.33$ per house $(\$ 27 ; 400$ total cost)

$\$ 3,830.00$ (est. $\$ 0.45$

\section{$\operatorname{cosT}$}

$\$ 0.46$ per house

$\$ 0.08$ per house

Aerial: \$14/acre

Ground: $\$ 39 /$ Building

(2) Aerial: \$15/acre

Grol'nd: \$25/Building

$\$ 3900.00$ first 150 acres, $\$ 700.00$ additional 100 acres

$\$ 500$ total cost

Remote Sensing

\author{
- per house)
}




\section{SURVEY PROGRAMS SUMMARY LIST}

\section{CTL\# TYPE}

19 Tennessee Energy. Authority Nashville, TN

561 square miles

20

City of Garland

Garland, TX

50 square miles

21 Seattle City Light

Seattle, WA

131 square miles

Washington Water Power Co. Spokane, WA

$100 \pm$ square miles

23

$\stackrel{+\infty}{\infty}$

Northern States Power Co.

Eau Claire, WI

4 communities

24

Northern Utilities, Inc.

Casper, WY

Casper-Laramie

Riverton-Lander-Rawlings

25

Arizona Department Revenue

Phoenix, Arizona

26

Hotchkiss School

Lakeville, Connecticut

27

\section{SURVEY}

Residential

Residential

Residential

Residential

Residential

Residential

Residential

Institutional

Residential

Belleville, dlinois

\section{FIRM}

Texas Instruments

Texas Instruments

Remote Sensing

Remote Sensing

Remote Sensing

Bendix Aerospace

Daedalus

Texas Instruments
$\$ 0.12$ per building

$\$ 0.065$ per house

$\$ 120$ per square mile

Not furnished

\section{COST}

$\$ 0.46$ per house

$\$ 0.43$ per house

$\$ 0.65$ per house

$\$ 29,000$ total cost $\$ 83.00$ per square mile $\$ 4,290.00$ total cost
$\$ 91$ per building

$\$ 30,000.00$ for survey data $\$ 25,000.00$ info program $\$ 0.30$ per house 


\section{SURVEY PROGRAMS SUMMARY LIST}

\section{CTL\# TYPE}

28

\section{City of Texarkana}

Texarkana, Texas

29

National Naval Medical Center

U.S. Navy

Bethesda, Maryland

31)

Naval Research Laboratory

U.S. Navy

Washington, D.C.

31 Washington Navy Yard

U.S. Navy

Washington, D.C.

Nèw. Mexico State Energy. and Minerals Departrnent

(Farmington, New Mexico, Survey Program)

\section{SURVEY}

Residential

Institutional

Institutional

Industrial

Residential

Demonstration

Program
Earth Satellite

\section{FIRM}

Texas Instruments

Daedalus

Daedalus

Ames Research

\section{$\cos T$}

$\$ 4,677.00$ for survey data $\$ 0.35$ per house

$\$ 6,400.00$ total cost $\$ 26.00$ per acre

$\$ 12,735.00$ total cost $\$ 37.00$ per acre

$\$ 6,090.00$ total cost $\$ 45.00$ per acre

$\$ 20.000 .00$ for survey data $\$ 45,000.00$ for info progra!n 


\section{THIS PAGE \\ WAS INTENTIONALLY \\ LEFT BLANK}


AERIAL SURVEY PROGRAM DESCRIPTIONS 
SPONSOR: Cedar Falls Utilities

No. 1

Cedar Falls, lowa

SURVEY LOCATION: Metropolitan Cedar Falls area (4X7 miles)

SUR VEY FLIGHT: December, 1976

The Cedar Falls Utilities Co, in cooperation with lowa Pubic Service Co., contracted with Remote Sensing Institute (RSI) for a residential aerial survey of its 13,000 customers at a cost for RSI services of $\$ 7500.00$ or $58 \xi$ per customer. Information was disseminated at company offices by utility employees informally trained to interpret thermograms by RSI. Publicity included TV coverage, direct mail, and newsletter. Representatives of the insulation industry, construction, and the financial community were encouraged to be present. To date $48 \%$ of homeowners have viewed thermograms, with 58\% of those coming in within 1 month after thermograms were made available, and $42 \%$ of those viewing indicated plans to add insulation.

Sponsors felt that the survey was very worthwhile, did a better job at showing insulation performance than visual inspection and considered the thermograms excellent. They are planning a follow-up aerial survey and noted that a DOE manual on thermography from airborne platforms would have been a great asset to the success of their program. They became aware of IR surveys initially through publicizing of Lincoln, NE survey results in trade journals. The survey cost per thermogram viewer was $\$ 1.21$. 
SPONSOR: lowa Public Service Company

No. 2

Sioux City, lowa

SURVEY LOCATION: All $200 \pm$ Incorporated Communities Serviced by IPSC.

SURVEY FLIGHT: December, 1977

The Iowa Public Service Co., in conjunction with Iowa Utility Association, contracted with Texas Instruments (TI) for an aerial survey of all incorporated areas within the state at a cost of approximately 55\% per customer. Information was disseminated at local utility offices, areas meetings, or mobile centers. ("Thermovans") by utility employees trained to interpret thermograms by TI. Continuous media coverage and direct mail campaigns kept awareness of the program at a high level. The insulation industry was invited to be present at centers. Approximately $30 \%$ of homeowners have seen the thermograms to date, with $40 \%$ of those upgrading insulation.

Sponsors felt that the program was superb and the resolution of thermograms was good. Some minor technical problems in data gathering were overcome. Their program success fostered "Operation Sky-Scan", a survey program for the entire state of lowa sponsored by lowa Utility Association. They did not feel that a DOE manual would have been helpful in conducting the program. They did feel that the market for IR surveys is expanding, and were planning for a resurvey of their area. Survey cost per thermogram viewer was $\$ 1.83$. 
SURVEY LOCATION: State of lowa $-900 \pm$ incorporated communities.

SURVEY FLIGHT: December, 1977

The Iowa Utility Association contracted with Texas Instruments (TI) for aerial IR surveys of the entire state's incorporated communities (Operation Sky Scan) at a cost for TI's services of approximately 50\& per building. Thermographic information was disseminated through local utility company offices and shopping center locations by utility employees trained by TI in thermogram interpretation. The publicity campaign began with a joint press conference with the Governor's office, and continued with the use of media notices to keep awareness high. Approximately $40 \%$ of the utility customers viewed thermograms, but in some communities over $75 \%$ have seen them. IUA's informal surveys indicated that a large percentage of viewers took some remedial insulation/weatherization actions.

Sponsors believed that the program was well run and the resolution of thermograms was sufficient for their purposes. They felt the market for IR surveys was expanding, and did not believe a DOE manual would have much value in such a program, preferring to rely on the expertise of the surveying firm. The Federal role should, in their opinion, be confined to recognizing qualified firms in this field. Survey cost per thermogram viewer was $\$ 1.25$. 
SPONSOR: University of lowa

No. 4

Iowa City, Iowa

SURVEY LOCATION: U.I. Main Campus (Steam Distribution System, Buildings,etc.)

SURVEY FLIGHT:. February, 1977

The University of lowa contracted with Daedalus Enterprises for a survey of the main campus roofs and grounds, approximately 450 acres of coverage, for a cost of $\$ 6,000$ ( $\$ 3900$ for first 150 ac., $\$ 700$ for each additional 100 ac.). Thermogram information was used to locate and repair steam leaks, electrical problems, and building insulation deficiencies. The material was also featured by local media and displayed for the public by utility companies and the university to enhance public conservation awareness.

Sponsors felt that the service was cost-effective and were planning to have a follow-up survey this fall. Minor residual solar loading was still evident in some thermograms, but this will be avoided next time by an early AM flight. They believed that a DOE manual would be useful for a firm interested in seeing what is available and what results can be realistically expected from an IR survey. They learned of aerial IR surveys from a trade journal article. The thermal survey program was thought to have provided benefits by indicating the merits of initiating a building roof insulation upgrading program and justifying the associated capital expenditures. A second survey, originally scheduled for last Fall (1978) but cancelled due to bad weather conditions, is to be conducted in the Fall-Winter period of 1979-1980. 
SPONSOR: Quaker Oats Company

No. 5

Cedar Rapids, lowa

SURVEY LOCATION: 100 acres of Quaker's facilities

SURVEY FLIGHT: March, 1977

The Quaker Oats Co. contracted with Daedalus Enterprises for a survey of its steam distribution system at a cost of $\$ 3900$ for 100 acres of coverage. Thermograms were used to locate leaks and expansion devices in the steam distribution system for the plant and were not publicized. Rooftop information collected was considered to be insufficient.

Sponsors were satisfied that the results met their primary goal, but desired more definitive thermal radiation information for rooftop evaluations of individual plant. buildings. They did not feel that a DOE manual would have been of assistance to them. They became aware of aerial IR surveys through articles in technical publications. 
SURVEY LOCATION: Lafayette, LA: 25 square miles

SURVEY FLIGHT: February, 1978

Lafayette Utilities contracted with Texas Instruments for a residential survey of their service area within the city limits of Lafayette, i.e., about 25 square miles. Approximately 30,000 buildings, predominantly residential with some commercial types were included in the area surveyed. The survey flights took place in February 1978 and the dissemination of results to homeowners was accomplished during the period May thru July of the same year. The estimated total cost of obtaining aerial survey, data was $\$ 8,500$ with a total cost of $\$ 4,000$ for the information dissemination phase of the program.

The purpose of the program was, in the sponsor's order of priority: to develop public awareness of energy conservation measures, encourage the addition of insulation to houses, and to develop good energy-oriented public relations. It was estimated that the program average cost-per-building of the survey was only 42 cents and cost-per-thermogram viewer only 16\%. The sponsor initially learned of the survey technique at a seminar sponsored by the American Public Power Association. A variety of publicity elements were used to develop public interest in visiting the data distribution centers. These included the use of radio, TV, posters and a newsletter delivered to all utility customers. The policy followed at the centers was to exclude the participation of any local bank or insulation sales representatives. Training of information center personnel was provided by Texas Instruments. The additional use of daytime aerial photographs to aid in the location of homes on thermograms was considered unnecessary. The sponsor's overall assessment of this project was that no major problems had been encountered and that it was probably the single most important and well received project that their conservation office had ever done. 
SPONSOR: Great Falls Gas Co.

SURVEY LOCATION: Great Falls, MT. (15 square miles)

SURVEY FLIGHT: March, 1978

The Great Falls Gas Company Company contracted with the Remote Sensing Institute at Brookings, South Dakota to perform an aerial infrared survey covering the metropolitan section of Great Falls, Montana. This section was estimated to include 23,000 residential units and 1,900 commercial, light industrial and public buildings. The aerial survey took place in March 1978 and the dissemination of resultant information in August, 1978. Aerial survey data was obtained at an estimated cost of $\$ 10,000$ and the dissemination part of the program at a cost of approximately $\$ 3,000$ to $\$ 4,000$. An assessment of the completed program indicated a per-building-cost of about $50 \xi$ and a per-thermogram viewer cost of $\$ 1.00$. A utility office display has been up from August 1978 to the present time. Utility personnel provided the only local company representation at the data centers. An individual was hired to provide training to center personnel. Good homeowner response to the thermal survey project was evidenced by the fact that approximately 10,000 people, almost $50 \%$ of consumers surveyed, visited the centers. As a result of conducting the program, certain improvement features were identified. These included the development of better record keeping, i.e., names of viewers, their addresses, their comments; and the use of a follow-up survey to determine how many responding homeowners actually used the information provided to insulate or otherwise upgrade their homes. Additionally, the purchase of a hand-held viewer with camera attachment was being investigated to provide consumers with individual dwelling thermograms. The quality or validity of aerial thermograms was limited to the extent that a significant portion of the city has heavy forestation, so that some houses were partially or completely "whited out" by the thermal effects of trees, and that some commercial buildings and mobile homes have metal roofs, thus causing misleading data interpretation. Because of the overall good results obtained with the program, some form of infra red survey project will be continued. 
SPONSOR: Cengas Div. of Minnesota Gas Co.

No. 8

Lincoln, Nebraska

SURVEY LOCATION: Lincoln, NE vicinity

SURVEY FLIGHT: February, 1975 and November, 1978

The aerial thermal survey program of Cengas Division of Minnesota Gas Company is one of the more extensive programs of its kind. Starting with the initial conduct of survey flights by the Remote Sensing Institute (RSI) in February, 1975 and the conduct of an information dissemination effort in June, 1975, this organization has maintained an active interest in such projects. A more recent flight survey was performed by Texas Instruments (TI) in November, 1978, with data dissemination done in January 1979. Future survey flights are planned. Five communities, with a total current population of 280,000 were included in the earlier project. Two communities, population total of 4000 , were covered in the later survey. The sponsor has contracted to have 22 additional communities surveyed as part of its current program. The average program cost per-building for the information dissemination phase was 20 cents. The technique used to distribute survey results information was to set up thermal scanning centers in the appliance merchandising areas of each of the communities surveyed and discuss with each visiting property owner the data for his building or home. Local company personnel were present at the scanning centers to assist interested homeowners. Training of center personnel was developed and conducted by the sponsor. Center personnel were also provided basic insulation training by industry representatives. Homeowners identified their homes on a large sectorized map of the city. The appropriate sector thermogram was then taken from a file and the specific house identified. Further public interest was developed by taking thermograms to several neighborhood associations and explaining their interpretation. Response to the program has been very good. As of June, $1979,53.7 \%$ or 52,603 people have visited the centers. Of this number, $40 \%$ used the information to insulate or upgrade their homes. Expected program benefits include a high degree of conservation effort by utility customers and good public relations. 
SPONSOR: Kansas-Nebraska Natural Gas Co., Inc.

No. 9 Hastings, Nebraska

SURVEY LOCATION: 30 square miles around Hastings, NE

SURVEY FLIGHT: March, 1976

The Kansas-Nebraska Natural Gas Co. contracted with Remote Sensing Institute (RSI) for a residential aerial survey of its customers in a 30 square mile area at a cost of approximately $\$ 1.00$ per customer for RSI services. Thermogram information was disseminated to homeowners at a central distribution office staffed by utility employees trained by RSI. Local insulation industry and peripherals were also invited. Publicity emphasized media coverage, and produced approximately $35 \%$ of total customers to view their thermograms. About $10 \%$ (K-N NGC estimate) have upgraded insulation as a result.

Sponsors felt that the program was successful from a public relations standpoint, but were disappointed that more people did not improve their buildings after viewing thermograms and that customers lost interest very fast after an initial surge of viewings. They did not feel that a DOE manual would have assisted in the conduct of the program. They expressed a desire for better spatial and thermal resolution in the prints. Sponsors learned about aerial IR surveys from other utility companies. Survey cost per thermogram viewer was $\$ 2.85$. A new survey contract was executed this past winter (78-79) with Texas Instruments to conduct a thermal scan in the towns of McCook and Holdrege, Nebraska and Colby, Kansas. (Approximately 7,500 customers total). However, weather conditions were such that it was not possible to properly conduct the survey. The contract was extended and the surveys will be conducted this winter (1979-1980) when weather conditions permit. 
SPONSOR: Metropolitan Utilities District

No. 10

Omaha, Nebraska

SURVEY LOCATION: Omaha, NE (90 square miles)

SURVEY FLIGHT: February, 1977

The Metropolitan Utilities District of Omaha contracted with Texas Instruments (TI) for a residential aerial survey of 120,000 customers in a 90 square mile area at a cost of $\$ 10,000$ for $\mathrm{TI}$ services (includes prints) and $\$ 47,000$ for distribution labor, or $48 \xi$ per customer. Thermogram information was disseminated at company offices and at shopping centers and community group meetings by TI-trained utility employees. The publicity campaign included public service announcements, annotation of monthly bills and direct mail pieces included with bills to control the pattern of viewing. Samples of insulation illustrating $R$-values and a list of installers were shown at the dissemination center. Twenty-eight percent of customers had viewed thermograms to date, and early indications were that many of those were taking corrective actions.

Sponsors indicated good PR value to company and image. Thermogram resolution was very good. Results were outstanding and equipment was more than adequate for the task. They felt that a DOE manual would have been helpful. They learned about aerial IR surveys from publicity surrounding the Cengas-sponsored survey in Lincoln, NE. Survey cost per thermogram viewer was $\$ 1.71$. 
SPONSOR: Minnesota Energy Agency

No. 11

SURVEY LOCATION: State of Minnesota (27 Communities)

SURVEY FLIGHT: December, 1976

The Minnesota Energy Agency had contracted with Mead Technology for an aerial residential survey of 27 communities covering 444,852 residences at a total cost of $46 \xi$ per residence for the flight, processing and dissemination of data. Eighteen percent of the total had improved thelr resldences' insulation as a direct result of viewing the thermograms. Significantly more viewed them. Data had been disseminated at central points in the communities. The insulation industry had not been invited, except at one center as a test program. MEA provided press releases at flyover times and before. Local centers re-established publicity as they prepared to open 60 days later. EPA and MEA trained the center thermogram interpreters.

The sponsor indicated a general satisfaction with the results of the survey and conservation interest generated by it, but had some reservations about imagery in light of later investigations. In general, when the film was good, the homeowner response was excellent. Ten percent of surveyed communities requested follow-up flyovers to verify improvements in homes. MEA and RSI have developed the Aerial IR Users Manual based on these experiences. MEA felt that IR surveys have a definite place in energy conservation programs both as an attention-arouser and as a potential loss locator. 
SPONSOR: Consolidated Edison of New York

No. 12

New York, NY

SURVEY LOCATION: Queens, Westchester - 72 square miles

SURVEY FLIGHT: March, 1978

Consolidated Edison contracted with Texas Instruments for an aerial survey of 142,000 homes in the Borough of Queens and in Westchester (72 square miles) at a survey cost of $\$ 11,000$ or $8 \xi$ per house. Dissemination centers were being operated by TI trained utility employees. A market survey was conducted prior to opening the centers to determine the best operating hours to encourage homeowner turnout. To date approximately $10 \%$ of residents had viewed their thermograms, and $6 \%$ had taken follow-up action in terms of Con Ed's total energy audit of the house.

Sponsor indicated tremendous PR value for conservation measures as a primary result. Data on resulting insulation/weatherization upgrading was not yet available. The program manager indicated plans to survey the balance of their heating service area, with possible future surveys of entire service area. He felt that investigation of "calibrated" thermograms and emissivity determinations were needed to refine the survey data obtained. He was satisfied with TI's preparation manual and did not feel a need for a DOE manual. Initial awareness of aerial IR survey came from publicity surrounding the lowa Public Service Company survey. 
SPONSOR: Brookhaven National Laboratory

No. 13

$$
\text { Upton, New York }
$$

SURVEY LOCATION: Upton, New York

SURVEY FLIGHT: November, 1976

Brookhaven National Laboratory (BNL) contracted with Daedalus Enterprises for an aerial survey of 465 acres of its facilities and a ground survey of 230 buildings at a cost of $\$ 14.00$ per acre and $\$ 39.00$ per building. The aerial survey was intended to detect leaks in buried steam lines and provide data on relative energy losses from rooftops. Results were satisfactory and deemed a relatively inexpensive and efficient means of achieving the goals.

Sponsors felt that the survey was an excellent means of obtaining qualitative data on energy losses. They have purchased a thermal imager for use in a continuing program of energy loss prevention. In terms of energy savings attributable to correction of survey-identified losses, they were extremely cost-effective. BNL felt that the market for IR surveys is expanding. They learned of the potential of IR surveys from a Daedalus presentation at ERDA's. Energy Symposium. BNL felt that a DOE manual would be useful to those contemplating surveys. 
SPONSOR: Cornell University

No. 14

Ithaca, New York

\section{SURVEY LOCATION: Cornell Campus}

\section{SURVEY FLIGHT: November, 1976}

Cornell University contracted with Daedalus Enterprises for an aerial survey of 4 square miles of its facilities and a ground survey of 400 buildings at a cost of $\$ 15.00$ per acre and $\$ 25.00$ per building. Goals of the aerial survey were identification of steam distribution system leaks or insulation faults and location of potential insulation faults in buildings. The sponsors felt the survey results were more helpful with the steam system than they were in rooftop insulation evaluation. They indicated that the multiple errors induced by other variables caused the rooftop results to be less valuable. Data was presented in aerial photo, continous tone analog image and DIGICOLOR image formats. Data was not publicly disseminated, but was used in the survey firm's promotional material. A follow-up aerial scan several months later confirmed the repairs made as a result of the first survey, and identified further repairs needed. Sponsors felt that the surveys were cost effective. They questioned the value of the aerial survey to homeowners, indicating that visual inspection 'of an attic is much easier. The sponsors became aware of aerial IR surveys from a magazine article. 
SPONSOR: State University of New York

No. 15

Albany, New York

SURVEY LOCATION: Ten campuses of S.U.N.Y

SURVEY FLIGHT: November, 1976

The State University of New York contracted with Daedalus Enterprises for an aerial survey of 150 developed acres on ten campuses of the University for a cost of $\$ 3900$. The survey results indicated several correctable energy losses, but costbenefit study has not yet been completed. University staff personnel were trained in data interpretation by Daedalus. Resolution was considered sufficient for survey goals. Sponsors considered the program very good, expeditiously handled, and were planning to survey 16 additional campuses. They believe that the aerial survey market is expanding, but did not feel that a DOE manual would have been helpful. The University officials learned about aerial surveys from the experience of an affiliated campus, Cornell. 
SPONSOR: Tompkins Cortland Community College No. 16 Dryden, New York

SURVEY LOCATION: College Campus in Dryden, NY

SURVEY FLIGHT: November, 1976

Tompkins Cortland Community College contracted with Daedalus Enterprises for an aerial survey of six acres of their campus for a cost of $\$ 500$. They felt that the program was "moderately successful", and were satisfied with the job done by the survey firm. Sponsors commented that imagery resolution was good, but that the data obtained was too subjective in their opinion. They would have preferred more detailed data and suggested the development of better measurement criteria. They indicated that a DOE manual would have helped them in conducting their survey program. College officials indicated that they became been aware of aerial IR surveys through an energy conference presentation. 
Vinita, Oklahoma

SURVEY LOCATION: 13 Municipalities in Northeast Oklahoma

SURVEY FLIGHT: January, 1978

This program of flight surveys and information dissemination is currently (August, 1979) in progress. It is being conducted by the Grand River Dam Authority in cooperation with the United States Department of Energy. The flight survey was performed on January, 1978 and the information dissemination phase initiated in March, 1978. The surveyed area is in the northeast quarter of Oklahoma containing 13 municipalities and 1 industrial park, within a total area of about 60 square miles. The total cost of obtaining aerial survey data is estimated at $\$ 13,000$, resulting in an average cost-per-building of about 33 cents. The thermal survey program is being conducted to develop public awareness of energy conservation measures and encourage addition of necessary insulation to buildings. The aerial infrared survey was conducted by Texas Instruments. In house training of personnel, consisting of 4 hour sessions, was utilized to develop a capability to perform thermographic data analysis and disseminate the resultant information. Although such personnel were initially placed in utility offices, they are now located in the public libraries. To generate public interest in visiting the centers, publicity used included radio, television, posters and newspapers. Direct mailing was also used. Response of homeowners to the program varied with cities. In some locations, as much as $25 \%$ was observed. In other cities, only a $5 \%$ response was achieved. To correct this problem, future programs of this type will employ much more publicity. The total cost of conducting such programs will also be considered in the future. The sponsors felt that an avenue should be developed for smaller cities to take advantage of some form of cooperative effort in order to reduce unit cost. Although cost was considered reasonable in early 1.978, the sponsor noted a substantial price increase from some companies. In assessing the survey programs conducted, further observations were that the quality of thermogram prints was extremely good and the use of conventional aerial photographs to help identify locations of homes was not necessary. 
SPONSOR: Northwestern Public Service Company

SURVEY LOCATION: Brookings, SD (4 square miles)

SURVEY FLIGHT: November, 1976

Northwestern Public Service Company contracted with Remote Sensing Institute (RSI) for a residential survey of Brookings, SD, an area covering 4 square miles at a cost of $\$ 3,830$. Thermogram information was disseminated at utility company offices, utilizing employees trained by RSI. Media advertising resulted in 1500 homeowners having their thermograms evaluated.

Sponsors felt the program was very good and had been a good publicity tool for energy conservation awareness. Thermogram resolution was good. Local insulation contractors were not in attendance at evaluations to maintain the "service" nature of interviews. The sponsors did not feel that a DOE manual would have been helpful. They learned about aerial IR surveys through contacts initiated by the surveying firm. Survey cost per thermogram viewer was $\$ 2.55$. 
SPONSOR: Tennessee Energy Authority

Nashville, Tennessee.

SURVEY LOCATION: State of Tennessee (700 square miles to date)

SURVEY FLIGHT: March, 1978

The Tennessee Energy Authority contracted with Texas Instruments' for a residential aerial survey of selected communities within the state. These included Memphis, Germantown, Jackson, Nashville, Hendersonville and Donelson, a total survey area of about 700 square miles. The survey flights took place in February and March, 1978 and dissemination of information was initiated in April, 1978. The latter phase was continuing as. of October, 1979. A subsequent phase of this statewide program, intended to be flown in the 1979-1980 Winter period, will add 20 cities (approximately 800 square miles) to the survey program total. About 260,000 residential single-family dwellings have thus far been surveyed. The estimated cost of obtaining aerial survey data was $\$ 120,000$. At present the average survey cost-per-building is estimated at 46 cents, while the estimated cost-per-thermogram viewer is 3 dollars. A variety of facilities are being used as information centers at various locations about the state. These have included libraries, city halls, electric and gas utilities, fairs and exhibitions. Gas company representatives have been on hand at information dissemination centers to help interested homeowners. Training of center personnel has been provided by the Tennessee Energy Authority (TEA). Centers have been operated either by community libraries or TEA staff. To date approximately 40,000 people have visited the centers. Statistics developed to date indicated that, of the homeowning thermogram viewers, $28 \%$ have added attic insulation, $40 \%$ weather-stripping and caulking, and $19 \%$ have added storm windows. The overall program has demonstrated sufficient merit to recommend its use on a wide scale by other states. 
SPONSOR:- City of Garland

No. 20

Garland, Texas

SURVEY LOCATION: Garland, TX (50 square miles)

SURVEY FLIGHT: December, 1977

The City of Garland contracted with Texas Instruments to perform their aerial surveys and with Energy Measures Corporation for the processing and analysis of thermal survey data. Within the 50 square miles of surveyed area, it is estimated that 40,000 residential structures, 80 apartment complexes (incorporating 6,774 apartment units), 2,300 commercial buildings and 300 industrial buildings were included. Survey programs were conducted in 1976 and 1977. In 1976, flight data was obtained during the month of February at an estimated cost of $\$ 21,000$, and information dissemination was conducted in August. In 1977, a flight survey took place in January, at an estimated cost of $\$ 4,500$ and data was made available to the public in August. The estimated cost of data interpretation and information dissemination (for both years) for the residential program was a total of $\$ 40,000$ of which one-half was funded by the city and the other half obtained as a grant from the Department of Energy through the Governor's Office of Energy Resources. The cost-per-building of the 1976 survey was placed at 52 cents and at 11.5 cents for the 1977 survey program. The average cost-per-thermogram viewer was 10 dollars. Thermogram interpretation for individuals was performed through the use of Public Library Energy Information Centers. Center personnel were trained to interpret thermographic data for viewers by the Energy Measures Corporation. Publicity was provided primarily through the use of radio announcements and utility billing enclosures. The overall assessment of the program by the sponsor was that the response by homeowners had been excellent, with no unusual problems encountered, and that such a program is recommended to other communities. 
SPONSOR: Seattle City Light

No. 21

Seattle, Washington

SURVEY LOCATION: Seattle, WA - 131 square miles

SURVEY FLIGHT: December, 1977

Seattle City Light contracted with Texas Instruments (TI) for a residential survey of the metropolitan area, 131 sq. mi., at a cost of $\$ 120$ per sq. mi., or $6.5 \xi$ per residential customer. Dissemination of thermogram information was by utility employees trained and experienced in interpretation. Initial training was furnished by TI. In addition to centers in the utility offices, community mextings, block workshops, neighborhood energy fairs and commercial seminars were used as vehicles. Data was also used for a rough survey of insulation levels in one rehabilitation project neighborhood and for specific guidance on energy savings for a number of schools and large companies.

Sponsors felt that the program was an effective tool for arousing conservation interest, and found that response depended on the quality of prints obtained. They felt that a survey manual aimed at the lay person which explained options, limitations and usage would have been helpful to them in the planning stages. They had become aware of aerial IR surveys through an article describing the Lincoln, NE survey. They were planning to conduct another flyover in 1979. 
SPONSOR: Washington Water Power Company

No. 22

Spokane, Washington

SURVEY LOCATION: Spokane, WA - 100 square miles

SURVEY FLIGHT: December, 1977

The Washington Water Power Company (WWP) contracted with Remote Sensing Institute (RSI) for a residential survey of over 100 square miles of Spokane and vicinity. Thermogram data was disseminated by WWP personnel at a central location. Sixteen percent of surveyed customers had viewed thermograms of their homes.

Sponsors indicated that weather conditions contributed to data problems in some areas, but overall the program was considered good. They learned of aerial IR surveys from a magazine article. They felt that a manual would have been useful to program planners. 
SPONSOR: Northern States Power Company

No. 23

Eau Claire, Wisconsin

SURVEY LOCATION: Eau Claire, Chippewa Falls, Altoona and Menomonie, WI

SURVEY FLIGHT: March, 1977

Northern States Power Company (NSPC) contracted with Remote Sensing Institute (RSI) for a residential survey of their service area at a cost of approximately $43 \mathrm{~F}$ per residential customer. Thermogram data was disseminated at central facilities in each community by utility employees trained by RSI and NSPC. Radio and newspaper annoucements were used to draw attention to the program. To date, approximately $20 \%$ of surveyed customers have had their thermograms evaluated.

Sponsors felt the data was good and allowed detection of poor or damaged insulation. The survey provided excellent public relations material, but in their opinion does not replace physical inspection of insulation. They felt that the print quality could have been better and that a DOE manual would have been helpful. Initial awareness of aerial IR surveys came from media announcements. 
SPONSOR5: Northern Utilities, Inc. and Northern Gas Company Casper, Wyoming

SUR VEY LOCATIONS: Casper and Laramie (RSI)

Riverton, Lander and Rawlins (TI)

\section{SURVEY FLIGHT: February, 1977}

Northern Utilities Company and Northern Gas Company sponsored aerial residential surveys of five Wyoming communities for a cost of approximately 65\& per customer. Data was disseminated at central locations by interpreters trained by their parent company, the Kansas-Nebraska Natural Gas Company. Approximately $25 \%$ of surveyed customers have had their thermograms interpreted to date, and an estimated $50 \%$ of these have taken remedial or corrective actions. Sponsors felt that the survey program was an excellent PR tool to highlight conservation needs. 
SPONSOR: Arizona Department of Revenue

No. 25

Phoenix, AZ

SURVEY LOCATION: Phoenix, AZ

SURVEY FLIGHT: September, 1976

The Arizona Department of Revenue contracted with Bendix Aerospace Systems Divison for a residential survey of the Phoenix area in air-conditioning load conditions.

Evaluation data was not furnished. 
SPONSOR: The Hotchkiss School

No. 26

Lakeville, Connecticut

SURVEY LOCATION: Lakeville, Connecticut Campus

SURVEY FLIGHT: December, 1977

The Hotchkiss School contracted with Daedalus Enterprises to conduct an aerial infrared survey and analysis of their school facilities. An area of some 150 acres was included in the survey. The facilities include 3 metal buildings, 3 storage or maintenance buildings, 21 residences, 20 masonry school buildings and 71 unheated structures. The aerial survey was performed in December, 1977 and the results of the survey and associated analysis were presented in February, 1978. The total cost of the survey was $\$ 4,290$. If only the heated buildings are considered, the average cost-per-building was about $\$ 91$. If all structures are considered, this was reduced to about $\$ 36$ per building. As a result of this survey, insulation has been added, storm windows installed, and other energy conservation corrective measures undertaken. A sidewall ground based thermal survey of 41 buildings was done the following year (December, 1978) in order to pinpoint further areas of heat loss. Cost of the survey was considered reasonable. The following quotation serves as the sponsor's overall assessment: "We found our original Daedalus Enterprises survey so useful - and moderate in cost - that we followed up with a Vanscan survey this last winter to discover areas of sidewall radiation that we could insulate. Since our fuel bill last year was over $\$ 171,000$ for the entire school, energy savings mean dollar savings. We are proud of our continuing energy saving program and its impact on our Annual Budget. Our central heating plant burned over 658,000 gallons of $\# 6$ oil in 1962-63 for a student population of 362 and only 255,596 gallons in 1978-79 for a student population of 495. These reductions have been made over a period of several years, an extensive building and rebuilding program, and with the help and assistance of many in the community. It cannot be done overnight but energy can be conserved." 
SURVEY LOCATION: Belleville, Illinois

SURVEY FLIGHT: December, 1978

St. Clair County contracted with Texas Instruments for an infrared survey of 150 square miles of the county. The area contained a total of about 100,000 commercial and residential buildings. The aerial survey took place in December, 1978. Dissemination of survey information was initiated in May 1979 and scheduled for operation through September, 1979. Cost of obtaining aerial survey data was estimated at $\$ 30,000$. The estimated total cost of conducting the associated data dissemination program was $\$ 25,000$ (salaries for 5 CETA employees). It is estimated that the average cost-per-building of the survey is only 30 cents. The cost per thermogram viewer (based upon a currently projected homeowner turn-out of 2400) was estimated to be 22 dollars. The county learned of infrared surveys from the Illinois Institute of Natural Resources. Actual distribution of information to the public was accomplished through the use of information centers which were established throughout the county in various municipal buildings. Radio, newspapers, posters and bulletin releases were all used to generate publicity prior to the opening of the centers. The program did not incorporate the presence of local company representatives (banks, construction, insulation sales, etc.) at the centers. Five CETA employees operated the individual centers. Training sessions for center personnel were conducted by representatives of Texas Instruments and the Illinois Institute of Natural Resources. Although the program has demonstrated sufficient merit to recommend its use on a wider scale in the future, sponsors felt that a more effective publicity program would be needed to obtain the desired viewer turn-out. Except for this factor, the total program was assessed to be good. 


\section{SURVEY LOCATION: Texarkana, Texas}

\section{SURVEY FLIGHT: January, 1979}

The City of Texarkana, Texas contracted with Texas Instruments to perform an aerial infrared community survey including an area of about 20 square miles. It was estimated that 11,600 residential buildings and 1,600 commercial and industrial type structures were contained in the area. The aerial survey was accomplished in January 1979 and dissemination of results to the public began in April, 1979. The information dissemination phase of the program is still in progress. The total cost of obtaining aerial survey data was $\$ 4,677$. The aerial survey program was originally conducted in association.with a program of ground interior surveys, but the latter is no longer in operation. The purpose of the combined and individual programs has been to develop awareness of energy conservation and encourage community action to make energy saving improvements. At the beginning of the program, community interest was encouraged through the use of newspaper, radio and television news annoucements. An aerial scan viewing room in the city's municipal building was then established for public inspection of the thermograms. The program did not include the participation of local business or bank representatives. Training of thermogram interpretation personnel was provided by Texas Instruments Infrared Services Staff. The training included an audio visual presentation and a handbook review. Program statistics to date indicate that the cost-per-building of the aerial survey was 35 cents and the associated cost-perviewer was 20 dollars. Overall impressions on the program to data are that the quality of survey thermograms was good, the aerial survey cost reasonable and program results thus far have been fair. Additional training of personnel in interpreting the thermograms would, however, have helped. Sponsors believe that program effectiveness would have been enhanced by the continued use of publicity to sustain the public's interest in viewing thermograms of their homes. 
SURVEY LOCATION: National Naval Medical Center

Bethesda, Maryland

SURVEY FLIGHT: December, 1977

The Chesapeake Division of the Naval Facilities Engineering Command contracted with Daedalus Enterprises to perform an aerial infrared survey and analysis of the National Naval Medical Center in Bethesda, Maryland. The survey area of 243 acres contains hospital, administrative and laboratory facilities. Aerial survey flights took place in December, 1977, with the resultant data analysis presented in May, 1978. The total cost of the aerial survey, including data analysis and presentation of results was $\$ 6,400$. The purpose of conducting the survey program was to determine the location of possible thermal faults in building roofs and in thermal distribution systems. Interest in this application of infrared was originally generated by articles in technical publications and information drawn from other Naval activities. Quality of thermograms was considered satisfactory with no improvements considered necessary. Conventional aerial photographs were used to aid in locating buildings on thermograms. The overall impression of the results of the program was that it is excellent for locating potential thermal faults which can then be further analyzed from the ground. 
SPONSOR: Department of the Navy

No. 30

SURVEY LOCATION: Naval Research Laboratory and Anacostia Annex, Washington, D.C.

SURVEY FLIGHT: February, 1978

The Chesapeake Division of the Naval Facilities Engineering Command contracted with Earth Satellite Corporation to perform an aerial infrared survey and to subsequently analyze the data to determine the extent of thermal deficiencies at the Naval Research Laboratory and Anacostia Annex facility complexes. The aerial survey encompassed an area of 34.5 acres, containing laboratory, administrative and shop types of buildings. Survey flights were conducted in the February - March 1978 period and survey results presented in May, 1978. The total cost of obtaining and analyzing aerial survey data was $\$ 12,735$. The survey was directed at determining the possible existence and extent of thermal deficiencies in either the building roof systems or the facility steam distribution lines. An awareness of the potential value of such infrared surveys was obtained from technical publications and a knowledge of other related technology Naval activities. Expected benefits of the program included the location of thermal faults which could be corrected by insulation repair or improvement, and the location and repair of steam or condensate leaks, such actions resulting in energy conservation improvements. No problems of any significance were encountered in the conduct of the survey program. Wider scale applications of this technique would be considered in the future but on the merits of specific cost-benefit assessments. A.lthough considered by them to be adequate for the purpose, sponsors felt that the quality of thermograms could have been better. Cost of the aerial IR survey was considered reasonable. An overall appraisal is that the aerial survey technique is most useful when combined with follow-on ground measurements. 
SUR VEY LOCATION: Washington Navy Yard

Washington, D.C.

SURVEY FLIGHT: December, 1977

This program of aerial infrared survey and data analysis was conducted by Daedalus Enterprises for the Chesapeake Division, Naval Facilities Engineering Command. The facility surveyed was the Washington Navy Yard in Washington, D.C. Facility elements included administrative, shop and warehouse buildings, contained within an area of 136 acres. Aerial survey work was conducted in December, 1977 and survey results presented in May 1978. Total cost of the program, including survey flights, data reduction, and analysis preparation was $\$ 6,090$. The purpose of the program was to determine the location of any possible thermal faults, either within building roof structures, or in any of the thermal distribution lines. Technical publications and other Naval activities were the source of infrared survey awareness development. Expected benefits of the program are the eniergy conservation measures which can be instituted as a result of locating the various insulation and steam line deficiencies. Thermogram quality, in terms of resolution required to indicate specific thermal faults, was considered sufficient. Aerial photographs of the survey area were used as an aid in locating buildings on thermograms. Because of the generally favorable results achieved with the survey, it will be considered for future use. 
SURVEY LOCATION: Farmington, New Mexico: 40 square miles

SURVEY FLIGHT: January, 1978

The Technology Application Center of the University of New Mexico, under contract to the New Mexico Energy and Minerals Department, coordinated an aerial infrared survey of Farmington, New Mexico. The actual survey flight was performed by the Ames Research Center at Moffit Field, California. The survey flight was made in January 1978. Dissemination of survey results to the community took place in July, 1978. Cost of the survey flight was approximately $\$ 20,000$ with an additional cost of about $\$ 45,000$ for thermal data interpretation and the information dissemination program. The purpose of the thermal survey program was to achieve a transfer of remote sensing and thermal scanning technology to the civilian user for the purpose of energy conservation. To assure the desired level of public interest and involvement in the project, a citizen's information campaign was initiated in September, 1977, almost five months before the survey flight was made. In December, one month before the survey flight, the local utility included a brochure explaining the program with its monthly customer billings. The brochure explained what the project was about, who was involved in it, and when and how homeowners could participate in it. Dissemination of information to the public was actually performed by utility personnel who were provided thermal image interpretation training by the Technology Application Center. Local company representatives, such as those of banks, construction firms, insulation sales firms, etc., were on hand to help homeowners interested in taking conservation actions. It is estimated that about $10 \%$ to $15 \%$ of the homeowners included in the aerial survey actually came to the information center. The cost of this survey program was considered reasonable, considering the fact that the Farmington Project was intended to serve as a demonstration project to other communities and did involve many features not expected to be incorporated in normal thermal surveys. 


\section{c. Overview of Conducted Projects}

Aerial thermographic surveys have been conducted in nearly all of the 48 contiguous States (see Figure 1). A summary list of survey locations compiled from surveying firms' client lists is provided in Tables 1 and 2, identified by general category of survey data user. The pattern of surveys performed shows a large majority in the cold climates. Initial efforts in cooling load environment data gathering were not as productive in meeting goals of the sponsor's original conservation program. The other pattern apparent is the concentration of activity in the Midwest, Great Lakes and South Central regions, which is attributable not only to cold weather, but also partially to the locations of major commercial surveying firms.

The hardware used to perform aerial thermographic surveys is relatively sophisticated and costly. Such instruments have generally benefitted and evolved from military technology. Aerial thermographic survey equipments are generally considered adequate for gross thermal loss detection by the survey user. For wide scale energy conservation application, however, airborne thermal surveys have significant limitations in data interpretation which are related to the accuracy of data collected, such data being influenced both by a variety of roof material and construction factors and by certain electronic characteristics of the equipment used.

Only four states, (Iowa, Minnesota, Oklahoma and Tennessee) have to date indicated that they are conducting or are planning conduct state-wide residential aerial survey programs. Residential programs have been identified in sixteen additional states but these were generally conducted on a more localized basis, either by a utility sponsor or at the initiative of a particular city or community. 




Figure 1 


\section{RESIDENTIAL AERIAL SURVEY SPONSORS}

Cedar Falls Utilities

Cedar Falls, Iowa

lowa Utility Association

Des Moines, lowa

Harlan Municipal Utilities

Harlan, Iowa

Iowa Public Service Company

Sioux City, Iowa

City of LaFayette

LaFayette, Louisiana

Great Falls Gas Company

Great Falls, Montana

Kansas-Nebraska Natural Gas

Company

Hastings, Nebraska

Cengas

Lincoln, Nebraska

Metropolitan Utilities District

Omaha, Nebraska

Consolidated Edison of New York

New York, New York

Hotchkiss School

Lakeville, Connecticut

St. Clair County

Belleville, Illinois

National Naval Medical Center

Bethesda, Maryland

Washington Navy Yard

Washington, D.C.
Fargo Chamber of Commerce

Fargo, North Dakota

Grand River Dam Authority

Vinita, Oklahoma

Bonneville Power Administration

Portland, Oregon

Northwestern Public Service Company

Brookings, South Dakota

Watertown Municipal Utilities Department

Watertown, South Dakota

Tennessee Energy Authority

Nashville, Tennessee

City of Garland

Garland, Texas

City of Seattle

Seattle, Washington

Washington Water Power Company

Spokane, Washington

Northern States Power Company

Eau Claire, Wisconsin

City of West End

West Bend, Wisconsin

Northern Utilities

Casper, Wyoming

City of Texarkana

Texarkana, Texas

Naval Research Laboratory

Washington, D.C.

New Mexico State Energy and

Minerals Department

Albuquerque, New Mexico

(Farmington City Program)

TABLE 1 


\section{NON-RESIDENTIAL SUR VEY SPONSORS}

Stanford University

Palo Alto, California

EPA

Denver, Colorado

State of Colorado - Aurora

Higher Education Center

Denver, Colorado

Trinity College

Hardtford, Connecticut

Hotchkiss School

Lakeville, Connecticut

Florida, University of

Miami, Florida

Florida Power \& Light

Miami, Florida

Emory University

Atlanta, Georgia

Valdosta State College

Valdosta, Georgia

Johnson \& Johnson

(2 sites)

Chicago, Illinois

Southern Illinois University

Edwardsville, Illinois

Fort Sheridan

Illinois

Great Lakes Naval Base

Great Lakes, Illinois

AB Dick Company

Niles Facility

Illinois

Wheaton College

Wheaton, Illinois

Indiana University

Bloomington, Indiana
Eli Lilly Company

Greenfield, Indiana

Indiana/Purdue University

Indianapolis, Indiana

Ball State University

Muncie, Indiana

Iowa State University

Ames, lowa

Northern Iowa, University of

Cedar Falls, lowa

Quaker Oats Company

Cedar Rapids, lowa

Iowa, University of

Iowa City, Iowa

Iowa Public Service Company

Sioux City, Iowa

Atchișon, Topeka \& Santa Fe Railway

Topeka, Kansas

IBM

Lexington, Kentucky

Kentucky, University of

Lexington, Kentucky

Louisiana State University

Baton Rouge, Louisiana

New Orleans, University of

New Orleans, Louisiana

Southern University

Louisiana

Bowdoin College

Brunswick, Maine

Maine, University of (Gorham)

Gorham, Maine

National Naval Medical Center/Bethesda

Bethesda, Maryland

TABLE 2A 
Maryland, University of

College Park, Maryland

U.S. Coast Guard - Curtis Bay

Curtis Bay, Maryland

Amherst College

Amherst, Massachusetts

Boston College

Boston, Massachusetts

Stone \& W'ebster Engineering

Company

Boston, Massachusetts

Smith College

Northampton, Massachusetts

Mount Holyoke College

South Hadley, Massachusetts

Norton Company

Worcester, Massachusetts

Albion College

Albion, Michigan

Ford Motor Company

Dearborn, Michigan

General Motors AC Spark Plug Division

Flint, Michigan

Michigan Technological University

Houghton, Michigan

Kalamazoo College

Kalamazoo, Michigan

Kalamazoo State Hospital

Kalamazoo, Michigan

Upjohn Company - 2 surveys

Kalamazoo, Michigan

Western Michigan University

Kalamazoo, Michigan
Northern Michigan University

Marquette, Michigan

Dow Chemical Company (2 surveys)

Midland, Michigan

General Motors Proving Ground

Milford, Michigan

Oakland County Service Center

Oakland, Michigan

General Motors Fisher Body

Division

Pontiac, Michigan

General Motors Technical Center

Warren, Michigan

Bendix/ERDA

Kansas City, Missouri

USA Corps of Engineers

Omaha, Nebraska

Fort Dix

New Jersey

Western Electric Company

Kearny, New Jersey

Rutgers University

New Brunswick, New Jersey

Ingersoll-Rand Corporation

Phillipsburg, New Jersey

State University of New York

(9 campuses)

Albany, New York

Tompkins-Cortland Community College

Dryden, New York

Fort Hamilton

New York, New York

Alelphi University

Garden City, New York

TABLE 2B 
Indiana University of Pennsylvania

Indiana, Pennsylvania

Ingersoll-Rand Corporation (1978)

Painted Post, New York

Rochester University

Rochester, New York

Ellis Hospital

Schenectady, New York

General Electric R\&D Center

Schenectady, New York

Brookhaven National Laboratory

Upton, L.I., New York

North Carolina, University of

Chapel Hill, North Carolina

Duke University

Durham, North Carolina

North Carolina State University

Raleigh, North Carolina

Cincinnati, University of

Cincinnati, Ohio

Ohio State Ùniversity

Columbus, Ohio

Monsanto Research Corporation

Miamisburg, Ohio

Wittenberg University

Springfield, Ohio

Sun Petroleum Products

Toledo, Ohio

Dickinson College

Carlisle, Pennsylvania
Danville State Hospital

Danville, Pennsylvania

Franklin \& Marshall College

Lancaster, Pennsylvania

Mansfield State College

Mansfield, Pennsylvania

Drexel University

Philadelphia, Pennsylvania

Pennsylvania, University of

Philadelphia, Pennsylvania

Pittsburg, University of

Pittsburg, Pennsylvania

Swarthmore College

Swarthmore, Pennsylvania

Pennsylvania State University

(2 surveys)

University Park, Pennsylvania

Brown University

Providence, Rhodes Island

South Carolina, University of

Columbia, South Carolina

First National Bank

Aberdeen, South Dakota

Tennessee, University of

Knoxville, Tennessee

Utah State University

Logan, Utah

USAMERDC

Fort Belvoir, Virginia

Norfolk Naval Base

Norfolk, Virginia

TABLE 2C 
American University

Washington, D.C.

George Washington University

Washington, D.C.

Lawrence University

Appleton, Wisconsin

Harnischfeger Corporation

Milwaukee, Wisconsin

Lakeland College

Sheboygan, Wisconsin
Georgetowne University

Washington, D.C.

Washington Navy Yard

Washington, D.C.

Allis-Ċhalmers

Milwaukee, Wisconsin

Rexnord, Inc.

Milwaukee, Wisconsin

West Bend, Wisconsin (City. of)

West Bend, Wisconsin 


\section{d. Companies that Provide Surveys}

Firms providing aerial thermographic survey services of a commercial nature are identified in Table 3. A brief summary of each firm's operations is included. In addition to thermographic data collection, all companies provide support services which include data analyses and results presentation. Most tend to specialize in a general category of survey client: residential, commercial/ industrial, institutional. The larger commercial firms utilize equipment of their own design and manufacture. Some utilize either their own or the sponsor's aircraft for the data mission. Thermographic output is generally provided in photographic print format, but it is tailored to the sponsor's intended use. It should be noted that the list of firms is intended only to be representative of those performing thermographic surveys. Inclusion or omission of companies from this list should not be considered as either a recommendation or criticism of any organization. 
Aerial Thermographic Survey Firms

- Air Image Technology

Stow, Massachusetts

- Daedalus Enterprises, Incorporated Ann Arbor, Michigan

- Earth Satellite Corporation Washington, D.C.

- Energy Measurures Conrpnration Austin, Texas

- ESCA-TECH Corporation Costa Mesa, California

- Gleason Romans Company Tulsa, Oklahoma

- Mead Technology Laboratories Dayton, Ohio

- Photo Science, Incorporated Gaithersburg, Maryland

- Remote Sensing Institute (RSI) South Dakota State University Brookings, South Dakota

- Texas Instrunientó, Incúi' pưr ated Science Services Division Dallas, Texas

TABLE 3 
Air Image Technology

Minuteman Airfield

Stow, Massachusetts 01775

(617) 897-8303

Air Image Technology provides a range of aerial infrared survey and image processing services. Thermal imaging and line scanner equipments are available for performing surveys from either helicopter or fixed wing aircraft. Thermographic data is processed either for hard copy or video tape presentation of survey results. Digital data processing equipment is available for image enhancement applications through filtering, edge sharpening or pattern recognition techniques. Available services include residential and non-residential building surveys. Nonresidential service options include building heat loss analysis and roof system surveys.

Daedalus Enterprises, Incorporated

Post Office Box 1869

Ann Arbor, Michigan 48106

(313) 769-5649

AIRSCAN continuous airborne thermography services are conducted for industrial, university and government facilities. Thermal measurements are recorded on magnetic tape and are laboratory processed to produce both black-and-white and color-coded thermograms. The service includes preparation of aerial photographs for comparison and location purposes. Calibrated scale color coding of thermogram for different temperature ranges permits enhancement of selected survey features. This organization also provides a VANSCAN service in which the same techniques are used for ground level thermal surveys by a moving vehicle. 
Earth Science and Consulting (ESCA-TECH) Corporation 3001 Red Hill Avenue

503 East 6th Avenue

Costa Mesa, California 92626

(714) 751-3630

(907) 277-2527

ESCA-TECH conducts aerial heat loss surveys. The firm has an inventory of remote sensing and data processing systems available for conducting a range of services. These services also include natural resource inventories and environmental assessment projects. Single and multi-sensor surveys are performed. Data interpretation services are provided for aircraft, spacecraft or ground sensing systems. An electro-optical and data processing laboratory, compututer facilities and software programs are available to support survey programs.

\section{Gleason Romans Company 2732 North Sheridan \\ Tulsa, Oklahoma 74115 \\ (918) 835-44}

The Gleason Romans Company is an aerial survey firm having bases in Oklahoma, Texas, Illinois, California, Oregon and Utah. The firm conducts thermal infrared surveys to detect heat loss from residential and non-residential building facilities. Thermographic data is produced directly on film during conduct of the survey, but is also available in tape recorded form. Annotated thermographic data is provided to the client.

The firm has been participating in a statewide aerial residential survey program called Thermocheck with the Oklahoma Department of Energy and the University of Oklahoma. The initial thermographic survey project will cover the twenty largest cities in the state. 


\section{Mead Technology Laboratories. \\ 3481 Dayton-Xenia Road \\ Dayton, Ohio 45432 \\ (513) 426-3111}

Mead Technology Laboratories performs airborne infrared scanning services, generally in participation with State and Federal ágency programs. Heat loss survey programs have been conducted in Minnesota, Ohio, Virginia and Washington, D.C. Refinement of airborne IR scanning techniques to obtain economical coverage of large areas was done for the Environmental Protection Agency (EPA) Office of Research and Monitoring. Mead's laboratory activities include investigation of image enhancement, false color and digital readout of infrared thermography.

Photo Science, Incorporated

7840 Airpark Road

Gaithersburg, Maryland 20760

(301) 948-8550
1630 North Broadway

Lexington, Kentucky 40505

(606) 293-0502

Photo Science, Incorporated's Aerial Energy Inspection Program utilizes infrared scanning techniques to locate sources of heat losses. Thermal surveying is used as a reconnaissance tool for identifying sources of heat loss due to a building's structural or material defects. They are also engaged-in performance of aerial infrared inspection of large installations employing a central steam distribution system. Their services include photogrammatic engineering and precision photographic reproduction. 
Remote Sensing Institute (RSI)

South Dakota State University

Brookings, South Dakota 57007

(605) 688-4184

RSI has established a program for conducting aerial thermal surveys of cities to determine if homes or business buildings are losing heat through the roof because of insufficient or inefficient attic insulation. Their program includes complete planning of thermal surveys over a designated city or community and subsequent information dissemination activities. Training of interpreters is available to sponsors.

Texas Instruments, Incorporated (TI)

Airborne Infrared Surveys

Post Office Box 5621

Dallas, Texas 75222

(214) 238-3444

TI conducts airborne infrared surveys, heat loss surveys and quantitative thermal analysis services. They offer a full line of data collection and interpretation services directed toward thermal energy conservation. Two data recording methods are available: (1) a black-and-white 70 millimeter negative filmstrip for use in producing positive film transparencies, paper contact prints or enlargements for visual analysis and (2) a 9-track magnetic tape digital record which can be used via a computer process to produce a map-like rendition of sensed thermal information for use in quantitative analysis of heat loss. 


\section{e. Index of Available Equipment}

Equipments known to be currently available for use in commercial aerial thermal surveys are indicated in Table 4. The Honeywell AAD-5 System is included even though it is essentially a military product, because its higher thermal and spatial resolution performance makes it a potential candidate for future large scale survey programs.

Aerial survey program sponsors indicated overwhelmingly (94\%) that the equipment used for data-gathering in their surveys was satisfactory and that end result data was satisfactory also, but $35 \%$ said they preferred better clarity or resolution in the images. The factors affecting image clarity are ones with which future survey sponsors should become acquainted: principally, thermal resolution and spatial resolution. Other instrument parameters will also impact image clarity, but these two parameters are the primary determinants of satisfactory imagery for survey purposes.

The list of aerial scanner systems is intended only to be representative of current technology commercially available, or, as in the case of the military design, systems which may be used for thermal survey applications in special instances. Inclusion or exclusion on the list should not be interpreted as either acceptance or rejection of equipments for this application. 


\begin{tabular}{|c|c|c|c|c|c|c|}
\hline System Cost & $\begin{array}{l}\text { Spectral } \\
\text { Range (IR) }\end{array}$ & $\begin{array}{l}\text { Temperature } \\
\text { Resolution }\end{array}$ & $\begin{array}{l}\text { Spatial } \\
\text { Resolution }\end{array}$ & $\begin{array}{l}\text { Field } \\
\text { of View }\end{array}$ & $\mathrm{V} / \mathrm{H}$ & Display Type \\
\hline $\begin{array}{l}\text { Bendix } \\
M^{2} S \\
\$ 180,000\end{array}$ & $8-14 \mu \mathrm{m}$ & $0.5^{\circ} \mathrm{C}$ & 2.5 milliradians & $\pm 50^{\circ}$ & $\begin{array}{l}0.15 \\
0.025 \\
0.015\end{array}$ & Magnetic Tape \\
\hline $\begin{array}{l}\text { Daedalus } \\
\text { DS } 1230 \\
\$ 125,000\end{array}$ & $9-12 \mu \mathrm{m}$ & $0.2^{\circ} \mathrm{C}$ & 1.0 milliradians & $\pm 39^{\circ}$ & 0.20 & Magnetic Tape \\
\hline $\begin{array}{l}\text { DS } 1260 \\
\$ 250,000\end{array}$ & $8-14 \mu \mathrm{m}$ & $0.2^{\circ} \mathrm{C}^{\circ}$ & 2.5 milliradians & $\pm 42^{\circ}$ & 0.25 & Magnetic Tape \\
\hline $\begin{array}{l}\text { Texas Instruments } \\
\text { RS- } 310 \\
\$ 100,000\end{array}$ & $\begin{array}{l}3-5 \mu \mathrm{m} \text { or } \\
\mathrm{B}-14 \mu \mathrm{m}\end{array}$ & $\begin{array}{l}0.10^{\circ} \mathrm{C} \\
0.15^{\circ} \mathrm{C}\end{array}$ & $\begin{array}{l}1.0 \text { milliradians } \\
0.82 \text { milliradians }\end{array}$ & $+50^{\circ}$ & $\begin{array}{l}0.50 \\
0.02\end{array}$ & $\begin{array}{l}\text { Magnetic Tape } \\
\text { or } 70 \mathrm{~mm} \text { Film }\end{array}$ \\
\hline $\begin{array}{l}\text { Honeywell } \\
\text { AAD-5 } \\
\$ 210,000\end{array}$ & $8-14 \mu \mathrm{m}$ & High* & High* & $\begin{array}{l}+60^{\circ} \\
\pm 30^{\circ}\end{array}$ & Fast & \\
\hline
\end{tabular}

TABLE 4. AERIAL THERMOGRAPHIC SCANNER SYSTEMS 
SECTION 2

GROUND SURVEYS

THERMAL IMAGING/LINE SCANNERS 


\section{2 - GROUND SUR VEYS (THERMAL IMAGERS/LINE SCANNERS)}

There is a relatively slow but growing trend in the formation of firms providing ground thermal surveys for residential and industrial clients. Such firms typically use either the relatively sophisticated imaging units or the less costly line scanners. This section includes a summary of the capabilities of such instruments, a list of companies that provide surveys and an index of available equipment.

\section{a. Demonstrated Capabilities}

\section{Thermal Imaging Equipment}

Thermal imaging devices used for ground surveys utilize a twodimensional scanning process to develop a map of the apparent radiance temperature of the surveyed scene, e.g., an element of the building envelope. The components generally surveyed from the exterior are a building's wall and visible roof surfaces. Interior measurements are made not only of walls, but of any surfaces, such as floors and ceilings, which are part of the building's thermal envelope. Hard copy thermograms can be produced and, when correctly interpreted, enable the assessment of apparent surface heat loss due to insulation defects, excessive infiltration or exfiltration, or other possible causes.

Thermal imaging devices provide thermal resolutions down to $0.2^{\circ} \mathrm{C}$ and spatial resolutions corresponding to 1 square centimeter out of a total scanned area of 1 square meter. Such instruments are currently considered capable of indicating the difference (for either interior or exterior surveys) between R-5 and R-15 levels of insulation under specified conditions of indoor-outdoor ambient temperature differentials. In the case of interior surveys, this capability is improved to providing a distinction between R-10 and R-15 performance levels under specified ambient temperature conditions. This is considered to be sufficient for gross insulation measurement and void detection. 


\section{Line Scanning Equipment}

Thermal line scanning devices used for ground surveys utilize a onedimensignal scanning process to develop a measure of the apparent radiance temperature along a line in the optically viewed scene. The application of such devices is similar to that of thermal imagers, i.e., exterior or interior surveys of buildings. A thermal image of a two-dimensional scene is, however, not produced in hard copy. Instead, a photographic image of the viewed scene with the thermal line scan superimposed on it can be produced. In typical application, the equipment operator searches for (by panning or other coverage of the surveyed area) surfaces warranting detailed survey for the record. Operator judgement determines how many and which scenes to photograph to form a complete record.

A currently available line scanner provides a thermal resolution of better than $0.5^{\circ} \mathrm{C}$ and a spatial resolution corresponding to less than 1 square centimeter at a wall distance of 1 meter. Although this category of instrumentation does not provide the more easily interpretable thermal image, its temperature resolution capability does permit gross-level total insulation resistance measurement.

\section{b. Companies that Provide Surveys}

Firms in the business of providing ground thermal surveys for clients were contacted to determine their general methods of operation and their requirements for further improvement of equipment or procedures. Their responses have been assembled in the form of contact reports. Figure 2 summarizes the locatiuns of these firms.

Surveying firms expressed the following preferences for new equipment features: Software Packages - 41\%; Videotape Recording - 35\%; Procedures and Applications Manual - 24\%; Quantitative Capability - 18\%; Wider F.O.V. optics -18\%; Color CRT

Display - 12\%. Primary uses of the equipment breaks down as follows for those firms responding:

$$
\begin{aligned}
& \text { Commercial/Industrial Uses - } 60 \% \\
& \text { Residential Uses - } 40 \%
\end{aligned}
$$


Conversations with a few instrument owners indicate the trend is toward proportionately more commercial/industry surveys. They cited economic factors and stability of repeat business as the primary causes of this trend. Instrument manufacturers indicate a strong, growing market for their equipment.

Most survey firms contacted were initially located by asking manufacturers to identify equipment purchases. Some manufacturers could not easily provide such lists. As might be expected, not all equipment was purchased for the purpose of providing thermal performance survey services to the public. A significant number are in fact used in corporate plant maintenance programs, while a growing number are used as quality control aids by firms which install retrofit insulation. The firms contacted should, therefore, be considered only as a representative sample and any omissions to have no intentional implication.

Survey firms incorporating the notation Energy Scanners in their company identity are part of a new national network of franchised infrared survey service contractors. These firms represent ten out of the total of thirty which provided information about their thermographic survey operations during this first assessment update. Most of the thirty firms indicated that the majority of their surveys are still being conducted for non-residential, i.e., industrial, commercial, institutional, clients as the homeowning public typically has not yet been responsive to the availability of a residential survey at an average cost of $\$ 100.00$ or more.

Firms were this time requested to provide full descriptions of their business operations for this assessment update. Because of the nature and extent of useful information received, this update report is organized to incorporate two types of contact report sets: (1) narrative summaries describing survey procedures and report formats used for residential and industrial clients, and other insights which may have been provided by a firm, and (2) tabular data provided in a standardized format for presenting essential features of each firm's operation.

An overview of the responses from the 30 firms suggests that the form and content of a thermal survey and the resultant report to the client can vary widely with the skill and discipline of the individual survey performer. The Energy Scanners organization has been giving an introductory course to its member firms to provide them with a basic understanding of the theory of thermal imaging, techniques of 
equipment operation, and thermographic data interpretation. Beyond this essential introduction, it is up to the survey firm to maintain and update the skill level of its survey performers.

The survey update reveals that there is still very little business activity in residential thermal surveys. Analysis of data received shows that 9 of the 30 firms responding do no residential work at all. One-half of the firms do less than $25 \%$ of their total business in residential surveys, and only $1 \mathrm{firm}$ indicated that all of its current business is in the home survey area. The opinion provided by one firm may essentially sum up the reason for this lack of growth in an industry which appeared to satisfy a valid conservation need of the homeowner: "People are not yet willing to pay $\$ 100$ for the information". 




Figure 2 


\section{GROUND SURVEY FIRMS}

1. Ryan Homes, Inc.

100 Ryan Court

Pittsburgh, Pennsylvania 15205

2. Infrared Technology of Alaska, Inc.

100 West International Airport Road

Suite 204

Anchorage, Alaska 99503

3. Infra Red Energy Consultants, Inc.

6897 Gillis Road

Victor, New York 14564

4. A.G. Associates

P.O. Box 17183

Montgomery, Alabama 36117

5. Thermal Surveys, Inc.

P.O. Box 2155

Rockford, Illinois 61130

6. Energy Recovery Engineering Inc.

Box 2327

Littleton, Colorado 80121

7. West Shore Industrial Testing, Inc.

700 Ottawa Avenue

Holland, Michigan 49423

8. Diversified Inspections, Inc.

2012 West Ironwood Drive

Phoenix, Ariznna 85021 
9. Thermography of California

610 Bryant Street

San Francisco, California 94107

10. Infra-Scan of Vermont

R.D. 非 2 Box 143

Shelburne, Vermont 05482

11. Environmental Thermography and Testing Services

P.O. Box 5462

Hilton Head Island, South Carolina 29928

12. Environmental Thermography and Testing Services

P.O. Box 1298

Dynedin, Florida 33528

13. Trinity Associates, Inc.

P.O. Box 146

Swarthmore, Pennsylvania 19081

14. General Electric Company

141 Providence Road

P.O. Box 30697

Charlotte, North Carolina 28230

15. Asplundh

Blair Mill Road

Willow Grove, Pennsylvania 19090

16. Westinghouse Electric Organization

1005 Sussex Boulevard

Lawrence Park Industrial District

Broomall, Pennsylvania 19008

17. Infra-Red Scanning Services

P.O. Box 343

Beaver, Pennsylvania 15009 
18. Air Image Technology

Minuteman Airfield

Stow, Massachusetts 01775

19. Power Save Systems, Inc.

Infra-Red Scanning

P.O. Box 523536

Miami, Florida 33152

20. Reed Consultants

2230 N. 166th Street

Brookfield, Wisconsin 53005

21. Ferguson, Brosz and Associates, Limited

77 Progress Avenue

Scarborough, Ontario, Canada MIP2Y7

22. Tymark Corporation

7728 Mullrany Drive

Dallas, Texas 75248

23. Infra-Red Energy Surveys

Box 564

Needham, Massadhusetts 02192

24. Agatronics LTD

Thermalchek Consulting

5230 South Service Road - Suite 125

Burlington, Ontario, Canada L7L 5K2

25. Helicopter Minit-Men, Inc.

P.O. Box 5625

Columbus, Ohio 43221 
26. Thermal Services, Inc.

P.O. Box 4171

Wilmington, Delaware 19807

27. PEDCo Thermal Inc.

4627 Executive Drive

Suite 101

Columbus, Ohio 43220

28. Thermoscan, Inc.

P.O. Box 566

Elmhurst, Illinois 60126

29. Charles C. Roberts, Jr., Phd, P.E.

Consulting Engineer

27W766 Greenview

Warrenville, Illinois 60555

30. Infrared Engineers

540 Straight Street

Paterson, New Jersey 07503 


\section{CROSS INDEX OF GROUND THERMOGRAPHIC SUR VEY FIRMS}




\section{Control Number List of Ground Survey Firms}

\section{Ground Survey Firm}

1. Ryan Homes, Inc.

2. Infrared Technology of Alaska, Inc.

3. Infrared Energy Consultants, Inc.

4. A.G. Associates

5. Thermal Surveys, Inc.

6. Energy Recovery Engineering, Inc.

7. West Shore Industrial Testing, Inc.

8. Diversitied Inspections, Inc.

9. Thermography of California

10. Infra-Scan of Vermont

11. Environmental Thermography (Sourth Carolina)

12. Environmental Thermography (Florida)

13. Trinity Associates, Inc.

14. General Electric Company

15. Asplundh

16. Westinghouse Electric Corporation

17. Infra-Red Scanning Services

18. Air Image Technology

19. Power Save Systems, Inc.

20. Reed Consultants

21. Ferguson, Brosz and Associates Limited

22. Tymark Corporation

23. Infra-Red Energy Surveys

24. Agatronics Limited

25. Helicopter Minit-Men, Inc.

26. Thermal Services, Inc.

27. PEDCO Thermal, Inc.

28. Thermoscan, Inc.

29. Charles C. Roberts, Jr., Consultant ।

30. Infrared Engineers 


\section{Aphabetical List of Ground Survey Firms}

Ground Survey Firm

Control Number

1. Air Image Technology

2. A.G. Associates

3. Agatronics Limited

4. Asplundh

5. Charles A. Roberts, Jr., Consultant

6. Diversified Inspections, Inc.

7. Energy Recovery Engineering, Inc.

8. Environmental Thermography

9. Environmental Thermography

10. Ferguson, Brosz and Associates Limited

11. General Electric Company

12. Helicopter Minit-Men, Inc.

13. Infra-Red Energy Consultants Inc.

14. Infra-Red Energy Surveys

15. Infrared Engineers

16. Infra-Red Scanning Services

17. Infrared Technology of Alaska

18. Infra-Scan of Vermont

19. PEDCO Thermal, Inc.

20. Power Save Systems, Inc.

21. Reed Consultants

22. Ryan Homes, Inc.

23. Thermal Services, Inc.

24. Thermal Surveys, Inc.

25. Thermography of California

26. Thermoscan, Inc.

27. Trinity Associates, Inc.

28. Tymark Corporation

29. Westinghouse Electric Corporation

30. West Shore Industrial Testing, Inc. 


\section{Cross Reference by State}

State

Control Number

Alabama

4

Alaska

2

Arizona

8

California

9

Colorado

6

Delaware

26

Florida

11,19

Illinois

$5,28,29$

Massachusetts

18,23

Michigan

7

New Jersey

30

New York

3

North Carolina

14

Ohio

25,27

Pennsylvania

$1,13,15,16,17$

South Carolina

12

Texas

22

Vermont

10

Wisconsin

20

Ontario, Canada

21,24 


\section{GROUND SURVEY FIRM DATA}


FIRM

No. 1

Ryan Homes

100 Ryan Court

Pittsburg, Pennsylvania 15025

CONTACT

RIchard H. Tracey

(412) 276-800

Infrared Scanning Equipment

AGA Thermovision 750

Barnes Thermatrace

Daedalus Vanscan

FLIR Systems 100

Hughes Probeye 650

Inframetrics 510

Residential Surveys Performed $D$

Thermogram Record Format

Polaroid Photograph

$35 \mathrm{~mm}$ Film

Video Tape

Black-White

Color

Survey Procedure

Interior Scans

Exterior Scans

(Using Mobile Van)

Report Contents

Thermograms

Control Photographs

Defects Analysis

Recommended Action

Average Survey Time: 2 hours

Average Survey Cost:

Residential Survey Client Categories

Homeowner

Municipality

Utility

Building Developer

Community Organization

Industrial Survey Client Categories Industrial Firms

Commercial Firms
Industrial Surveys Performed

Thermogram Record Format

Polaroid Photograph

$35 \mathrm{~mm}$ Film

Video Tape

Black-White

Color

Survey Procedure

Interior Scans

Exterior Scans

(Using Mobile Van)

(Using Helicopter)

Report Contents

Thermograms

Control Photographs

Defects Analysis

Recommended Actions

Summary Report

Full Report

Audio Tape Report

Video Tape. Report

Average Survey Time

Average Survey Cost:
Public Buildings

Utilities 


\section{GENERAL}

Ryan Homes, Inc. is a large scale homebuilder utilizing thermographic inspection techniques as part of its own thermal envelope quality control program. The Pittsburgh, Pennsylvania, based firm uses an Inframetrics Model 510 Thermal Imaging System to conduct a thermal survey of a home in the presence of the new homeowner. The Inframetrics system has a number of data output capabilities in addition to its basic thermal image television-type display, including videotape recording and Polaroid film hard copy with black-white imagery. Additional data recorded during a ground survey includes indoor and outdoor temperatures obtained from thermocouple readings of interior and exterior building wall surfaces. The temperature data, in conjunction with thermal imagery, are used as : the basis for evaluation. Typical survey procedure is to perform an interior scan, with outside at least $30^{\circ} \mathrm{F}$ below interior temperature and the structure allowed to thermally stabilize by having its heating system inoperative for at least one hour prior to the survey. Reference temperatures of various heights within each room inspected are taken in order to compensate for air thermal stratification. Areas where thermal flaws exist are compared to a properly functioning surface within the room. An estimate of the resultant additional heat loss for each such area is made and recorded. This procedure suits the builder's need to establish parameters of performance found in normal construction. 
FIRM

Infrared Technology of Alaska $\therefore$

No. 2

100 West International Airport Road - Suite 204

(Energy Scanners) Anchorage, Alaska 99503

CONTACT

Richard L. Town

(907) 272-0856

Infrared Scanning Equipment

AGA Thermovision 750

Barnes Thermatrace

Daedalus Vanscan

FLIR Systems 100

Hughes Probeye 650

. Inframetrics 510

Residential Surveys Performed

- Thermogram Record Format

\begin{tabular}{l|l|}
\hline Polaroid Photograph__ & \multicolumn{1}{|c|}{} \\
$35 \mathrm{~mm}$ Film & \\
Video Tape & \\
Black-White & $\sqrt{ }$ \\
Color &
\end{tabular}

Survey Procedure Interior Scans

Exterior Scans

(Using Mobile Van)

\section{Report Contents}

Thermograms

Control Photographs

Defects Analysis

Recommended Action

Average Survey Time: 1 hour

Average Survey Cost: $\$ 125$

Residential Survey Client Categories

Homeowner

Municipality

Utility

Building Developer

Community Organization

Industrial Survey Client Categories

Industrial Firms

Commercial Firms
Industrial Surveys Performed

$\nabla$

Thermogram Record Format

\begin{tabular}{l|l|}
\hline Polaroid Photograph____ & $\gamma$ \\
\hline $35 \mathrm{~mm}$ Film & \\
\hline Video Tape & \\
Black-White & \\
\hline Color & \\
\hline
\end{tabular}

Survey Procedure

Interior Scan's

Exterior Scans

(Using Mobile Van)

(Using Helicopter)

Report Contents

Thermograms

Control Photographs

Defects Analysis

Recommended Actions

Summary Report

Full Report

Audio Tape Report

Video Tape Report

Average Survey Time 1 day

Average Survey Cost:

$5 \%$

$95 \%$

Public Buildings

Utilities 


\section{GENERAL}

Infrared Technology of Alaska, Inc. is an Energy Scanners affiliate based in Anchorage, Alaska, which performs both residential and industrial types of thermographic surveys. Infrared surveys are done with the AGA Thermovision 750 System, with thermographic data output available on either Polaroid or $35 \mathrm{~mm}$ film. Survey procedures developed by Energy Scanners are used. These include the survey of the building's exterior and outside-wall interior, assembling of a record of thermograms and associated conventional photographs essential for the development of conclusions and recommended actions. Data forms and checklists are also incorporated in the report so that the complete document package may be used for future reference.

\section{RESIDENTIAL THERMAL SURVEYS}

Currently, about $95 \%$ of the surveys performed are related to electrical inspections. It is hoped that more homeowners in this region will be concerned enough in the future to request residential thermal.inspections. School or hospital energy audit business will probably not develop until Federal funding of this type program is made available.

A thermographic survey of both the building's exterior and interior is performed. The requirement that a temperature difference of $20^{\circ} \mathrm{F}$ exist between inside and outside at the time of survey is always obsierved. A pictorlal and written survey report is prepared for the homeowner.

\section{INDUSTRIAL SUR VEYS}

Industrial surveys are similarly conducted by making measurements of the building's exterior wall thermal performance. Flat areas of the building's roof surface are also walked. Included in the survey are infrared measurements at doors and windows, and of pumps, motors, insulated lines, steam traps, and various electrical equipments. Conventional photographs, thermograms and narrative development of analyses, conclusions and recommendations are incorporated into a single package for the industrial client. 


\section{GENERAL}

Infrared Energy Consultants, Inc., is a New York based Energy Scanners affiliate which provides thermographic inspection services to both residential and nonresidential clients. Infrared surveys are currently performed with the AGA Thermovision 750 System and the Hughes Probeye Unit. The firm feels that the AGA system provides them with good thermographic resolution and flexibility of application, while the Probeye gives them survey speed and a lower operating cost. The general technique of data presentation to the client is to deliver a detailed written critique of what was done and what was observed, in addition to providing proof of data in the form of thermograms and conventional photographs. The firm is generally optimistic about the projected volume of business, e.g., estimating a possible four-fold increase in total annual sales.

\section{RESIDENTIAL THERMAL SURVEYS}

The survey is conducted by first performing infrared scans from outside the building to look for areas of heat loss and to locate any major heat leaks. This step is followed by going inside to pinpoint heat losses and to check the quality of insulation, for window losses, and the effectiveness of heating duct systems and/or radiators. The procedure used to present results is to request the owner to personally view the thermal display and see what is happening to the energy in the home, and then provide the thermograms and photographs with recommendations for making improvements.

\section{INDUSTRIAL SURVEYS}

Industrial surveys are conducted in a manner generally the same as for residences but with the additional calculation of heat loss (BTU values) and the preparation of cost-benefit analyses for alternative corrective-action recommendations. Helicopter aerial scanning of the facility can also be provided. The survey report is presented to the customer in the form of written narrative, along with support for the conclusions in terms of a series of thermograms and photographs. If desired by the customer, a video tape record is substituted. 
A.G. Associates

P.0. Box 17183, 4930 Troy Highway

Montgomery, Alabama 36117

CONTACT

C.C. Mitchel1

(205) 281-7237

\section{Infrared Scanning Equipment}

AGA Thermovision 750

Barnes Thermatrace

Daedalus Vanscan

FLIR Systems 100

Hughes Probeye 650

Inframetrics 510

Residential Surveys Performed $\square$

Thermogram Record Format

Polaroid Photograph

$35 \mathrm{~mm}$ Film

Video Tape

Black-White

Color

Survey Proceduré

Interior Scans

Exterior Scans

(Using Mobile Van)

Report Contents

Thermograms

Control Photographs

Defects Analysis

Recommended Action

Average Survey Time: 2 hours

Average Survey Cost: $\$ 100$

Residential Survey Client Categories

Homeowner

Municipality

Utility

Building Developer

Community Organization

Industrial Survey Client Categories Industrial Firms

Commercial Firms
Industrial Surveys Performed $\emptyset$

Thermngram Record Format

Polaroid Photograph

$35 \mathrm{~mm}$ Film

Video Tape

Black-White

Color

Survey Procedure

Interior Scans

Exterior Scans

(Using Mobile Van)

(Using Helicopter)

Report Contents

Thermograms

Control Photographs

Defects Analysis

Recommended Actions

Summary Report

Full Report

Audio Tape Report

Video Tape Report

Average Survey Time 1 day

Average Survey Cost:
Public Buildings Utilities 


\section{GENERAL}

A. G. Associates is an Energy Scanners affiliate based in Montgomery, Alabama, providing both residential and non-residential thermal survey services. Infrared surveys are performed with the AGA Thermovision 750 System, which provides both a display capability and a Polaroid film record of thermograms. Standardized procedures developed by Energy Scanners for the performance of surveys and analysis of resultant data are used. The survey report package for the homeowner or industrial client contains black-white thermograms, associated conventional color photographs, analysis results which identify defects and corrective action priorities and a summary of areas investigated. Infrared surveys are typically conducted from the building interior and, in the case of non-residential structures, may include roof scanning. Specific procedures will vary with the survey project.

Business is targeted at the following client-type breakdown: private industry, architects and consulting engineers, and building owners. Future trends include the expansion of electro-mechanical and energy conservation studies for private industry and the expansion of roof inspections for architect/engineer firms.

\section{RESIDENTIAL SURVEYS}

Residential surveys are performed from the inside and include an infrared examination of all ceilings, exterior walls, windows, doors, etc. As indicated in the general comments, the resultant report contains an analysis of noted faults and provides recommended actions. Air velocity measurements are taken where appllcable.

\section{INDUSTRIAL SURVEYS}

Most of the industrial surveys done have either been of electro-mechanical systems contained in or about the facility or of roofs. The typical procedure is to use one infrared camera operator plus accompanying plant personnel. All roof scans are done at night. The industrial survey report consists of a summary listing all items inspected whether defective or not, and each defect covered on a separate page containing the thermogram and matching color control photograph, plus a card with identification, location, temperature, probable cause of defect and recommended corrective action. Roof data includes a roof drawing with defects marked. 
FIRM

No. 5

Thermal Surveys, Inc.

Post Office Box 2155

Rockford, Illinois 61130

CONTACT

Henry H. Schmalz

(815) $633-2473$

Infrared Scanning Equipment

AGA Thermovision 750

Barnes Thermatrace

Daedalus Vanscan

FLIR Systems 100

Hughes Probeye 650

Inframetries 510

Residential Surveys Performed

Thermogram Record Format

Polaroid Photograph

$35 \mathrm{~mm}$ Film

Video Tape

Black-White

Color

Survey Procedure

Interior Scans

Exterior Scans

(Using Mobile Van)

Report Contents

Thermograms

Control Photographs

Defects Analysis

Recommended Action

Average Survey Time: 45 minutes

Average Survey Cost: $\$ 98$
Industrial Surveys Performed

Thermogram Record Format

Polaroid Photograph

$35 \mathrm{~mm}$ Film

Video Tape

Black-White

Color

Survey Procedure

Interior Scans

Exterior Scans

(Using Mobile Van)

(Using Helicopter)

Report Contents

Thermograms

Control Photographs

Defects Analysis

Recommended Actions

Summary Report

Full Report

Audio Tape Report

Video Tape Report

Average Survey Time 4-8 hours

Average Survey Cost: $\$ 400-\$ 1,000$

Residential Survey Client Categories

Homeowner

Municipality

Utility

Building Developer

Community Organization

Industrial Survey Client Categories

Industrial Firms

Commercial Firms

Public Buildings

Utilities 


\section{GENERAL}

Thermal Surveys, Incorporated, is a Rockford, Illinois, based firm which performs both residential and industrial thermal surveys using an AGA Thermovision 750 System. Thermographic data is recorded as hard copy using black-white Polaroid film. Additionally, data recorded during the ground survey can include outdoor temperature, indoor temperature and material emissivity. The survey procedure is to measure the interior surface temperature on exterior building components only. Data resulting from the thermographic inspection is presented to the client in the form of tabular equivalent insulation R-value, and both hourly and annual cost of heat loss per unit surface area. Data accuracies quoted are in the order of $R \pm 0.5$ for the range of $R-1$ to $R-5, R \pm 1$ for the range of $R-6$ to $R-15$ and $R \pm 3$ for the $\mathrm{R}-16$ to $\mathrm{R}-25$ range of thermal performance.

The current annual volume of business indicated is comparable to other firms of similar size. However, the projected annual volume is estimated to be about $2 \frac{1}{2}$ times the current volume. The future business trend noted by this firm is towards a greater emphasis on building heat loss surveys and energy audits.

\section{RESIDENTIAL THERMÁL SURVEYS}

An interior qualitative thermographic inspection is made of the home and photographs made where appropriate. Survey results are presented in the form of mounted photographs, thermal interpretation notes, and indicated correction actions, all assembled in a bound report.

\section{INDUSTRIAL SURVEYS}

Time to perform an industrial thermal survey varies with plant size and specific client needs, but will generally fall in the range of 4 to 8 hours. Interior surface temperature measurements only are made and photographs of areas warranting corrective action taken. Data is assembled and results presented in the manner described earlier. 
FIRM

Energy Recovery Englneering, Inc.

No. 6

Post Office Box 2327

(Energy Scanners)

Littleton, Colorado 80121

CONTACT

Heydon 2. Lewis, P.E. (303) $755-1884$

Infrared Scanning Equipment

AGA Thermovision 750

Barnes Thermatrace

Daedalus Vanscan

FLIR Systems 100

Hughes Probeye 650

Inframetrics 510

Residential Surveys Performed

Thermogram Record Format

\begin{tabular}{|c|c|}
\hline Polaroid Photograph & $D$ \\
\hline $35 \mathrm{~mm}$ Film & \\
\hline Video Tape & \\
\hline Black-White & $\sqrt{ }$ \\
\hline
\end{tabular}

Survey Procedure

Interior Scans

Exterior Scans

(Using Mobile Van)

Report Contents

Thermograms

Control Photographs

Defects Analysis

Recommended Action

Average Survey Time: 1 hour

Average Survey Cost: $\$ 100$ per $\mathrm{hr}$
Industrial Surveys Performed $\nabla$

Thermogram Record Format

\begin{tabular}{l|l} 
Polaroid Photograph__ & _ \\
$35 \mathrm{~mm}$ Film & \\
Video Tape & \\
Black-White & Color \\
\hline
\end{tabular}

Survey Procedure

Interior Scans

Exterior Scans

(Using Mobile Van)

(Using Helicopter)

\section{Report Contents}

Ther mograms

Control. Photographs

Defects Analysis

Recommended Actions

Summary Report

Full Report

Audio Tape Report

- Video Tape Report

Average Survey Time 1 or more days

Average Survey Cost: $\$ 500-\$ 1,000$

Residential Survey Client Categories

Homeowner

Municipality

Utility

Building Developer

Community Organization

Industrial Survey Client Categories

Industrial Firms

Commercial Firms

r.

Public Buildings

Utilities 


\section{GENERAL}

Energy Recovery Engineering, Inc., is an Energy Scanners affiliate based in Littleton, Colorado, which performs both residential and industrial types of thermal surveys. Infrared surveys are performed with an AGA Thermovision 750 System which provides both a televison-type display and Polaroid film record of a thermogram. Standard procedures developed by Energy Scanners are used in the conduct of thermal surveys and in the resulting data interpretation and report preparation.

The firm will be adding a "super sucker" (high capacity exhaust fan to reduce inbuilding air pressure) capability to its survey procedures to track down air infiltration easier at lower indoor-outdoor temperature differentials. This feature will also enable surveys to be conducted on the warmer winter days when such thermographic inspections are not normally conducted. The firm will also be adding a computerized building-envelope heat loss audit capability for use in the thermal inspection of residential resales. In the current first year of its operation, the firm has done a modest volume of business when compared to more established organizations. It does, however, project a 3 to 5 times increase in future annual business.

\section{RESIDENTIAL THERMAL SURVEYS}

Residential surveys are conducted mostly from within the home except that the outside of the house will be checked to determine if there are any thermal problems with the foundation, structure overhang or the second floor ring joist. An engineering report incorporating paired photographs and thermograms and a summary sheet of problem areas detected is given to the homeowner.

\section{INDUSTRIAL SURVEYS}

Industrial surveys are planned in advance of the actual inspection process. A survey route within the industrial facility is laid out and preparations are made to have all areas opened by client personnel ahead of the survey team. The resulting engineering report includes all items requiring documentation, paired thermograms and photographs, and identification cards for each pair. Hospitals additionallyreceive a complete list of items surveyed for incorporation into their annual inspection reports. 
FIRM

West Shore Industrial Testing, Inc.

700 Ottawa Avenue

Holland, Michigan 49423

CONTACT

Don Wiersma

(616) $396-8060$

Infrared Scanning Equipment

AGA Thermovision 750

Barnes Thermatrace

Daedalus Vanscan

FLIR Systems 100

Hughes Probeye 650

Inframetrics $510^{\circ}$

Residential Surveys Performed

Thermogram Record Format

\begin{tabular}{l|l|}
\cline { 2 - 2 } Polaroid Photograph_ & \\
35mm Film & \\
Video Tape & D \\
Black-White & \\
Color &
\end{tabular}

Survey Procedure Interior Scans Exterior Scans

(Using Mobile Van)

\section{Report Contents}

Thermograms

Control Photographs

Defects Analysis

Recommended Action

Average Survey Time: 1 hour

Average Survey Cost: $\$ 75$
Industrial Surveys Performed

Thermogram Record Format

\begin{tabular}{l|l} 
Polaroid Photograph__ & $\emptyset$ \\
$35 \mathrm{~mm}$ Film & \\
Video Tape & \\
Black-White & \\
\hline Color & \\
\hline
\end{tabular}

Survey Procedure

Interior Scans

Exterior Scans

(Using Mobile Van)

(Using Helicopter)

\section{Report Contents}

Thermograms

Control Photographs

Defects Analysis

Recommended Actions

Summary Report

Full Report

Audio Tape Report

Video Tape Report

Average Survey Time 6-12 hours

Average Survey Cost: $\$ 53$ per hour

\section{Residential Survey Client Categories}

Homeowner

Municipality

Utility

Building Developer

Community Organization

Industrial Survey Client Categories

Industrial Firms

$95 \%$

Commercial Firms

Public Buildings

Utilities 
FIRM West Shore Industrial Testing, Inc.

No. 7

\section{GENERAL"}

West Shore Industrial Testing, Inc., is a Holland, Michigan, based firm which performs residential and industrial types of thermal surveys using an AGA Thermovision 750. System. Most surveys currently being performed are for industrial clients and are primarily concerned with locating electrical system defects and plant roof degradation. A walk-around survey procedure is used, observing thermal imagery to locate possible defects. Results are presented to the client in the form of an, informal report containing Polaroid film records of thermograms and related conventional photographs.

\section{RESIDENTIAL' THERMAL SURVEYS}

A thermal survey of a home will include thermographic inspection of the building's envelope from the interior. Results are presented to the homeowner in a report format consisting of one thermogram-photograph pair and related commentary per page.

\section{INDUSTRIAL SURVEYS}

A walk-around procedure is used to inspect the thermal performance of electrical systems and roofs of an industrial facility. Polaroid film records of thermograms and associated photographs are made where defective conditions are noted. The survey report incorporates the hard-copy film record, descriptions of observed thermal defects and appropriate recommended action. 
FIRM

Diversified Inspections, Inc.

No. 8

2012 West Ironwood Drive

(Energy Scanners)

Phoenix, Arizona 85021

CONTACT

Leland S, Bisbee, III

(602) $944-4497$

Infrared Scanning Equipment

AGA Thermovision 750

Barnes Thermatrace

Daedalus Vanscan

FLIR Systems 100

Hughes Probeye 650

Inframetrics 510

Residential Surveys Performed $\nabla$

Thermogram Record Format

\begin{tabular}{l|l}
\cline { 2 - 2 } Polaroid Photograph__ & \\
$35 \mathrm{~mm}$ Film & \\
Video Tape & \\
Black-White & \\
Color &
\end{tabular}

Survey Procedure

Interior Scans

Exterior Scans

(Using Mobile Van)

Report Contents

Ther mograms

Control Photographs

Defects Analysis

Recommended Action

Average Survey Time: 1 hour

Average Survey Cost: ' $\$ 75$
Industrial Surveys Performed

Thermogram Record Format

\begin{tabular}{l|l} 
Polaroid Photograph__ & _ \\
$35 \mathrm{~mm}$ Film & \\
Video Tape & $\checkmark$ \\
Black-White & \\
Color &
\end{tabular}

Survey Procedure Interior Scans Exterior Scans

(Using Mobile Van)

(Using Helicopter)

Report Contents

Thermograms

Control Photographs

Defects Analysis

Recommended Actions

Summary Report

Full Report

Audio Tape Report

Video Tape Report

Average Survey Time 4 hours

Average Survey Cost: $\$ 400$ per b1dg

\section{Residential Survey Client Categories}

Homeowner

Municipality

Utility

Building Developer

Community Organization:

Industrial Survey Client Categories

Industrial Firms _

Commercial Firms

Public Buildings

Utilities 
FIRM Diversified Inspections, Inc.

\section{GENERAL}

Diversified Inspections, Inc., is an Energy Scanners affiliate based in Phoenix, Arizona, which performs thermal surveys for both residential and industrial clients. Infrared surveys are performed with an AGA Thermovision 750 System which provides a thermographic display and Polaroid hard-copy film record. Energy. Scanners' developed standard thermal survey procedures and report preparation format are used. In addition to thermogram and conventional photographic records, data recorded during the survey includes: inside-outside air temperature, building internal air pressure (+ or - ), time of survey, wind velocity, reference temperature and isotherm difference.

The initial current volume of business is modest when compared to similar established firms, but is expected to grow to 4 times this level in the second year of operation. This firm believes that the future trend is a growing public awareness of infrared technology and equipment and their application to heat loss assessment.

\section{RESIDENTIAL THERMAL SURVEYS}

The procedure used for residential surveys is to perform a thermographic inspection overview from outside the house and conduct a more detailed interior survey. Results of the inspection are presented in a report incorporating real and infrared pictures with corresponding data report cards noting observed abnormalities and suggested corrective actions.

\section{INDUSTRIAL SURVEYS}

Industrial thermal surveys are conducted initially from outside the building. Exterior survey results are then used to provide guidance in the conduct of the more detailed interior inspections. Report format is essentially the same as for residential surveys. 
FIRM

Thermography of California

Division of Harbor Electric Company Inc.

610 Bryant Street

San Francisco, California 94107

\section{CONTACT}

Nick Morgan

(415) $986-4085$

\section{Infrared Scanning Equipment}

AGA Thermovision 750

Barnes Thermatrace

Daedalus Vanscan

FLIR Systems 100

Hughes Probeye 650

Inframetrics 510

No. 9

(Energy Scanners)
Residential Surveys Performed

Thermogram Record Format

Polaroid Photograph

$35 \mathrm{~mm}$ Film

Video Tape

Black-White

Color

Survey Procedure

Interior Scans

Exterior Scans

(Using Mobile Van)

Report Contents

Ther mograms

Control Photographs

Defects Analysis

Recommended Action

Average Survey Time:

Average Survey Cost:
Industrial Surveys Performed D

Thermogram Record Format

\begin{tabular}{l|l}
\hline Polaroid Photograph___ & \\
$35 \mathrm{~mm}$ Film & \\
Video Tape & \\
Black-White & \\
Color & \\
\hline
\end{tabular}

Survey Procedure Interior Scans

Exterior Scans

(Using Mobile Van)

(Using Helicopter)

\section{Report Contents}

Thermograms

Control Photographs

Defects Analysis

Recommended Actions

Summary Report

Full Report

Audio Tape Report

Video Tape Report

Average Survey Time 1 day

Average Survey Cost:

\section{Residential Survey Client Categories}

Homeowner

Municipality

Utility

Building Developer

Community Organization

Industrial Survey Client Categories Industrial Firms

Commercial Firms

Public Buildings

Utilities 


\section{GENERAL}

Thermography of California is an Energy Scanners affiliate based in San Francisco, which performs both residential and industrial types of thermal surveys. Infrared surveys are performed with an AGA Thermovision 750 System which provides a thermographic display and a Polaroid hard-copy film record. Standard thermal survey and report preparation procedures are used in accordance with Energy Scanner provided guidelines. A report is submitted which includes a letter of explanation and an analysis of the thermogram. Other information may also be submitted, such as the results of moisture probes and core cuts on roofs if the client desires more detailed information.

This firm is directing its initial survey efforts at the industrial and institutional client market. Business in such areas is expected to grow as conservation sensitivities and needs increase with the rising cost of energy.

\section{RESIDENTIAL THERMAL SURVEYS}

Current thermal survey activity is initially being targeted towards the nonresidential type of client. It is expected that residential surveys will be provided in the future as this market develops.

\section{INDUSTRIAL SURVEYS}

The procedure for an industrial survey will depend upon the size of the facility inspected, the information required of the survey by the client, and other sitespecific factors. Data is collected by an operator or a team of specialists appropriate to survey needs. This is coordinated with any consultant's or engineer's efforts related to the survey project. Data collected at the site is returned to the survey firms office for more detailed analysis and preparation of the survey report. 
FIRM

Infra-Scan of Vermont

No. 10

$\mathrm{RD}-2$, Box 143

Shelburne, Vermont 05482

CONTACT

Paul Grover

(802)

$985-2500$

Infrared Scanning Equipment

AGA Thermovision 750

Barnes Thermatrace

Daedalus Vanscan

FLIR Systems 100

Hughes Probeye 650

Inframetrics 510

Residential Surveys Performed $\downarrow$

Thermogram Record Format

Polaroid Photograph

$35 \mathrm{~mm}$ Film

Video Tape

Black-White

Color

Survey Procedure

Interior Scans

Exterior Scans

(Using Mobile Van)

\section{Report Contents}

Thermograms

Control Photographs

Defects Analysis

Recommended Action

Average Survey Time: 2 hours

Average Survey Cost: $\$ 150$
Industrial Surveys Performed

Thermogram Record Format

Polaroid Photograph

$35 \mathrm{~mm}$ Film

Video Tape

Black-White

Color

Survey Procedure

Interior Scans

Exterior Scans

(Using Mobile Van)

(Using Helicopter)

\section{Report Contents}

Thermograms

Control Photographs

Defects Analysis

Recommended Actions

Summary Report

Full Report

Audio Tape Report

Video Tape Report

Heat Loss - 2 hours

Average Survey Time Roof -2 days

Average Survey Cost Heat Loss $\$ 150$

\section{Residential Survey Client Categories}

Homeowner

Municipality

Utility

Building Developer

Community Organization

Industrial Survey Client Categories

Industrial Firms

Commercial Firms

Public Buildings

Utilities 


\section{GENERAL}

Infra-Scan of Vermont performs both residential and industrial types of thermal surveys. Thermographic inspections are made with a Hughes Probeye Model 650 thermal imaging unit which incorporates the use of $35 \mathrm{~mm}$ film to make control photograph and thermogram hard copy records. Company developed procedures are used in the conduct of WINTER CHECK Home Heat Loss Surveys and preparation of the survey report. Industrial surveys include the option of conducting flat roof inspections according to company prepared inspection and reporting procedures.

\section{RESIDENTIAL THERMAL SURVEYS}

Survey features indicated here include those incorporated into both residential and commercial/industrial building heat loss surveys. Typical survey procedure is to first scan the house from the outside and then scan exterior walls from the inside. The attic is then entered and the floor scanned. Finally, fuse boxes and circuit breakers are checked with an infrared scan to locate any hot-spot electrical faults. Results are presented in a report summarizing findings and recommended corrective actions. Included are thermograms and control photographs of problem areas (4 to 6 areas are typically significant), sketches of all sidewall insulation voids and Infra-Scan technical handout sheets discussing different problems and solutions.

\section{INDUSTRIAL SURVEYS}

Industrial heat loss surveys are conducted as described above. An additional survey program available to commercial/industrial clients is the Infra-Scan Roof Moisture Survey. A roof is scanned, on foot, at night, and thermal anomalies detected are marked on the roof membrane with spray paint. As a result of this scan process, a map of indicated anomalies is prepared and roof surface core samples are taken for subsequent analysis. A report is prepared summarizing findings and recommending corrective actions. Included in the report are thermograms and control photographs, a map delineating areas of wet insulation in the roof, and analysis data for the roof core sample. 
FIRM

Environmental Thermography and Testing Services, Inc. Post Office Box 5462

Hilton Head Island, South Carolina 29928

CONTACT

Frank T. Caruso

(803) 785-8797

Infrared Scanning Equipment

AGA Thermovision 750

Barnes Thermatrace

Daedalus Vanscan

FLIR Systems 100

Hughes Probeye 650

Inframetrics 510

Residential Sürveys Performed

Thermogram Record Format

\begin{tabular}{l|l|}
\hline Polaroid Photograph & \\
$35 \mathrm{~mm}$ Film & \\
Video Tape & \\
Black-White & ل \\
Color & \\
\hline
\end{tabular}

Survey Procedure

Interior Scans

Exterior Scans

(Using Mobile Van)

\section{Report Contents}

Thermograms

Control Photographs

Defects Analysis

Recommended Action

Average Survey Time: 2 hours

Average Survey Cost:.$\$ 200$
Industrial Surveys Performed $\square$

Thermogram Record Format

Polaroid Photograph

$35 \mathrm{~mm}$ Film

Video Tape

Black-White

Color

Survey Procedure

Interior Scans

Exterior Scans

(Using Mobile Van)

(Using Helicopter)

Report Contents

Thermograms

Control Photographs

Defects Analysis

Recommended Actions

Summary Report

Full Report

Audio Tape Report

Video Tape Report

Average Survey Time 2 days

Average Survey Cost: $\$ 500 \&$ up

\section{Residential Survey Client Categories}

Homeowner

Municipality

Utility

Building Developer

Community Organization

\begin{tabular}{|l|l|}
\hline & $d$ \\
\hline & $d$ \\
\hline & $y$ \\
\hline
\end{tabular}

Industrial Survey Client Categories

Industrial Firms

Commercial Firms

Public Buildings

Utilities 


\section{GENERAL}

Environmental Thermography and Testing Services, Inc., is a firm having bases in Florida and South Carolina. This firm uses an AGA Thermovision 750 System to conduct both residential and industrial types of thermal surveys. The company also performs aerial rooftop surveys and provides thermographic video tapes when required. In addition to thermograms and control photographs, additional data recorded includes: date, time, ambient conditions, weather, various reference temperatures taken with digital contact instrumentation, as well as emissivity differentials, inside ambient temperatures and noted extraneous heated sources. Typical ground survey procedure is to first conduct an outside survey of the sidewalls, windows, doors and the rooftop. The inside survey includes exterior wall surfaces, windows and doors. Substantial use is made of thermographic mosaic overlays, especially for industrial and commercial clients, and for all aerial rooftop surveys. The current volume of business indicated for both residential and industrial clients combined is somewhat better than that generally reported. Projected annual volume indicated is about twice the current level reported.

\section{RESIDENTIAL THERMAL SURVEYS}

The typical survey is performed with a crew of 2 which travels by vehicle and sets up in each locale. All surveys are performed during evening hours and at least 4 sides of a dwelling are covered whenever possible of a building with a single thermogram. Results are presented to the client in the form of a written/graphic report. The details and depth of the report will depend upon the survey requested. Dollar costing and payback data can also be prepared.

\section{INDUSTRIAL SURVEYS}

In an industrial survey, the entire building envelope is recorded in the form of a multi-thermogram mosaic, with close ups of areas of interest and detailed temperature measurements recorded both with the Thermovision's isotherm measuring mode and remote sensing equipment such as a Wahl Digital Unit. Multimedia presentation is ávailable, either on slide, opaque, video tape, or the conventional thermogram, generally as an $8 \times 10$ inch enlargement. Internegatives of thermogram mosaic overlays are generally constructed with conventional photograph side-by-side comparisons. 
Environmental Thermography and Testing Services, Inc. Post Office Box 1298

Dunedin, Florida 33528

CONTACT

Frank. T. Caruso

(813) $734-8398$

Infrared Scanning Equipment

AGA Thermovision 750

Barnes Thermatrace

Daedalus. Vanscan

FLIR Systems 100

Hughes Probeye 650

Inframetrles $510^{\circ}$

Residential Surveys Performed $\square$

Thermogram Record Format

\begin{tabular}{l|l} 
Polaroid Photograph__ & \\
$35 \mathrm{~mm}$ Film & \\
Video Tape & $\checkmark$ \\
Black-White & \\
Color &
\end{tabular}

Survey Procedure

Interior Scans.

Exterior Scans

(Using Mobile Van)

\section{Report Contents}

Thermograms

Control Photographs

Defects Analysis

Recommended Action

Average Survey Time: 2 hours

Average Survey Cost: $\$ 200$
Industrial Surveys Performed

$\phi$

Thermogram Record Format

\begin{tabular}{l|l|}
\hline Polaroid Photograph__ & $\gamma$ \\
$35 \mathrm{~mm}$ Film & $\gamma$ \\
Video Tape & $\gamma$ \\
Black-White & $\checkmark$ \\
\hline Color & $\checkmark$ \\
\hline
\end{tabular}

Survey Procedure

Interior Scans

Exterior Scans

(Using Mobile Van)

(Using Helicopter)

Report Contents

Ther mograms

Control Photographs

Defects Analysis

Recommended Actions

Summary Report

Full Report

Audio Tape Report

Video Tape Report

Average Survey Time 2 days

Average Survey Cost: $\$ 500 \&$ up

Residential Survey Client Categories

Homeowner

Municipality

Utility

Building Developer

Community Organization

Industrial Survey Client Categories

Industrial.Firms

Commercial Firms

88\% Public Buildings

Utilities 


\section{GENERAL}

Environmental Thermography and Testing Services, Inc., is a firm having bases in Florida and South Carolina. This firm uses an AGA Thermovision 750 System to conduct both residential and industrial types of thermal surveys. The company also performs aerial rooftop surveys and provides thermographic video tapes when required. In addition to thermograms and control photographs, additional data recorded includes: date, time, ambient conditions, weather, various reference temperatures taken with digital contact instrumentation, as well as emissivity differentials, inside ambient temperatures and noted extraneous heated sources. Typical ground survey procedure is to first conduct an outside survey of the sidewalls, windows, doors and the rooftop. The inside survey includes exterior wall surfaces, windows and doors. Substantial use is made of thermographic mosaic overlays, especially for industrial and commercial clients, and for all aerial rooftop surveys. The current volume of business indicated for both residential and industrial clients combined is somewhat better than that generally reported. Projected annual volume indicated is about twice the current level reported.

\section{RESIDENTIAL THERMAL SURVEYS}

The typical survey is performed with a crew of 2 which travels by vehicle and sets up in each locale. All surveys are performed during evening hours and at least 4 sides of a dwelling are covered whenever possible of a building with a single thermogram. Results are presented to the client in the form of a written/graphic report. The details and depth of the report will depend upon the survey requested. Dollar costing and payback data can also be prepared.

\section{INDUSTRIAL SURVEYS}

In an industrial survey, the entire building envelope is recorded in the form of a multi-thermogram mosaic, with close ups of areas of interest and detailed temperature measurements recorded both with the Thermovision's isotherm measuring mode and remote sensing equipment such as a Wahl Digital Unit. Multimedia presentation is available, either on slide, opaque, video tape, or the conventional thermogram, generally as an $8 \times 10$ inch enlargement. Internegatives of thermogram mosaic overlays are generally constructed with conventional photograph side-by-side comparisons. 
FIRM

No. 13

Trinity Associates, Inc.

(Energy Scanners)

Post Office Box 146

Swarthimore, Pennsylvania 19081

CONTACT

Al Loch or Jerry Rafter

(215) $544-0496$

Infrared Scanning Equipment

AGA Thermovision 750

Barnes Thermatrace

Daedalus Vanscan

FLIR Systems 100

Hughes Probeye 650

Inframetrics 510

Residential Surveys Performed

Thermogram Record Format

\begin{tabular}{l|l|} 
Polaroid Photograph & \\
$35 \mathrm{~mm}$ Film & \\
Video Tape & \\
Black-White & ل \\
Color &
\end{tabular}

Survey Procedure

Interior Scans

Exterior Scans

(Using Mobile Van)

\section{Report Contents}

Thermograms

Control Photographs

Defects Analysis

Recommended Action

Average Survey Time: 2 hours

Average Survey Cost: $\$ 80$
Industrial Surveys Performed

Thermogram Record Format

\begin{tabular}{l|l}
\hline Polaroid Photograph___ & \\
\hline $35 \mathrm{~mm}$ Film & \\
Video Tape & \\
Black-White & V \\
\hline Color & V
\end{tabular}

Survey Procedure

Interior Scans

Exterior Scans

(Using Mobile Van)

(Using Helicopter)

Report Contents

Thermograms

Control Photographs

Defects Analysis

Recommended Actions

Summary Report

Full Report

Audio Tape Report

Video Tape Report

Average Survey Time Varies

Average Survey Cost: $\$ 500$ plus

\section{Residential Survey Client Categories}

Homeowner

Municipality

Utility

Building Developer

Community Organization

Industrial Survey Client Categories

Industrial Firms

$795 \%$

Commercial Firms

Public Buildings

Utilities 


\section{GENERAL}

Trinity Associates, Inc., is an Energy Scanners affiliate based in Swarthmore, Pennsylvania, providing both residential and industrial types of thermal surveys. Infrared surveys are performed with the AGA Thermovision 750 System. Energy Scanners standardized procedures are used for the performance of surveys and analysis of resultant data. The survey report package will include thermograms, control photographs, analysis results and recommended actions. Additional data recorded during the ground survey includes emissivity of surfaces, surface temperature, distance from thermal imager sensor to the wall, and both inside and outside temperatures. The current volume of annual business by this firm is indicated in the typical range. The projected increase in annual sales is about $50 \%$ of the current level.

\section{RESIDENTIAL THERMAL SURVEYS}

The survey is usually performed at night with the homeowner present. Thermal inspection is made of both the interior and exterior surfaces of the buildings thermal envelope. An oral report to the client, with an on-site prepared handwritten report and typically 2 thermograms, will cost in the range of $\$ 40.00$ to $\$ 60.00$, while the cost of a typewritten report with thermograms of each problem area would be about $\$ 100.00$ to $\$ 140.00$.

\section{INDUSTRIAL SURVEYS}

Industrial thermal surveys will include thermographic inspection of a building's exterior, roof scans for flat roof building structures, interior scans of exterior walls, and may include checks of steam line distribution sytems and electrical power distribution components. Thermal surveys may also incorporate building energy audits indicating existing and potentially improved energy consumption data. A full survey report will include thermograms, control photographs, analysis results and recommended actions. 
FIRM

General Electric Company

No. 14

P.0. Box 30697, 141 Providence Road

Charlotte, North Carolina 28207

CONTACT

M.C. Jones

(704) $371-3300$

Infrared Scanning Equipment

AGA Thermovision 750

Barnes Thermatrace

Daedalus.Vanscan

FLIR Systems 100

Hughes Probeye 650

Inframetrics 510

Residential Surveys Performed

Thermogram Record Format

Polaroid Photograph

$35 \mathrm{~mm}$ Film

Video Tape

Black-White

Color

Survey Procedure

Interior Scans

Exterior Scans

(Using Mobile Van)

Report Contents

Thermograms

Control Photographs

Defects Analysis

Recommended Action

Average Survey Time:

Average Survey Cost:

\section{Residential Survey Client Categories}

Homeowner

Municipality

Utility

Building Developer

Community Organization

Industrial Survey Client Categories

Industrial Firms

Commercial Firms
Industrial Surveys Performed

Thermogram Record Format

Polaroid Photograph

$35 \mathrm{~mm}$ Film

Video Tape

Black-White

Color

Survey Procedure

Interior Scans

Exterior Scans

(Using Mobile Van)

(Using Helicopter)

\section{Report Contents}

Thermograms

Control Photographs

Defects Analysis

Recommended Actions

Summary Report

Full Report

Audio Tape Report

Video Tape Report

Average Survey Time $\frac{1}{2}$ to 6 days

Average Survey Cost: $\$ 400-\$ 5,000$

\section{$r$}

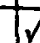

[1]
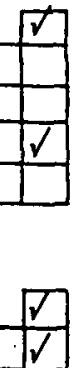

1

\begin{tabular}{|l|l|}
\cline { 2 - 2 } & 7 \\
\hline & 7 \\
\hline & 7 \\
\hline & 7 \\
\hline & \\
\hline
\end{tabular}

Public Buildings

Utilities 


\section{GENERAL}

This facility of the General Electric Company, based in Charlotte, North Carolina, uses an AGA Thermovision 750 System, as do other G.E. facilities providing similar services, to conduct thermal surveys of a particular type, i.e., primarily the inspection of electrical devices and electrical power distribution components such as switch-gear, circuit breakers, transformers and transmission line connection elements. Thermal faults in electrical equipment fall generally into two categories, localized hot spots at electrical contact or connection points and areas of excessive heat such as may occur on motors or transformers due to overload conditions. General Electric has developed its own procedures for the conduct of surveys and preparation of reports. Survey documentation is similar to that prepared for búilding heat loss assessment in that it will incorporate thermograms and their associated control photographs in the fault analysis report. The current volume of annual business at this company location appears modest but is expected to increase in the future. Most survey clients are in either the industrial or electric utility category.

\section{RESIDENTIAL THERMAL SURVEYS}

These are not currently performed.

\section{INDUSTRIAL SURVEYS}

These surveys are primarily directed at the use of thermographic inspection procedures to locate points or areas of excessive heat on electrical equipments, such conditions generally being indicative of a fault in the component. The survey is conducted by a General Electric field engineer who subsequently develops the report incorporating hard copy data, analyses and recommended actions. 
FIRM

Asplundh

Infrared Services Division

Blair Mill Road

No. 15

Willow Grove, Pennsylvania 19090

CONTACT

Nick Hirsch

(215) $784-4245$

Infrared Scanning Equipment

AGA Thermovision 750

Barnes Thermatrace

Daedalus. Vanscan

FLIR Systems 100

Hughes Probeye 650

Inframetrirs 510

Residential Surveys Performed

Thermogram Record Format

\begin{tabular}{l|l|}
\hline Polaroid Photograph_. & \\
$35 \mathrm{~mm}$ Film & \\
Video Tape & \\
Black-White & \\
Color &
\end{tabular}

Survey Ṕrocedure Interior Scans

Exterior Scans

(Using Mobile Van)

Report Contents

Thermograms

Control Photographs

Defects Analysis

Recommended Action

Average Survey Time:

Average Survey Cost:
Industrial Surveys Performed $\nabla$

Thermogram Record Format

\begin{tabular}{l|l|} 
Polaroid Photograph___ & \\
$35 \mathrm{~mm}$ Film & \\
Video Tape & \\
Black-White & $\swarrow$ \\
\hline Color & \\
\hline
\end{tabular}

Survey Procedure Interior Scans Exterior Scans

(Using Mobile Van)

(Using Helicopter)

Report Contents

Thermograms

Control Photographs

Defects Analysis

Recommended Actions

Summary Report

Full Report

Audio Tape Report

Video Tape Report

Average Survey Time $1-3$ days

Average Survey Cost: $\$ 600-\$ 1,500$

Residential Survey Client Categories

Homeowner

Municipality

Utility

Building Developer

Community Organization

Industrial Survey Client Categories

Industrial Firms

Commercial Firms

Public Buildings

Utilities 


\section{GENERAL}

The Infrared Services Division of ASPLUNDH is a Willow Grove, Pennsylvania, based firm providing. primarily industrial thermal surveys. The firm's major activity is the conduct of infrared inspection services for detecting electrical equipment "hot spots", building heat leakage, and faulty processing equipment. Inspections are performed at either aerial or ground levels using the AGA Thermovision 661 or 750 Systems, each of which has both thermogram display. and Polaroid hard copy preparation capabilities. Company developed procedures are used in the conduct of surveys and preparation of survey reports which incorporate thermograms, control photos, fault analysis and recommended actions.

\section{INDUSTRIAL SURVEYS}

Surveys' will be conducted from either the inside or outside depending upon equipment locations. Where equipment locations are spread out over a large area, inspections are conducted from a vehicle. Thermograms and associated control photographs are incorporated in a standardized report format which provides for the indication of location, date, time and weather data and specific fault descriptions with recommended corrective actions. 'Temperature data provided includes ambient, reference and hot spot values. 
FIRM

No. 16

Westinghouse Electric Corporation.

1005 Sussex Boulevard

Lawrence Park Industrial District

Brooma11, Pennsylvania 19008

CONTACT

D.R. Boone

(215) $543-9030$

\section{Infrared Scanning Equipment}

AGA Thermovision 750

Barnes Thermatrace

Daedalus.Vanscan

FLIR Systems 100

Hughes Probeye 650

Inframetrics 510

Residential Surveys Performed

Thermogram Record Format

\begin{tabular}{l|l} 
Polaroid Photograph_. & \\
$35 \mathrm{~mm}$ Film & \\
Video Tape & \\
Black-White__ & \\
Color &
\end{tabular}

Survey Procedure

Interior Scans

Exterior Scans

(Using Mobile Van)

\section{Report Contents}

Thermograms

Control Photographs

Defects Analysis

Recommended Action

Average Survey Time:

Average Survey Cost:
Industrial Surveys Performed [n]

Thermogram Record Format

Polaroid Photograph

$35 \mathrm{~mm}$ Film

Video Tape

Black-White

Color

Survey Procedure

Interior Scans

Exterior Scans

(Using Mobile Van)

(Using Helicopter)

\section{Report Contents}

Thermograms

Control Photographs

Defects Analysis

Recommended Actions

Summary Report

Full Report

Audio Tape Report

Video Tape Report

Average Survey Time 2 days

Average Survey Cost: $\$ 500$ per day

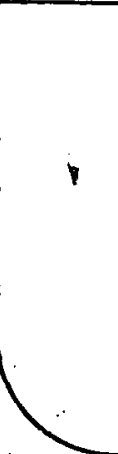

Residential Survey Client Categories

Homeowner

Municipality

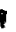

Utility

Building Developer.

Community Organization

Industrial Survey Client Categories Industrial Firms

Commercial Firms

Public Buildings

Utilities 


\section{GENERAL}

The Westinghouse Electric Corporation in their Philadelphia, Pennsylvania, area location uses an AGA Thermovision 750 System, with its thermogram display and Polaroid film hard copy features, to conduct thermal surveys which currently are used primarily to detect equipment hot spots. A full report is prepared indicating fault conditions found and incorporating black-white thermograms and associated Polaroid control color photographs. The near term volume of annual business is indicated as steady for this primarily industrial business category. A favorable business growth is expected due to the firm's belief that thermographic inspection is a very good preventive maintenance tool. About $95 \%$ of the survey assignments are related to electrical equipment fault detection and steam line insulation checks.

\section{RESIDENTIAL THERMAL SURVEYS}

Residential heat loss surveys are not performed at this time.

\section{INDUSTRIAL SUR VEYS}

Electrical equipment hot spot inspections are conducted by a Westinghouse engineer accompanied by the client's electrician. The electrician identifies equipment locations, records inspection and local site data and, where required, provides access to equipment interior. Typical time to conduct on industrial survey is 2 days. 
FIRM

Infra-Red Scanning Services

No. 17

Post Office Box 343

Beaver, Pennsylvania 15009

CONTACT

Edward R. Schaufler, P.E.

(412) $775-3735$

Infrared Scanning Equipment

AGA Thermovision 750

Barnes Thermatrace

Daedalus .Vanscan

FLIR Systems 100

Hughes Probeye 650

Inframetrics 510

Residential Surveys Performed

Thermogram Record Format

Polaroid Photograph

$35 \mathrm{~mm}$ Film

Video Tape

Black-White

Color

Survey Procedure

(For Homeowners) Interior Scans

(For Contractors) Exterior Scans

(Using Mobile Van)

\section{Report Contents}

Thermograms

Control Photographs

Defects Analysis

Recommended Action

A verage Survey Time: 1 hour

Average Survey Cost: $\$ 100$
Industrial Surveys Performed



Thermogram Record Format

Polaroid Photograph

$35 \mathrm{~mm}$ Film

Video Tape

Black-White

Color

Survey Procedure

Interior Scans

Exterior Scans

(Using Mobile Van)

(Using Helicopter)

\section{Report Contents}

Thermograms

Control Photographs

Defects Analysis

Recommended Actions

Summary Report

Full Report

Audio Tape Report

Video Tape Report

Average Survey Time $1-3$ days

Average Survey Cost: $\$ 600$ per day

Residential Survey Client Categories

Homeowner

Municipality

Utility

Building Developer

Community Organization

Industrial Survey Client Categories

Industrial Firms

$75 \%$

Commercial Firms

Public Buildings

Utilities 


\section{GENERAL}

Infra-Red Scanning Services is a Pennsylvania based firm which performs thermal surveys for both residential and industrial clients. Infrared surveys are performed with an AGA Thermovision 750 System. This firm also utilizes a color thermographic display. Additional data recorded during a ground survey includes date, time, air temperature, wind velocity and direcțion, and atmospherlc conditions. The general procedure is to conduct an outside infrared inspection of the entire building exterior wall surface and roof, and an inside inspection which would include the entire interior wall, ceiling and floor surface. The current volume of annual business is above that indicated as average for such firms. The projected annual sales volume is $2 y_{2}$ times the current level. The firm feels that there is a strong future business trend in both industrial and residential areas of thermal survey. Because of the engineering capability available, projects undertaken have included R/D applications and litigation cases.

\section{RESIDENTIAL THERMAL SURVEYS}

Two types of residential survey are conducted, depending on client requirements. The exterior type takes about 10 minutes and is provided at an average cost of $\$ 40.00$. This service is made available only to building contractors and clients requiring multiple home surveys. The interior type, available to homeowners and others, takes about 1 hour and costs an average of $\$ 100.00$. In both cases, reports include problem definition, evaluation and recommendations. For residential surveys, data presented to the homeowner consists of black-white Polaroid prints of the thermograms and control photographs mounted in report form with engineering analysis and correction recommendations.

\section{INDUSTRIAL SURVEYS}

Thermograms and visual prints are assembled into a bound report with engineering analysis. Problem definition, evaluation and recommendations are included. The entire survey and report preparation are under the supervision of a registered professional engineer. Non-residential survey results may use color thermograms and also include a video tape or transparencies record with the engineering analysis. 
FIRM

Air Image Technology

No. 18

Minuteman Airfield

Stow, Massachusetts 01775

CONTACT

Robert Pooler

(617) 897-8303

\section{Infrared Scanning Equipment}

AGA Thermovision 750

Barnes Thermatrace

Daedalus. Vanscan

FLIR Systems 100

Hughes Probeye 650

Inframetrjçs 510

- Residential Surveys Performed

- Thermogram Record Format
$35 \mathrm{~mm}$ Film
Video Tape
Black-White
Color

Survey Procedure

$\therefore \quad$ Interior Scans

- Exterior Scans

.

(Using Mobile Van)

$1:$

Report Contents

$\because$ Thermograms

- Control Photographs

Defects Analysis

'.. "Récommended Action $+$.

Average Survey Time:

Average Survey Cost:
Industrial Surveys Performed

Thermogram Record Format

Polaroid Photograph

$35 \mathrm{~mm}$ Film

Video Tape

Black-White

Color

Survey Procedure

Interior Scans

Exterior Scans

(Using Mobile Van)

(Using Helicopter)

Report Contents

Thermograms

Control Photographs

Defects Analysis

Recommended Actions

Summary Report

Full Report

Audio Tape Report

Video Tape Report

Average Survey Time .2 days

A.verage Survey Costı $\$ 1,000$

Residential Survey Client Categories

Homeowner

Municipality

Utility

Building Developer

Community Organization

Industrial Survey Client Categories

Industrial Firms

$70 \%$

Commercial Firms

Public Buildings

$730 \%$

Utilities 


\section{GENERAL}

Air Image Technology is a Massachusetts based firm which performs ground and aerial thermal surveys primarily for industrial clients. Infrared surveys are performed with an Inframetrics 510 System. Thermal color imagery is available on a video tape record. Aerial thermal surveys are performed with a Bendix LN-2 Line Scanner. Additional data recorded during a ground survey includes date, time, air temperature, wind velocity, humidity, noted roof and sidewall conditions and their material composition. An on-site commentary is also developed during the course of the survey on an audio sound track. Exterior thermal scanning is conducted from either a modified van or a Bell Jet Ranger helicopter. Future business trends are expected to be sharply upward.

\section{RESIDENTIAL THERMAL SURVEYS}

Individual residential thermal survey services are not normally provided. The thermographic inspection equipment is instead made available for rental by firms, utilities or municipal agencies intending to conduct their own residential survey programs.

\section{INDUSTRIAL SUR VEYS}

The conduct of an industrial survey will include an aerial flyover (if specified), an infrared ground scan of the building's exterior, a building walk through, operational analysis and editing of the final presentation video tape record. The survey further includes a written report, presentation of all data to the client with a question and answer period, and ongoing consultation on a no-charge-as-available basis. Two video tapes are provided as part of the complete report, a tape of the entire survey conducted and an edited version of the tape which incorporates survey highlights and a 12 minute training film on the basic concepts of infrared techniques and heat loss surveys. 


\section{FIRM}

Power Save Systems, Inc.

1401 N.W. 78th Avenue - Suite 305

Miami, Florida 33126

CONTACT

Paul K. Duffy

Infrared Scanning Equipment

AGA Thermovision 750

Barnes Thermatrace

Daedalus Vanscan

FLIR Systems 100

Hughes Probeye 650

Inframetrics 510

Residential Surveys Performed

Thermogram Record Format

- Polaroid Photograph

$35 \mathrm{~mm}$ Film

Video Tape

Black-White

Color

Survey Procedure

Interior Scans

Exterior Scans

(Using Mobile Van)

\section{Report Contents}

Thermograms

Control Photographs

Defects Analysis

Recommended Action

Average Survey Time:

Average Survey Cost:

Residential Survey Client Categories

Homeowner

Municipality

Utility

Building Developer

Community Organization

Industrial Survey Client Categories

Industrial Firms

$75 \%$

Commercial Firms
Industrial Surveys Performed

th

Thermogram Record Format

Polaroid Photograph

$35 \mathrm{~mm}$ Film

Video Tape

Black-White

Color

Survey Procedure

Interior Scans

Exterior Scans

(Using Mobile Van)

(Using Helicopter)

Report Contents

Thermograms

Control Photographs

Defects Analysis

Recommended Actions

Summary Report

Full Report

Audio Tape Report

Video Tape Report

Average Survey Time 2 days

Average Survey Cost: $\$ 1,000$
Public Buildings Utilities 


\section{GENERAL}

Power Save Systems is a Miami, Florida, based firm which performs thermal surveys primarily for industrial clients. Infrared surveys are performed with a Hughes Probeye Infrared Viewer which utilizes a video display accessory to provide a thermographic display and Polaroid hard copy. film record. A video tape recording of the thermal survey is made for later playback through a standard television set. An audio channel is included with the video record to provide an onsite critique of conditions noted. Survey procedure consists of a building walk through for pertinent infrared image data gathering and observation of the building's construction, design, materials employed, etc. An assessment is also made of the building's problem history, maintenance procedures, and any retrofit activities.

\section{RESIDENTIAL THERMAL SURVEYS}

The firm is not currently attempting to market their services to the individual residential client. This area may be developed at a future date.

\section{INDUSTRIAL SUR VEYS}

In the conduct of an industrial survey, plant personnel are requested to accompany the inspector. During the walk through, plant personnel provide the inspector with a maintenance and repair history of the building and any other significant data. The basic infrared viewer is employed initially for general observations. The video camera is later attached to develop documentation. Typical procedure is to provide playback of the data at the end of the survey day and later follow-up with the client by providing Polaroid pictures and the analysis. A recommendation is generally made to the client that a follow-up inspection be made immediately after a maintenance program is completed. In addition to thermal envelope defects, the infrared survey will detect poor bonds in stucco walls and abnormal moisture in roofs due to poor workmanship when using certain construction materials. The current volume of annual business is in the average range. The volume of business is expected to double within the next 2 years. The firm believes that the increasing acceptance and understanding of infrared thermal surveys promises a very bright future. 


\section{FIRM}

Reed Consultants

No. 20

2230 N. 166th Street

(Energy Scanners)

Brookfield, Wisconsin 53005

CONTACT

George Reed

(414) 786-8099

\section{Infrared Scanning Equipment}

AGA Thermovision 750

Barnes Thermatrace:

Daedalus Vanscan

FLIR Systems 100

Hughes Probeye 650

Inframetrics 510

\section{Residential Surveys Performed $\emptyset$}

Thermogram Record Format

Polaroid Photograph

$35 \mathrm{~mm}$ Film

Video Tape

Black-White

Color

- Survey Procedure

Interior Scans

Exterior Scans

- (Using Mobile Van)

\section{Report Contents}

Thermograms

Control Photographs

Defects Analysis

Recommended Action

Average Survey Time:

Average Survey Cost:
Industrial Surveys Performed

Thermogram Record Format

Polaroid Photograph

$35 \mathrm{~mm}$ Film

Video Tape

Black-White

Color

Survey Procedure

Interior Scans
Exterior Scans

(Using Mobile Van)

(Using Helicopter)

Report Contents

Thermograms

Control Photographs

Defects Analysis

Recommended Actions

Summary Report

Full Report

Audio Tape Report

Video Tape Report

Average Survey Time

Average Survey Cost:

\section{Residential Survey Client Categories}

Homeowner

Municipality

Utility

Building Developer

Community Organization

Industrial Survey Client Categories

Industrial Firms

(7) $50 \%$

Commercial Firms

Public Buildings

Utilities 


\section{GENERAL}

Reed Consultants is an Energy Scanners affiliate based in Wisconsin which provides ground thermal survey services to both residential and non-residential categories of clients. Infrared surveys are performed with the AGA Thermovision 750 System. Detailed temperature, wind, and emissivity reference' data are recorded during the survey for post-analysis of thermographic results. Survey procedures are adjusted to meet specific project conditions, i.e., walk around, mobile van, or airborne type surveys. Techniques employed for effective presentation of results to the client include narrative report, analysis cards, Polaroid thermograms, black-white or color photographs, and use of video tape recording.

\section{RESIDENTIAL THERMAL SURVEYS}

Surveys are conducted from the inside of the building on a room-by-room basis. A data analysis card is prepared for each thermogram recorded. Thermal imagery can be conveniently assessed prior to making a decision to obtain a record and prepare the associated data card. A go or no-go type of comment is noted on the card depending upon whether or not a corrective action is warranted.

\section{INDUSTRIAL SURVEYS}

Surveys of the building exterior are usually performed from a mobile van. In this procedure, the infrared imaging system is used to make thermograms of outside walls in sequence. Data is assembled and results presented in the form of Polaroid film thermograms with their associated data analysis cards. A mosaic of adjacent wall thermograms may be prepared if a composite thermal image of an extended industrial building wall surface enhances data analysis or presentation of results. The typical time to conduct an industrial-type survey can vary widely. Total survey performance time will depend on factors such as the nature and amount of information requested by the industrial client, the size and type. of construction of buildings surveyed, weather conditions, etc. 
FIRM

Ferguson, Brosz and Associates, Limited

77 Progress Avenue

Scarborough, Ontario

Canada MIP 217

CONTACT

G.N.C. Ferguson

\section{Infrared Scanning Equipment}

AGA Thermovision 750

Barnes Thermatrace

Daedalus. Vanscan

FLIR Systems 100

Hughes Probeye 650

Inframetrics 510

Residential Surveys Performed

Thermogram Record Format

Polaroid Photograph

$35 \mathrm{~mm}$ Film

Video Tape

Black-White

Color

Survey Procedure

Interior Scans

Exterior Scans

(Using Mobile Van)

\section{Report Contents}

Thermograms

Control Photographs

Defects Analysis

Recommended Action

Average Survey Time: $\frac{1}{2}$ to 2 hours

Average Survey Cost: $\$ 80-\$ 200$
Industrial Surveys Performed

Thermogram Record Format

Polaroid Photograph

$35 \mathrm{~mm}$ Film

Video Tape

Black-White

Color

Survey Procedure

Interior Scans

Exterior Scans

(Using Mobile Van)

(Using Helicopter)

Report Contents

Ther mograms

Control Photographs

Defects Analysis

Recommended Actions

Summary Report

Full Report

Audio Tape Report

Video Tape Report

Average Survey Time 1-5 days

Average Survey Cost: $\$ 1,000-\$ 5,000$

Residential Survey Client Categories

Homeowner

Municipality

Utility

Building Developer

Community Organization

Industrial Survey Client Categories 90\%

Industrial Firms

Commercial Firms

Public Buildings

Utilities 


\section{GENERAL}

Ferguson, Brosz and Asśociates is an Ontario, Canada, based firm which provides ground thermal survey services to both residential and industrial clients. Infrared equipment available for infrared surveys icludes Inframetrics Models 525, 510 and 510 Pinto Thermal Imaging Systems, AGA Thermovision 750 Thermal Imaging System, and an Inframetrics Colorizer. Thermographic data is displayed and can be recorded in a variety of forms including $35 \mathrm{~mm}$, Polaroid film and video tape, each in black and white or in color. The basic ground survey includes data on ambient conditions, temperature references, and black and white video tape recordings of scanned areas. Digital spot contact thermometer calibration is used. Surveys are conducted from either portable carrier, mobile van or aircraft platform. The projected annual volume of business is expected to be about $20 \%$ over the current level. Most clients are either in the industrial, commercial or utility category. The future business trend is good. The firm feels that a particularly useful feature of its Inframetrics equipment is the video tape capability which allows for "comfort of office analysis".

\section{RESIDENTIAL THERMAL SURVEYS}

Average time to conduct a residential survey will fall in the range of $1 / 2$ to 2 hours. The corresponding average cost of a survey will range from $\$ 80$ to $\$ 200$. The survey is conducted with the man portable infrared equipment utilizing a Polaroid camera. Results are presented to the homeowner at the time of survey.

\section{INDUSTRIAL SURVEYS}

Typical time to perform an industrial survey can take from 1 to 5 days. The resultant average cost will range from $\$ 1,000$ to $\$ 5,000$. The survey may be conducted with hand held, mobile or aerial equipment mounting. Depending upon client requirements, data can be presented as hard copy Polaroid thermograms, $35 \mathrm{~mm}$ color film, and/or video tape records. 
FIRM

Tymark Corporation

7728 Mullraney Drive

Dallas, Texas 75248

CONTACT

Nancy V. Coalter
No. 22

(Energy Scanners)

\section{Infrared Scanning Equipment}

AGA Thermovision 750

Barnes Thermatrace

Daedalus Vanscan

FLIR Systems 100

Hughes Probeye 650

Inframetrics 510

(214) $386-8805$

Residential Surveys Performed

Thermogram Record Format

Polaroid Photograph_

$35 \mathrm{~mm}$ Film

Video Tape

Black-White

Color

Survey Procedure

Interior Scans

Exterior Scans

(Using Mobile Van)

Report Contents

Thermograms

Control Photographs

Defects Analysis

Recommended Action

Average Survey Time:

Average Survey Cost:
Industrial Surveys Performed

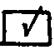

Thermogram Record Format

Polaroid Photograph

$35 \mathrm{~mm}$ Film

Video Tape

Black-White

Color

Survey Procedure

Interior Scans

Exterior Scans

(Using Mobile Van)

(Using Helicopter)

Report Contents

Thermograms

Control Photographs

Defects Analysis

Recommended Actions

Summary Report

Full Report

Audio Tape Report

Video Tape Report

Average Survey Time

Average Survey Cost:

Residential Survey Client Categories

Homeowner

Municipality

Utility

Building Developer

Community Organization

Industrial Survey Client Categories

Industrial Firms

Commercial Firms

Public Buildings

Utilities 
FIRM Tymark Corporation

No. 22

\section{GENERAL}

Tymark Corporation is an Energy Scanners affiliate based in Dallas, Texas, which performs residential and non-residential types of thermographic surveys. Infrared scans are performed with the AGA Thermovision 750 system which provides both a display and a Polaroid film thermographic hard copy ouptut. Survey procedures developed by Energy Scanners are used. These include the survey of the building's interior and exterior, preparation of a record of thermograms and the associated control photographs, and the formulation of conclusions and recommended actions. Data cards and checklists are also utilized in the report to obtain a document package suitable for future use. 
FIRM

Infra-Red Energy Surveys

No. 23

Box 654

Needham, Massachusetts 02192

CONTACT

Joseph McCarthy

(617) $449-3790$

\section{Infrared Scanning Equipment}

AGA Thermovision 750

Barnes Thermatrace

Daedalus Vanscan

FLIR Systems 100

Hughes Probeye 650

Inframetrics 510

Residential Surveys Performed $\square$

Thermogram Record Format

\begin{tabular}{l|l} 
Polaroid Photograph__ & \\
$35 \mathrm{~mm}$ Film & \\
Video Tape & $\checkmark$ \\
Black-White & \\
Color &
\end{tabular}

Survey Procedure

Interior Scans

Exterior Scans

(Using Mobile Van)

Report Contents

Thermograms

Control Photographs

Defects Analysis

Recommended Action
Industrial Surveys Performed

Thermogram Record Format

\begin{tabular}{l|l} 
Polaroid Photograph__ & \\
$35 \mathrm{~mm}$ Film & \\
Video Tape & $\checkmark$ \\
Black-White & \\
Color &
\end{tabular}

Survey Procedure

Interior Scans

Exterior Scans

(Using Mobile Van)

(Using Helicopter)

Report Contents

Thermograms

Control Photographs

Defects Analysis

Recommended Actions

Summary Report

Full Report.

Audio Tape Report

Video Tape Report

Average Survey Time 8 hours

Average Survey Cost: $\$ 800$
Average Survey Time: $1 \frac{1}{4}$ hours

Average Survey Cost: $\$ 90$

\section{Residential Survey Client Categories}

Homeowner

Municipality

Utility

Building Developer

Community Organization

Industrial Survey Client Categories Industrial Firms

Commercial Firms
$30 \%$

$10 \%$ \begin{tabular}{l|l} 
Public Buildings $\perp 10 \%$ \\
Utilities & $\square$
\end{tabular} 


\section{GENERAL}

Infra-Red Energy Surveys is a Massachusetts based firm providing ground thermal survey services to both residential and non-residential types of clients. Infrared surveys are performed with an Inframetrics Model 510 System. The system has a built-in 4:1 electronic zoom feature which enables the operator to use a wider field of view for initial overall assessment of surface thermal conditions and then to zoom in, i.e., to magnify the display image of a localized area, to obtain more detailed thermal data. A small tape recorder is used to develop a record of observations made during the course of the survey to supplement the thermographic hard copy data. The customer is presented with a folder prepared at the survey site at the conclusion of the inspection, which includes at least four thermograms in a mounted format and a completed form noting the thermal anomalies located, environmental data and notations associated with each thermogram. The survey process is believed capable of detecting even relatively small defects in the building's thermal envelope. Insulation "misses" of only several square inches area have been located as have areas of cold air infiltration through small gaps (1/16) around windows and doors. The current volume of business is considered good while the future volume of business is projected to be very good by this firm.

\section{RESIDENTIAL THERMAL SUR VEYS}

The survey is performed in the evening by appointment; with the owner in attendance, encouraged to follow the operator and occasionally view the thermographic display. Results are presented in a file folder containing mounted annotated thermograms along with a completed report sheet listing the location and severity of thermal anomalies noted.

\section{INDUSTRIAL SUR VEYS}

The building's thermal envelope is evaluated from the structure's interior in a manner generally similar to the residential survey. Industrial surveys are usually made with the additional inspection of heat-generating components, steam lines and traps, electrical switching and distributions systems, etc. The industrial-type survey report is developed in a formal. bound format and additionally includes qualitative and quantitative data. Thermograms are annotated with comments. 
FIRM No. 24

Agatronics Limited/Thermal Chek Cònsulting

5230 South Service Road - Suite 125

Burlington, Ontario

Canada L7L' 5K2

CONTACT

Greg McIntosh, P.E.

(416) $637-5696$

\section{Infrared Scanning Equipment}

AGA Thermovision 750

Barnes Thermatrace

Daedalus Vanscan

FLIR Systems 100

Hughes Probeye 650

Inframetrics 510

Residential Surveys Performed $\square$

Thermogram Record Format

Polaroid Photograph

$35 \mathrm{~mm}$ Film

Video Tape

Black-White

Color

Survey Procedure

Interior Scans

Exterior Scans

(Using Mobile Van)

Report Contents

Thermograms

Control Photographs

Defects Analysis

Recommended Action


V
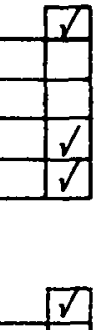

Average Survey Time: 1-2 hours

Average Survey Cost: $\$ 175$
Industrial Surveys Performed

Thermogram Record Format Polaroid Photograph

$35 \mathrm{~mm}$ Film

Video Tape

Black-White

Color

Survey Procedure

Interior Scans

Exterior Scans

(Using Mobile Van)

(Using Helicopter)

Report Contents

Thermograms

Control Photographs

Defects Analysis:

Recommended Actions

Summary Report

Full Report

Audio: Tape Report

Video Tape Report

Average Survey Time 1 week

Average Survey Costz $\$ 5,000$

Residential Survey Client Categories
Homeowner
Municipality
Utility.
Building Developer
Community Organization

Industrial Survey Client Categories

Industrial Firms

Commercial Firms

Public Buildings

Utilities 


\section{GENERAL}

AGAtronics Limited is a Canada based firm providing both residential and industrial thermal survey services. Surveys are performed with the AGA Thermovision 750 System. The firm uses the registered name THERMALCHEK to identify its established infrared survey procedures and its standardized method of reporting. Thermographic data is provided on Polaroid film in either color or black and white. Survey data recorded includes temperatures, surface emissivities, relative humidity and wind velocity. Data developed includes the calculation of average wall values and specific fault condition values of Temperature Index, such indices being directly relatable to insulation $\mathrm{R}$-value performance.

\section{RESIDENTIAL THERMAL SURVEYS}

Residential surveys are generally performed only from inside the building. A formal report is prepared complete with observations, thermograms and control photographs.

\section{INDUSTRIAL SUR VEYS}

Industrial surveys utilize thermographic data and thermocouple reference temperature calibration to detect areas of heat loss. Wind speeds and emissivities are recorded. The assembled data is reduced and calculations made of radiated and convective heat losses. Estimates are then developed of yearly heat loss values. 







\section{GENERAL}

Helicopter Minit Men, Inc. is a Columbus, Ohio based firm providing both residential and non-residential infrared survey services. Available infrared equipments include the Bofors T101 and AGA Thermovision 750 systems. Surveys are performed either on foot or by the use of a vehicle or helicopter. A standardized report format is used to assemble thermographic data, appropriate control photographs and an analysis of thermal deficiencies noted.

\section{RESIDENTIAL THERMAL SURVEYS}

A residential survey is generally performed from the building interior by scanning all exterior walls and ceilings. The homeowner is present during the survey and observes the thermographic display. Polaroid thermographs and control photos are later given to the homeowner as part of the survey results package.

\section{INDUSTRIAL SUR VEYS}

Industrial thermal surveys are conducted from the interior and exterior of the building structure. Exteritior surveys are further conducted, where required, from either a vehicle or helicopter platform. A standard report format with both thermograms and regular Polaroid photographs attached is used to present survey results. 
FIRM

No. 26

Thermal Services, Inc.

Post Office Box 4171

Wilmington, 'Delaware 19807

CONTACT

George S. Baird

(302) $658-7590$

Infrared Scanning Equipment

AGA Thermovision 750

Barnes Thermatrace

Daedalus Vanscan

FLIR Systems 100

Hughes Probeye 650

- Inframetrics 510

\section{Residential Surveys Performed}

Thermogram Record Format

\begin{tabular}{l|l|}
\hline Polaroid Photograph & \\
$35 \mathrm{~mm}$ Film & \\
Video Tape & \\
Black-White_. & \\
Color &
\end{tabular}

Survey Procedure

Interior Scans

Exterior Scans

(Using Mobile Van)

\section{Report Contents}

Thermograms

Control Photographs

Defects Analysis

Recommended Action

Average Survey Time:

Average Survey Cost:
Industrial Surveys Performed $\square$

Thermogram Record Format

Polaroid Photograph

$35 \mathrm{~mm}$ Film

Video. Tape

Black-White

Color

Survey Procedure

Interior Scans

Exterior Scans

(Using Mobile Van)

(Using Helicopter)

Report Contents

Thermograms

Control Photographs

Defects Analysis

Recommended Actions

Summary Report

Full Report

Audio Tape Report

Video Tape Report

Average Survey Time 1-2 days

Average Sürvey Cost: Estimates

Provided

Residential Survey Client Categories

Homeowner

Municipality

Utility

Building Developer

Community Organization

Industrial Survey Client Categories

Industrial Firms

Commercial Firms

Public Buildings

Utilities 
FIRM Thermal Services, Inc.

No. 26

\section{GENERAL}

Thermal Services, Inc., is a Wilmington, Delaware, based company which primarily conducts industrial thermal surveys. Infrared scans are performed with an Inframetrics 510 Thermal Imaging System which provides both a thermographic display and Polaroid film hard copy capability. This firm uses its high-resolution imaging equipment as a non-destructive testing tool to provide technical services to building owners and managers. Services include preventative maintenance surveys, research and development projects, process troubleshooting; building and equipment energy-loss analyses, and surveys of built-up roof structures. Thermal performance is recorded using either photographs or videotape and is described in a written inspection report. The firm forsees an upward business trend in industrial thermal inspections. 
FIRM

PED Co Thermal, Inc. (Bryant, Inc:)

No. 27

4627 Executive Drive - Suite 101

(Energy Scanners)

Columbus, Ohio 43220

CONTACT

P.E. Martin

(614) 451-9404

Infrared Scanning Equipment

AGA Thermovision 750

Barnes Thermatrace

Daedalus Vanscan

FLIR Systems 100

* Hughes Probeye 650

Inframetries 510

\section{Residential Surveys Performed}

Thermogram Record Format

Polaroid Photograph

$35 \mathrm{~mm}$ Film

Video Tape

Black-White

Color

Survey Procedure

Interior Scans

Exterior Scans

(Using Mobile Van)

\section{Report Contents}

Thermograms

Control Photographs

Defects Analysis

Recommended Action

Average Survey Time:

Average Survey Cost:

\section{Residential Survey Client Categories}

Homeowner

Municipality

Utility

Building Deyeloper

Community Organization

Industrial Survey Client Categories

Industrial Firms

Commercial Firms
Industrial Surveys Performed

I

Thermogram Record Format

Polaroid Photograph

$35 \mathrm{~mm}$ Film

Video Tape

Black-White

Color

Survey Procedure

Interior Scans

Exterior Scans

(Using Mobile Van)

(Using Helicopter)

Report Contents

Thermograms

Control Photographs

Defects Analysis

Recommended Actions

Summary Report

Full Report

Audio Tape Report

Video Tape Report

Average Survey Time $1-3$ days

Average Survey Cost: $\$ 750-\$ 1,500$

Public Buildings D $15 \%$ Utilities 
FIRM PEDCo Thermal Inc. (Bryant, Inc.)

No. 27

\section{GENERAL}

PEDCo Thermal, Inc., is an Energy Scanners affiliate based in Columbus, Ohio, which primarily performs industrial surveys. Infrared surveys are conducted with an AGA Thermovision 750 System which has both thermographic display and Polaroid film hard copy features. Standardized Energy Scanner survey and reporting procedures are used to evaluate heat loss and temperature affecting fault conditions in industrial facilities and equipments. Report contents include Polaroid thermograms, control photographs and an analysis of fault conditions. Recorded data includes temperature, surface emissivities, distance to objects scanned and the location of problem items. Surveys are conducted from both the interior and exterior of building facilities. The indicated current level of business volume is comparable to similar firms in the industrial client category.. The projected volume of business is twice the present level. 


\section{FIRM}

Thermoscan, Inc.

No. 28

Post Office Box 566

(Energy Scanners)

E1mhurst, Illinois 60126

CONTACT

Gene Schultz

(312) 833-1735

\section{Infrared Scanning Equipment}

AGA Thermovision 750

Barnes Thermatrace

Daedalus Vanscan

FLIR Systems 100

Hughes Probeye 650

Inframetrics $510^{\circ}$

Residential Surveys Performed $\nabla]$

Thermogram Record Format

\begin{tabular}{l|l}
\cline { 2 - 2 } Polaroid Photograph & \\
35mm Film & \\
Video Tape & \\
Black-White & \\
Color &
\end{tabular}

Survey Procedure

Interior Scans

Exterior Scans

(Using Mobile Van)

Report Contents

Thermograms

Control Photographs

Defects Analysis

Recommended Action

Average Survey Time: 2 hours

Average Survey Cost: $\$ 100$
Industrial Surveys Performed [D]

Thermogram Record Format

Polaroid Photograph

$35 \mathrm{~mm}$ Film

Video Tape

Black-White

Color

Survey Procedure

Interior Scans

Exterior Scans

(Using Mobile Van)

(Using Helicopter)

\section{Report Contents}

Thermograms

Control Photographs

Defects Analysis

Recommended Actions

Summary Report

Full Report

Audio Tape Report

- Video Tape Report

Average Survey Time $1-10$ days

Average Survey Cost: Estimates

Residential Survey Client Categories

Homeowner

Municipality

Utility

Building Developer

Community Organization

Industrial Survey Client Categories

Industrial Firms

7) $60 \%$

Commercial Firms

Public Buildings

Utilities 


\section{GENERAL}

Thermoscan, Inc., is an Illinois based Energy Scanners affiliate which performs both residential and industrial types of thermographic surveys. Infrared scans are done with an AGA Thermovision 750 System having both thermographic display and Polaroid film output capabilities. Energy Scanners standardized procedures for survey conduct and report preparation are used. Additional data recorded includes climatic conditions and other information, depending on customer needs. Data presented to the client includes thermograms, control photographs, report cards and commentary. Video tape is also available for industrial client reporting.

\section{RESIDENTIAL THERMAL SURVEYS}

The average time to perform the survey includes 1 hour at the homeowner site and 1 hour at the office for report compilation. Average cost of a residential survey is $\$ 100$ plus. The infrared survey is conducted from inside the home. The report to the homeowner will include Polaroids, report cards and commentary.

\section{INDUSTRIAL SURVEYS}

Specific procedures for conducting industrial surveys will vary depending upon customer needs. The resultant report may include, in addition to the above report elements, a video tape of recorded thermograms. The typical time to perform an industrial survey can range from 1 to 10 days. Cost of a survey will depend on the specific type of thermal survey, amount of quantification and the depth of analysis required by the client. 


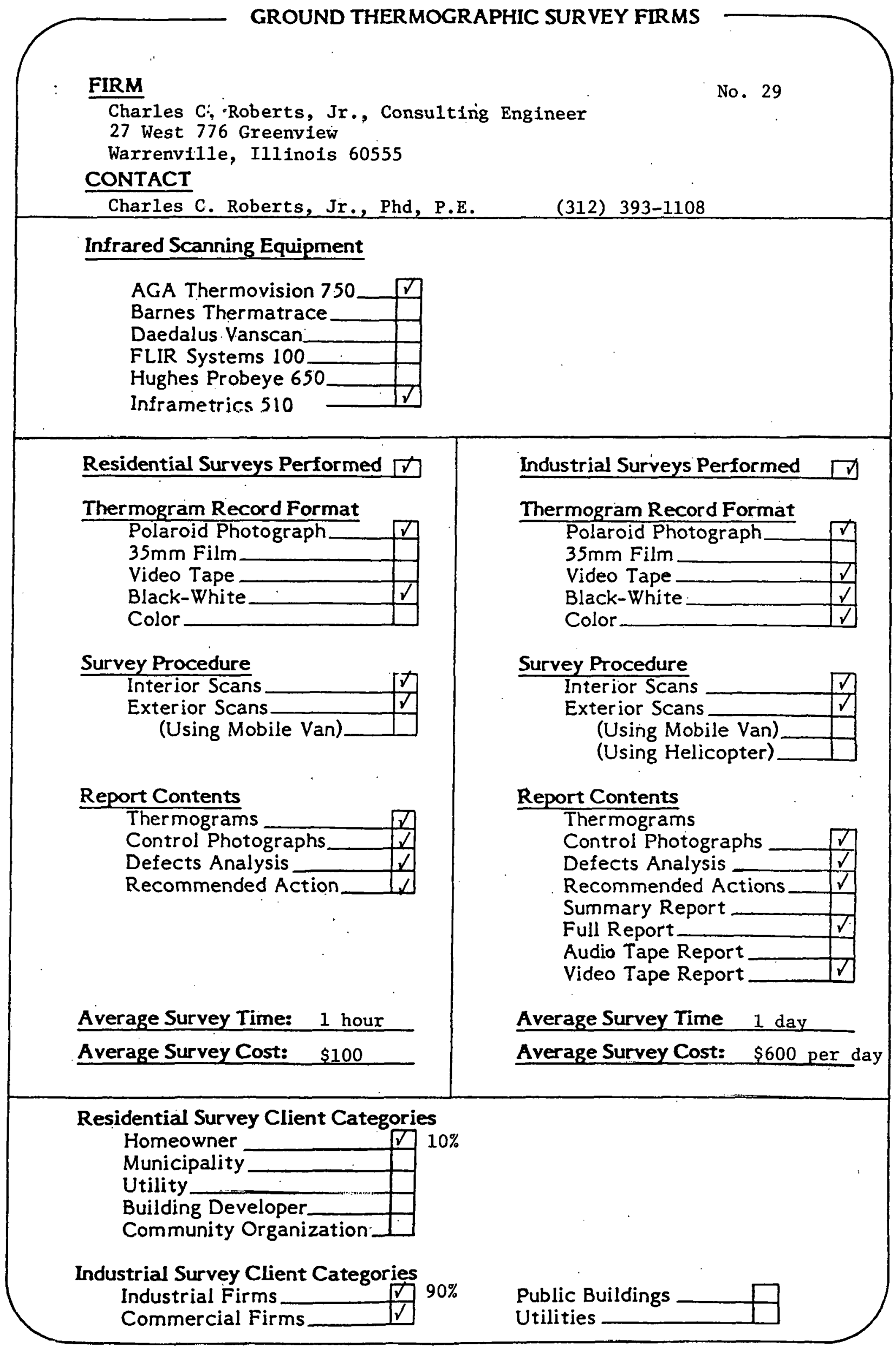




\section{GENERAL}

Charles C. Roberts, Jr., is a consulting engineering firm based in Warrenville, Illinois which performs both residential and industrial types of thermographic surveys. AGA Thermovision 750 and Inframetrics 510 thermal imaging systems are used for infrared surveys. Color and black-white thermographic imagery is available and can be provided as hard copy in either Polaroid film or video tape forms. Additional data recorded during ground survey includes temperature, windspeed and direction, and humidity. The general survey procedure utilizes infrared scanning for obtaining a general thermal view and the performance of semi-quantitative work. Heat flow meters and thermocouples are employed for obtaining detailed thermal data. Computer programs are utilized for data analysis. Levels of data accuracy include: R-values (plus or minus $25 \%$ ), temperatures (plus or minus 1 degree F) and heat flow (plus or minus 20\%). A representative current volume of business is indicated for thermal analysis work. The projection, however, is for a $2 \frac{1}{2}$ times increase in future activity. The indicated future trend is in the industrial market area.

\section{RESIDENTIAL THERMAL SURVEYS}

Average time to perform a residential survey is 1 hour. The average cost of the survey is $\$ 100$. Thermograms, control photographs and the resulting analysis are assembled in a client report.

\section{INDUSTRIAL SURVEYS}

The typical time to perform an industrial survey is 1 day. Average cost of the survey is based upon a rate of $\$ 600$ per day. An industrial survey will involve a walk through of the facility with the energy manager, recording of defects, and presentation of results in the form of thermograms, video tape and a report containing manual and computer developed data. 
FIRM

Infrared Engineers

No. 30

540 Straight Street

Patterson, New Jersey 07503

CONTACT

Roland Straten, P.E.

(201) $274-5500$

Infrared Scanning Equipment

AGA Thermovision 750

Barnes Thermatrace

Daedalus Vanscan

FLIR Systems 100

Hughes Probeye 650 (649) $\checkmark$

Inframetrics 510

Residential Surveys Performed $n$

Thermogram Record Format

Polaroid Photograph

$35 \mathrm{~mm}$ Film

Video Tape

Black-White

Color

Survey Procedure

Interior Scans

Exterior Scans

(Using Mobile Van)

Report Contents

Thermograms

Control Photographs

Defects Analysis

Recommended Action

Average Survey Time: $2-3$ hours

Average Survey Cost: $\$ 100$
Industrial Surveys Performed $\emptyset$

Thermogram Record Format

Polaroid Photograph

$35 \mathrm{~mm}$ Film

Video Tape

Black-White

Color

Survey Procedure

Interior Scans

Exterior Scans

(Using Mobile Van)

(Using Helicopter)

Report Contents

Thermograms

Control Photographs

Defects Analysis

Recommended Actions

Summary Report

Full Report

Audio Tape Report

Video Tape Report

Average Survey Time 1 day

Average Survey Cost: $\$ 500$ per day

\section{Residential Survey Client Categories}

Homeowner

Municipality

Utility

Building Developer

Community Organization

$20 \%$

Industrial Survey Client Categories

Industrial Firms

Commercial Firms

$80 \% \quad$ Public Buildings

Utilities 


\section{GENERAL}

Infrared Engineers is a New. Jersey based firm which provides thermographic inspection services to both residential and industrial clients. Infrared surveys are performed with a Hughes Probeye unit which provides both for operator viewing of a thermographic display and Polaroid film recording. Data recorded as part of the survey includes temperatures, thermograms, fault location and problem description.

\section{RESIDENTIAL THERMAL SURVEYS}

The average time to perform a survey is 2 to 3 hours. Average survey cost is $\$ 100$. Survey data is assembled in a report package containing thermograms, control photographs, faults conditions, and recommended actions:

\section{INDUSTRIAL THERMAL SURVEYS}

Data assembled for industrial surveys is similar to that of residential surveys but will include thermal faults in electrical and mechanical equipments. A complete report is prepared incorporating thermograms, identification photographs and an analysis of noted fault conditions. An industrial survey is typically performed in 1 day. Average survey cost is $\$ 500$ per day. 


\section{c. Index of Available Equipment}

Characteristics of currently available portable ground thermal survey equipments are indicated in the partial listing of Table 5. The list attempts to identify those equipments which are known to be in use for determining the thermal performance of insulation in buildings. Summary descriptions are provided to indicate essential features of such devices, their methods of operation, and major specifications. The equipment source should be contacted for specific information. 


\begin{tabular}{|c|c|c|c|c|c|c|c|}
\hline Manufacturer & Type & $\begin{array}{c}\text { Spectral Range } \\
\text { (microns) }\end{array}$ & $\begin{array}{c}\text { FOV } \\
\text { (degrees) }\end{array}$ & $\begin{array}{l}\text { MRT } \\
\left({ }^{0} \mathrm{C}\right)\end{array}$ & $\begin{array}{l}\text { Temperature } \\
\text { Range }\left({ }^{\circ} \mathrm{C}\right)\end{array}$ & $\begin{array}{l}\text { Display } \\
\text { Type }\end{array}$ & $\begin{array}{c}\text { Cost } \\
\text { (Approximate) }\end{array}$ \\
\hline $\begin{array}{l}\text { AGA } \\
\text { Model } 750\end{array}$ & Imaging & 2 to 5.6 & $20 \times 20$ & $\begin{array}{c}0.2 \text { at } \\
30\end{array}$ & -20 to +900 & CRT & $\$ 40,000$ \\
\hline $\begin{array}{l}\text { Inframetrics } \\
\text { Model } 510\end{array}$ & Imaging & 8 to 11 & $14 \times 18$ & 0.2 & 0 to 100 & CRT & $\$ 30,000$ \\
\hline $\begin{array}{l}\text { Hughes } \\
\text { Probeye }\end{array}$ & Imaging & 2 to 5.6 & $7.5 \times 18$ & $\begin{array}{c}0.1 \text { at } \\
22\end{array}$ & -25 to 850 & Monocular & $\$ 7,000$ \\
\hline $\begin{array}{l}\text { Barnes } \\
\text { TermAtrace }\end{array}$ & $\begin{array}{l}\text { Line } \\
\text { Scanner }\end{array}$ & 3.2 to 20 & $36 \times 36$ & $\begin{array}{c}0.5 \text { at } \\
25\end{array}$ & 0 to 100 & $\begin{array}{l}\text { Visual } \\
\text { Plus Line }\end{array}$ & $\$ 8,000$ \\
\hline $\begin{array}{l}\text { FLIR Systems } \\
\text { Model } 100\end{array}$ & Imaging & 8 to 12 & $21 \times 28$ & $\begin{array}{c}0.4 \text { to } \\
22\end{array}$ & -20 to +600 & Television & $\$ 47,000$ \\
\hline
\end{tabular}

TABLE 5. PORTABLE GROUND THERMAL SURVEY EQUIPMENT 
AGA Corporation

550 County Avenue

Secaucus, New Jersey 07094

\section{Equipment}

Thermovision Model 750

\section{Description}

This portable infrared camera system, functioning like closed circuit television, presents the temperature distribution over a viewed scene. The basic system consists of an infrared camera unit coupled directly to a thermal image display unit. The infrared camera converts infrared tadiation from an object into equivalent video signals which are amplified in the camera before being fed by cable to the display unit. A prism scanning mechanism in the camera scans the object and focuses infrared radiation on a sensitive, liquid nitrogen cooled, detector element. Conventional photographic cameras can be attached to the display unit to permit simultaneous viewing and photorecording of the thermal picture. A color monitor is available as are a wide variety of accessories.

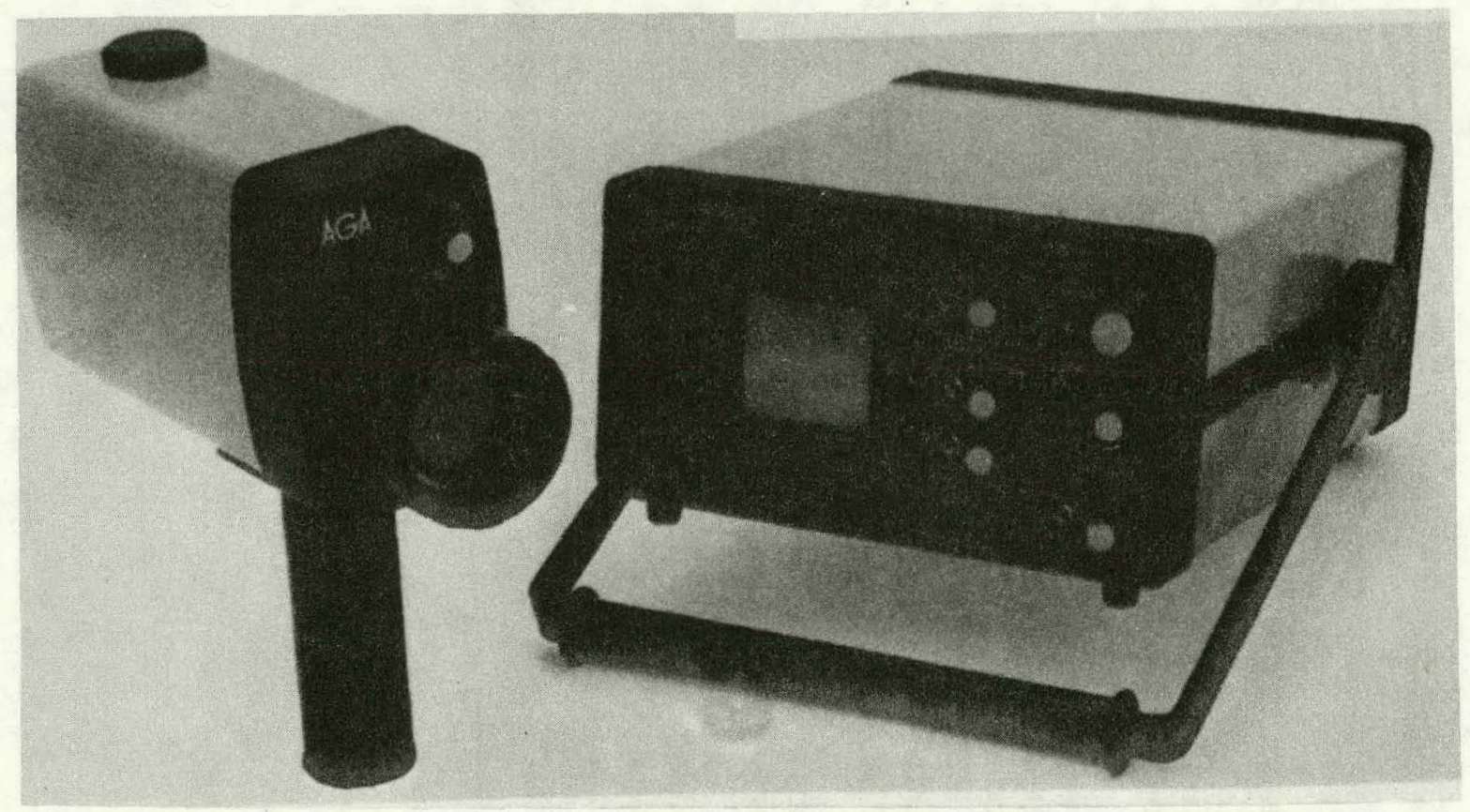




\section{Specifications}

Temperature Measurement Range: $-20^{\circ} \mathrm{C}$ to $+900^{\circ} \mathrm{C}$ Minimum Detectable Temperature: $0.2^{\circ} \mathrm{C}$

Typical Field of View (FOV): $20^{\circ} \times 20^{\circ}$ Instantaneous FOV: 3.4 milliradians Lines per Frame: 280 (interlaced) Resolving Power: 100 picture elements per line Picture Size: $50 \times 45$ millimeters 
Flir Systems, Incorporated

7000 Southwest Hampton Street

Suite 238

Tigard, Oregon 97223

(503) 620-6650

\section{Equipment}

\section{Model 100}

\section{Description}

This is a thermal infrared imaging television system designed to provide high quality imagery. A basic system consists of three portable elements: 1) an infrared sensing module incorporating optics, a scanning cryogenically-cooled detector set and television imaging electronics; 2) a sensor and display control module; and 3) a standard television monitor. The Thermal Television (TTV) sensor and display control system produces thirty television frames per second image data. The TTV is self-contained, light-weight and intended for use in either fixed or portable applications. The signal output can be directly coupled to any standard type of television equipment, e.g., displays, special effects generations, television transmission systems and video analysis devices, eithout requiring additional television scan conversion accessories.






\section{Specifications}

Temperature Measurement Range: $-20^{\circ} \mathrm{C}$ to $+600^{\circ} \mathrm{C}$

Minimum Resolvable Temperature Difference: $0.4^{\circ} \mathrm{C}$ @ $0.27 \mathrm{cycles} / \mathrm{mrad}$ Typical Field of View (FOV): $21^{\circ} \times 28^{\circ}$ Instantaneous FOV: 1.8 milliradians Lines per Frame: 525

Resolving Power: 400 picture elements per line Picture Size: Selectable ( 9 inch television screen typical) 
Inframetrics, Incorporated

225 Crescent Street

Waltham, Massachusetts 02154

(617) $275-8990$

\section{Equipment}

Model 510

\section{Description}

This portable infrared thermal imaging system consists of a basic camera unit and a display unit. With scanning mirrors and a sensitive liquid cooled detector, a scene is scanned and the naturally emitted infrared radiation is converted into a television-like heat picture. Temperature differences in the scene are indicated by the level of brightness in the picture. In normal image operation, black is cold and white is hot. The basic system includes an infrared camera unit, a control unit and display unit, a battery case with battery, and a Polaroid photographic camera assembly. Available accessories include a TV compatibility circuit, a color monitor and a video tape recorder.

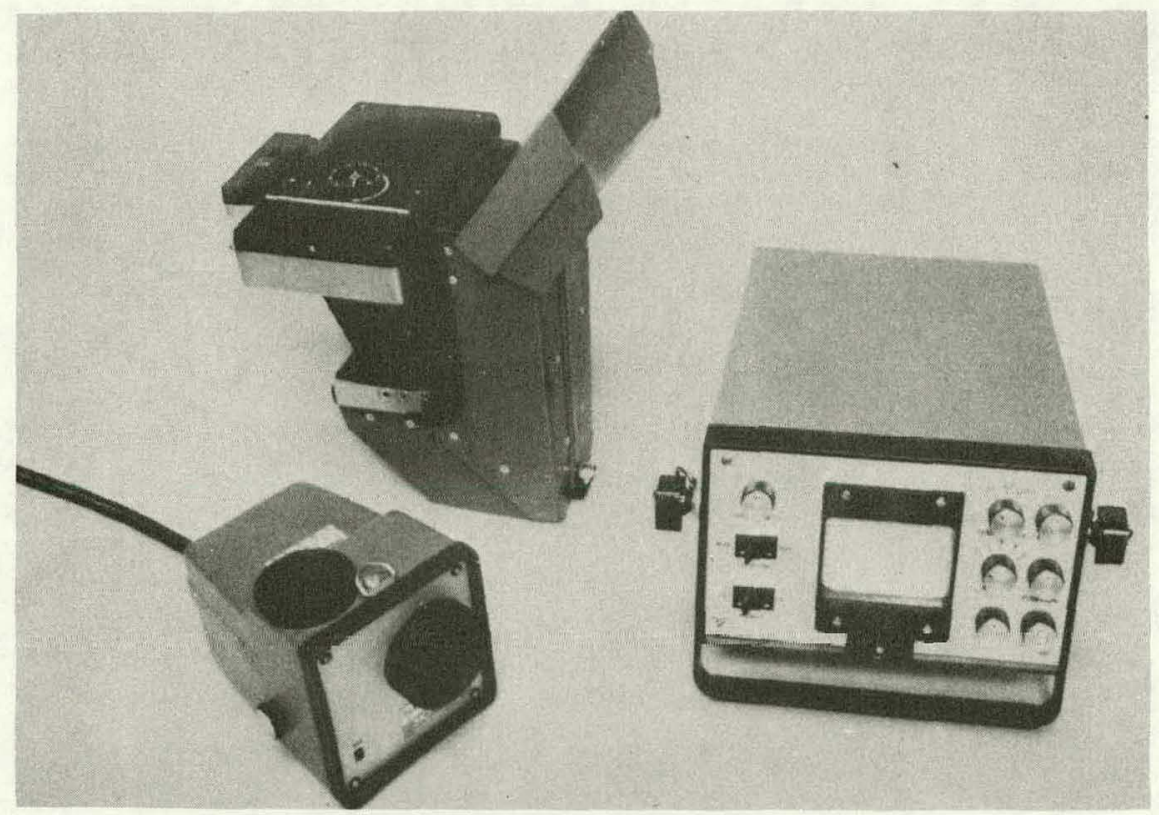




\title{
Specifications
}

\author{
Temperature Measurement Range: $-20^{\circ}$ to $200^{\circ} \mathrm{C}$ \\ Minimum Detectable Temperature: $0.2^{\circ} \mathrm{C}$ \\ Typical Field of View: $14^{\circ} \times 18^{\circ}$ \\ Lines per Frame: 180
}

Resolving Power: 150-plus picture elements per line Picture Size: $2.1 \times 2.8$ inches Spectral Range: 8 to 12 microns Detector Coolant: Liquid Nitrogen 
Hughes Aircraft Company

Industrial Products Division

6155 El Camino Real

Carlsbad, California 92008

(714) 438-9191

\section{Equipment}

Probeye Model 560

\section{$\underline{\text { Description }}$}

This hand-held, portable thermal imager is a monocular device which views a scene and converts the infrared radiation to visible light, producing a TV-like image. The instrument accepts an argon cylinder (for cooling the detectors) and uses a 10segment, double-sided, rotating mirror with 6 LEDs to give a 60-line scan image. The hottest objects appear bright red, ronler areas black. $\Lambda$ Folaroid cannera accessory is available.

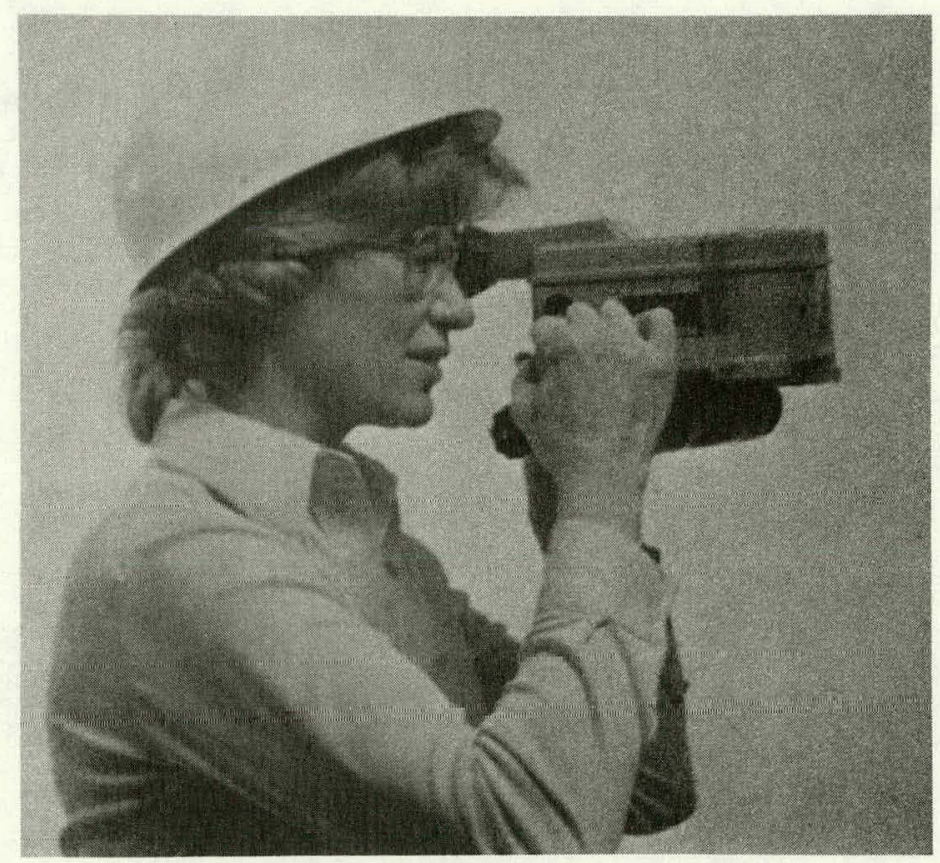




\section{Specifications}

Field of View: $18^{\circ}$ Horizontal by $7.5^{\circ}$ vertical Temperature Resolution: $0.1^{\circ} \mathrm{C}$ at $22^{\circ} \mathrm{C}$ Controls: Power, Focus, Brightness, Contrast Cryostat Coolant: Argon 
Barnes Engineering Company

30 Commerce Road

Stamford, Connecticut 06904

(203) 348-5381

\section{Equipment}

\section{Barnes ThermAtrace}

\section{Description}

This single line thermal scanning instrument permits one to view a scene and see superimposed on it a thermal line scan. This line scan or A-trace represents the temperature distribution along a single line. The device uses a scanning mirror which is transparent to visible light, thus permitting scene viewing, but reflects infrared energy which is then focused on a sensitive infrared detector. The resulting electronic signal drives an LED display and illuminates a display element in proportion to the temperature of the target. The reflected image of the display element from the rotating mirror appears to the viewer as a red A-trace superimposed over the visible scene. Equipment accessories include a Polaroid camera and spare battery pack.

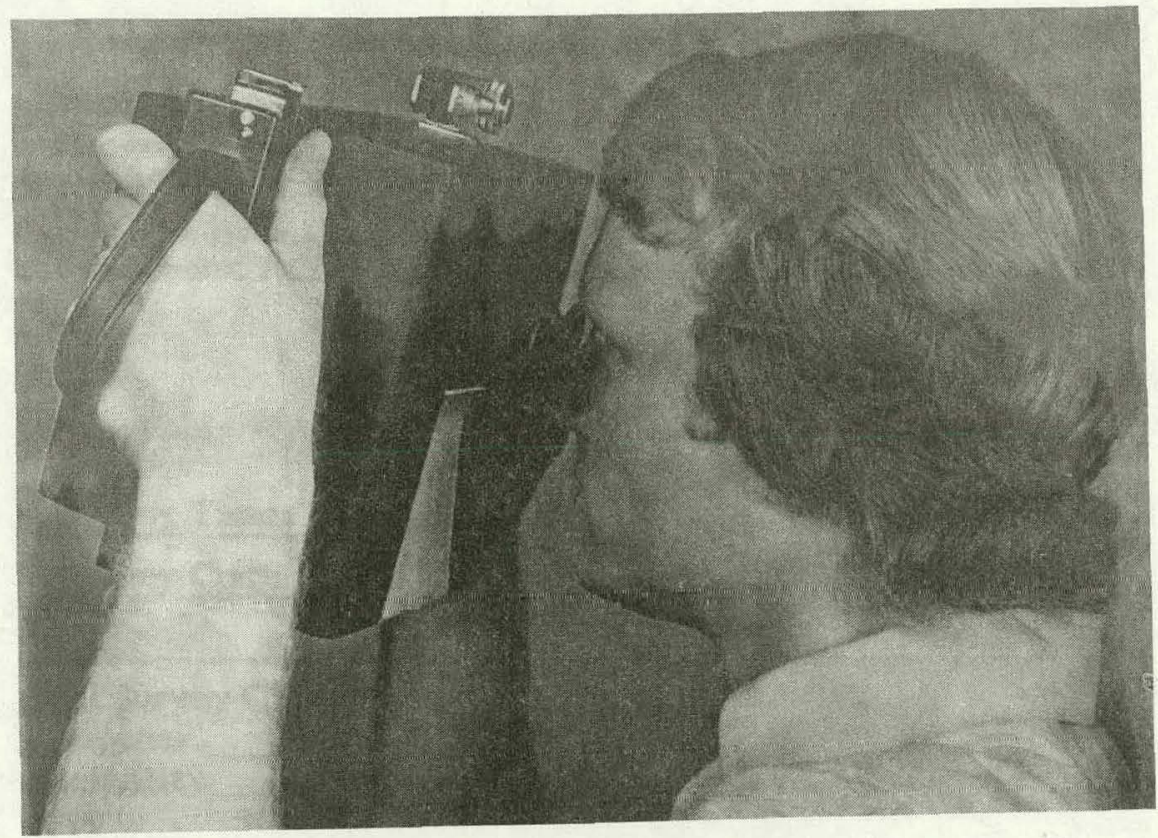




\section{Specifications}

Temperature Measurement Range: $10^{\circ} \mathrm{C}$ to $1000^{\circ} \mathrm{C}$ Minimum Detectable Temperature: $0.5^{\circ} \mathrm{C}$ at $25^{\circ} \mathrm{C}$

Field of View (IR): $24^{\circ} \times 0.5^{\circ}$

Instantaneous Field of View (IR): $0.25^{\circ} \mathrm{W} \times 0.5^{\circ} \mathrm{H}$

Field of View (Film): $36^{\circ} \times 36^{\circ}$

Vertical Display: 32 elements

Resolution: 3 percent of full scale

Spectral Range: 3.2 to 20 microns 
THIS PAGE

WAS INTENTIONALLY

LEFT BLANK 
SECTION 3

GROUND SURVEYS

SPOT RADIOMETERS 


\section{3 - GROUND SUR VEYS SPOT RADIOMETERS}

Spot radiometers are not generally used alone in the performance of thermal surveys. They are used to check for insulation voids at specific locations. When used by survey firms, their application is in conjunction with previously discussed (Section 2) imaging or line scanning equipment.

This section covers the use of spot radiometers in ground thermal surveys and other related applications. It includes a summary of the capabilities of equipments which may be used in currently performied surveys, a list of companies that use spot radiometers as a regular part of surveys, and an index of available equipment.

a. Demonstrated Capabilities

\section{Survey Application}

A spot radiometer is a relatively simple and compact device (often provided with a pistol grip handle), which is aimed at a wall location to obtain a measure of apparent radiance temperature. When used in thermal survey work, the device is held close to the wall, typically 1 to 4 feet. In such applications, it is used to supplement a thermal imaging or line scanning device. Spot radiometers incorporate a temperature indicating display and may additionally provide an audio signal whose tone varies with measured temperature to facilitate a search for thermal anomalies. With most devices, the temperature measurement is essentially an average value within a wall spot diameter of less than three inches at a distance of four feet. This capability is considered adequate: Not all available devices, however, have the minimum thermal resolution capability considered necessary to performing gross insulation resistance determinations. The current trend is to require temperature resolutions of $0.5^{\circ} \mathrm{C}$ or better, whereas different product specifications indicate values ranging from $0.2^{\circ} \mathrm{C}$ to $2^{\circ} \mathrm{C}$. Within the above constraints, spot radiometers are useful accessories to the performance of ground thermal surveys with either thermal imagers or line scanners. 


\section{Non-Survey Application}

Spot radiometers, when used alone, are not recommended for conducting surveys. They can be used to perform local spot checks to detect the presence or absence of thermal insulation in a building component. They may also be used to determine the local apparent thermal resistance of a component of the building. However, the same constraints indicated above still apply.

\section{b. Companies that Provide Surveys}

As indicated previously, companies do not generally use spot radiometers alone in the performance of thermal surveys. The ground survey company summaries contained in Section $2 \mathrm{~b}$ identify those firms who included spot radiometers in their response on equipments used.

Such devices are used alone by firms engaged in the retrofit installation of blown and foam-in-place insulation for quality control purposes. In this application, spot radiometers having adequate spatial and thermal resolutions, and when used by knowledgeable instrument operators, can be effective for locating insulation voids which are to be corrected or which were missed during the correction process. Firms in this category are not included in this report.

\section{c. Index of Available Equipment}

Characteristics of currently available infrared temperature measurement equipments are indicated in the partial listing of Table 6. The list attempts to identify those devices which have been advertised as suitable for checking building insulation effectiveness, as an aid to the location of voids in thermal insulation, or simply as non-contact infrared thermometers. Summary descriptions are provided to indicate essential features of such devices and major specifications. The equipment source should be contacted for specific.information. 




TABLE 6. SPOT RADIOMETERS 
Barnes Engineering Company

30 Commerce Road

Stamford, Connecticut 06904

(203) 348-5381

\section{Equipment}

\section{Model 14-220-1 Instatherm}

\section{Description}

This pocket-sized, hand-held, non-contact temperature measuring instrument uses a built-in optical sight for precise target location. The instrument collects infrared energy emitted by an object, and the electrical signal generated by the sensitive thermal detector is amplified to drive a meter that reads out directly in degrees centigrade. This model has a temperature range of -10 to $60^{\circ} \mathrm{C}$. The visual field of view (FOV) is 30 degrees and the infrared FOV is 2.8 degrees. Instrument sensitivity is $0.2^{\circ} \mathrm{C}$ at $20^{\circ} \mathrm{C}$. Spectral response is 6.5 to 20 microns. An audible energy level indicator accessory is available.




3M Company - New Business Ventures Division

3M Center

Saint Paul, Minnesota 55101

\section{Equipment}

Heat Scanner Model 201M

\section{Description}

This pistol grip type of hand held non-contact device is sensitive to small differences in temperature. The device detects infrared radiation to aid in location of voids in thermal insulation or poor weatherstripping. Object temperature can be any value from $-40^{\circ} \mathrm{F}$ to more than $4000^{\circ} \mathrm{F}$. The meter display has center-based coolor/warmer indicator with a switch which enables selection of high or low (ratio of 10:1) sensitivity levels. The field of view is 28 degrees. Spectral response is 1 to 35 microns. To detect differences in temperature across a surface, scanning rate of 1 to 4 feet per second is recommended.




Mikron Instrument Company, Inc.

Post Office Box 211

Ridgewood, New Jersey 07451

(201) $891-7330$

\section{Equipment}

Mikron Model 15A Infrared Thermometer

\section{Description}

This hand held pistol grip type non-contact thermometer for heat loss measurements is used to check building insulation effectiveness. The dual temperature range meter display provides for either indoor temperature levels $\left(50^{\circ} \mathrm{F}\right.$ to $\left.100^{\circ} \mathrm{F}\right)$ or outdoor levels $\left(-20^{\circ} \mathrm{F}\right.$ to $\left.130^{\circ} \mathrm{F}\right)$. Its resolution is $1.5^{\circ} \mathrm{F}$. The device incorporates features for adjustment with respect to a reference thermometer. The field of view is 2 degrees. Spectral response is 8 to 14 microns, with 7 to 20 micron range also available.

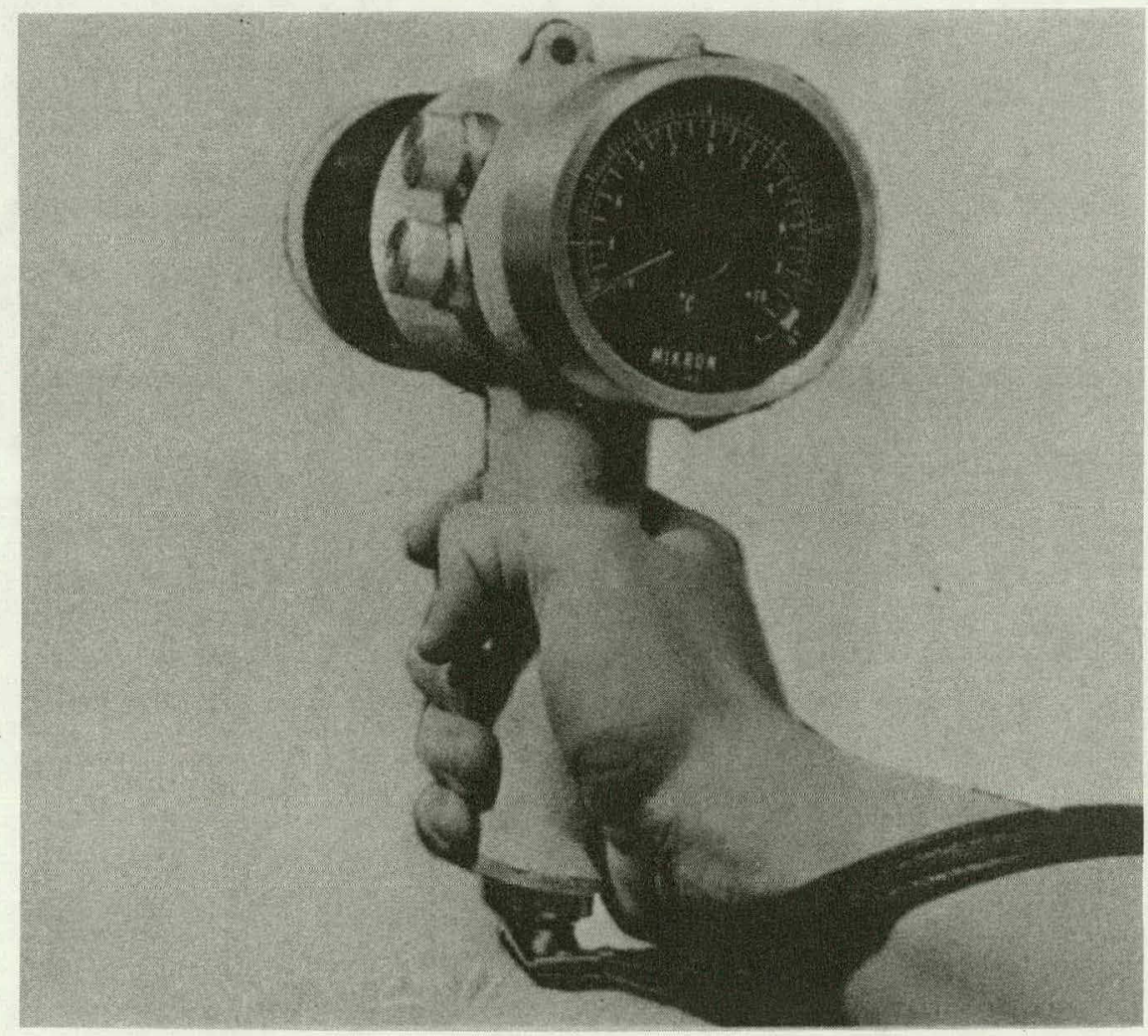


William Wahl Corporation

12908 Panama Street

Los Angeles, California 90066

(213) 822-6144

\section{Equipment}

Heat Spy Model DHS-14P

\section{Description}

This hand-held, non-contact, infrared detecting type of thermometer is used for measuring surface temperatures. It is available in a variety of temperature range models with either meter deflection or digital readout displays. This model has an LED digital display. Its temperature range is $0-600^{\circ} \mathrm{F}$, with accuracy of $\pm 0.5 \%$ Full Scale or \pm 1 digit (RMS). The target size is 2 inches diameter at distance of 0 to 4 feet.

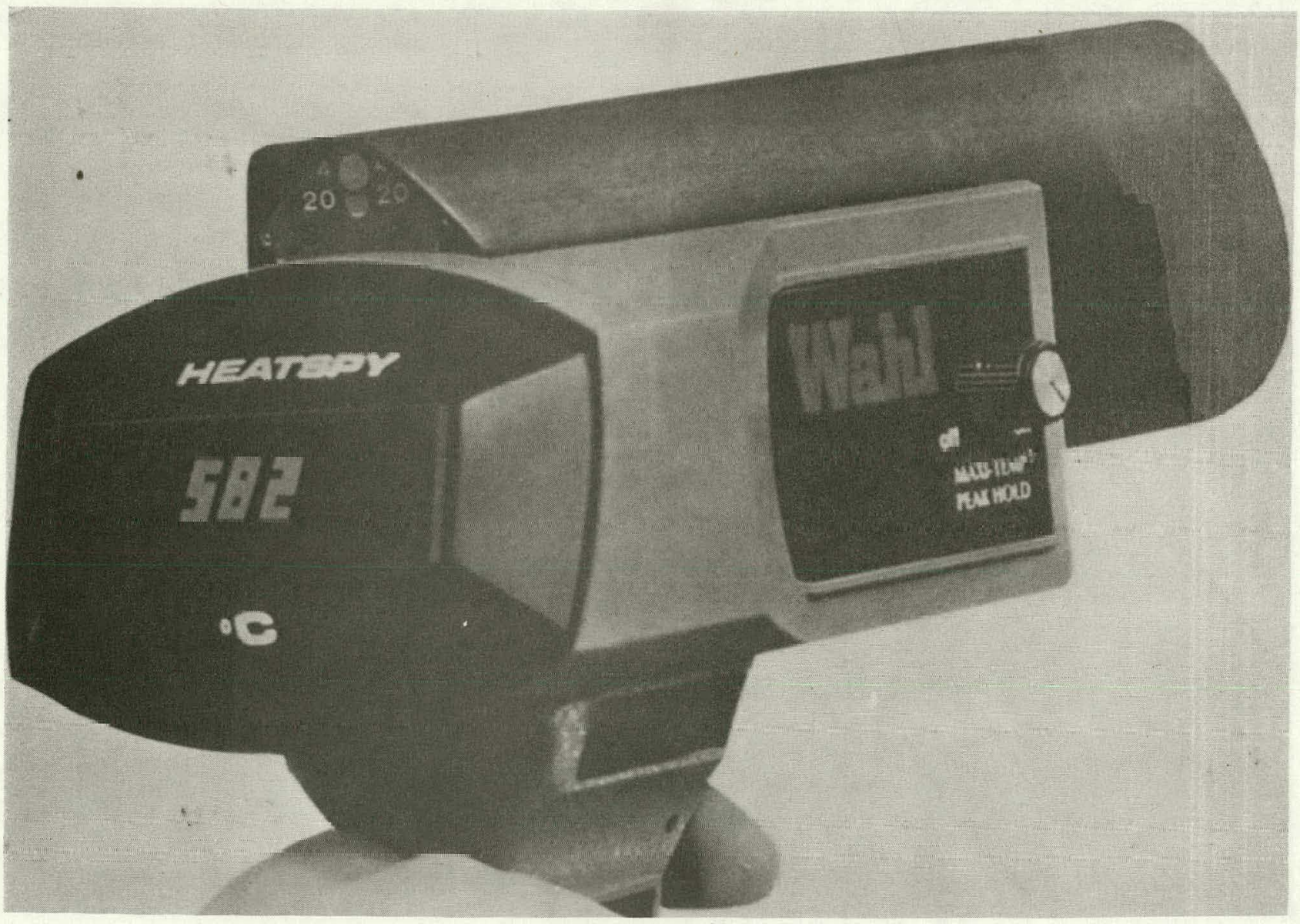


Raytek Division, Optical Coating Laboratory, Inc.

325 East Middlefield Road

Mountain View, California 94043

(415) $961-1650$

(800) $227-8074$

\section{Equipment}

Raynger Model R380RV

\section{Description}

This pistol grip type of hand held infrared thermometer for non-contact temperature measurement is used to obtain insulation performance indications. Apparent surface temperatures of walls, ceilings, floors, doors and roofs are measured simply by aiming at the surface and pulling the trigger. The device operates on two scales. The indoor scale reads from $50^{\circ} \mathrm{F}$ to $100^{\circ} \mathrm{F}$ and is sensitive enough to detect a temperature change of $0.5^{\circ} \mathrm{F}$. The outdoor scale reads from $-20^{\circ} \mathrm{F}$ to $+150^{\circ} \mathrm{F}$ and has a reading sensitivity of $2^{\circ} \mathrm{F}$. The field of view is 4 degrees. Spectral response is 8 to 14 microns.

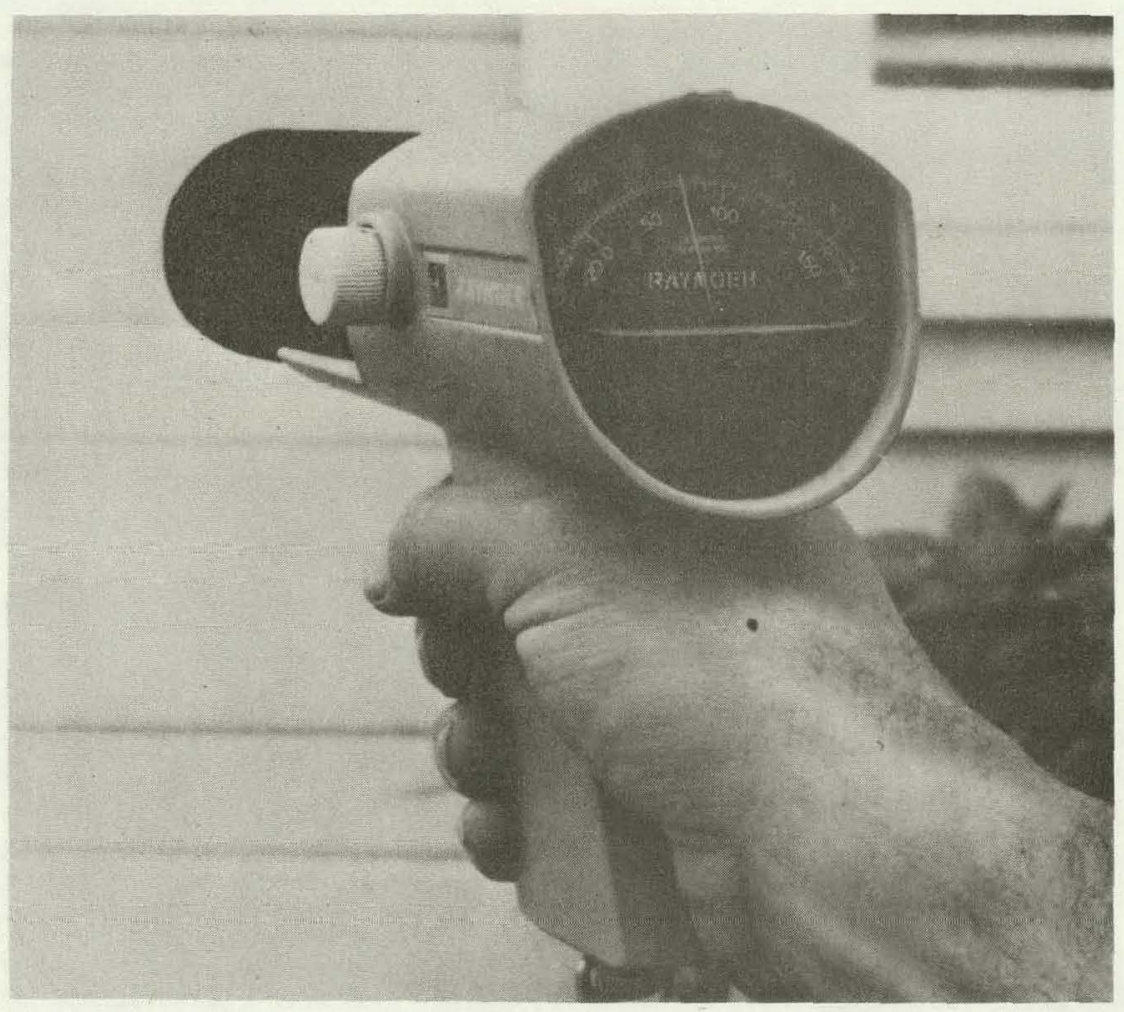


THIS PAGE

\section{WAS INTENTIONALLY \\ LEFT BLANK}


1

-

1

SECTION 4

APPLICATION NEEDS

167 


\section{4 - APPLICATION NEEDS}

There are a number of areas in which further work should be done if the full potential of thermal survey technology is to be realized. Conclusions herein are drawn from information acquired during performance of this assessment, including questionnaire responses provided by aerial survey sponsors, discussions with equipment manufacturers and survey service organizations, a review of applicable literature, and participation in many discussons with members of the ASHRAE Standard Project Committee (SPC-10IP) assembled to create a first procedural standard for this new technology.

\section{a. Standards-ASHR AE/ STM}

\section{ASHRAE}

There is growing interest in the application of infrared sensing devices to assessment of building heat loss characteristics. In response to this emerging demand, a variety of equipment and survey service firms are becoming available. Due to the wide technology gaps which occur between equipment designers, users, and the public to whom survey services are provided, there is a need for the development and promulgation of standardized survey procedures. In response to this need, the American Society of Heating, Refrigerating and Air-Conditioning Engineers (ASHRAE) is currently preparing a Preliminary Draft Standard (SPC10IP) which identifies equipment performance requirements, necessary environmental conditions, and data which should be obtained and recorded to enable proper interpretation of survey data. The draft standard also attempts to identify limits to the expected accuracy of survey results. A final version of the draft standard has been prepared during this assessment update period and is presently undergoing the last stages of technical content review and revision required by ASHRAE before submission of the document to public review. The document is currently identified as Draft Standard 101P - Application of Intrared Sensing Devices to the Assessment of Building Hcat Loss Characteristics. The standard is structured according to five major categories whose sequence indicates increasing levels of detailed thermographic data capability:

\footnotetext{
- Imaging, Airborne Survey

- $\quad$ Non-Imaging Spot Radiometer
} 
- Imaging, Exterior Survey

- Imaging, Interior Survey

As this standard is intended to provide only overall guidance for the performance of thermal surveys, there remains a need for the identification of measurement. techniques which will enable the determination of results beyond qualitative levels. There is also a need for further refinement of standardized measurement procedures to enable data interpretation which is less affected by individual equipment operator differences.

\section{ASTM}

The American Society for Testing and Materials (ASTM) Subcommittee C16.30 on Thermal Measurements includes a task group on Test Methods for In Situ Testing, Section 7. Its primary purpose is the development of measurement procedures for evaluating in situ the performance of insulation systems. Four subtask groups were formed to make-up this Section:

7.1 o Infrared Inspection Task Group

7.2 - Heat Flux Transducers Task Group

7.3 - Portable Hot Box Task Group

7.4 - Dynamic Performance Characterization Task Group

The Infrared Inspection Task Group is developing standard practices for utilizing IR imaging as both an independent qualitative measuring device and as a potential complementing instrument for locating heat flow meters and/or portable hot boxes for more quantitative evaluations of insulation systems. The Heat Flux Transducers Task Group and the Portable Hot Box Transducers Task Group are concentrating on calibration procedures and standard measurement practices while the Dynamic Performance Characterization Task Group is evaluating dynamic models for wall performance to provide guidelines for in situ measurements which insure proper consideration of the dynamic characteristics of the inside and outside environment.

Each is concerned with a different type of hardware and will be develuping test procedures for situations best suited for the capabilities of that type equipment. A major task of the committee is the selection and evaluation of candidate 
mathematical models for predicting insulation system U-values. Preliminary model assessment will include performing sensitivity analyses to determine the accuracies and precisions that will be required of the three types of hardware.

The standards development activities of both ASHRAE and ASTM establish a need for training personnel to properly perform thermal surveys. Preliminary studies are now required to determine required skill levels appropriate to a given standard. A subsequent need is the formulation of training programs which will provide operators with certifiable levels of competency to perform surveys. 


\section{b. Environmental Effects on Data Collection}

There is a need to identify the effects of typically encountered environmental conditions on survey data. Currently used procedures for thermal survey data interpretation require, in addition to sufficiently large temperature differentials between the building interior and exterior, that specified environmental conditions be met.

Airborne surveys require that sky conditions be homogeneous, either clear or solid overcast, in order to permit a more uniform spatial and temporal radiation exchange to occur between building rooftops and the local environment. Such conditions reduce the uncertainty in data interpretation. The need to meet these conditions, however, can restrict considerably the occasions on which survey flights can be performed and complicate attempts to schedule them. Further knowledge of the effects of non-ideal sky conditions would increase the number of reliable survey flights.

Airborne surveys generally require that the surface wind speed be less than $20 \mathrm{MPH}$ when surveying flat roof industrial type buildings and less than $5 \mathrm{MPH}$ for pitched residential búildings. Even when performed near these limits, accurate data interpretation is dependent on the use of limited accuracy correction curve data. Expanded knowledge of the effects of wind and associated development of analytical procedures would enhance survey accuracy.

Building exterior ground surveys are similarly impacted by the above environmental effects. Data interpretation for both exterior ground and airborne surveys is also affected by site factors such as shading, sun loading, and nearby shrubs and trees which can function as natural radiative sources. Although there currently exists a general understanding of such environmental effects on data collection, there remains a need for assembling information useful to thermal survey performance.

\section{c. Building Material Characteristics}

Variations in apparent temperature are interpreted as building component surface temperature changes when they may actually be caused by changes in material emissivity, i.e., how well that surface radiates thermal energy. Aerial 
surveys, although potentially cost-effective because of the large number of buildings included in each flight, can be particularly degraded if building rooftop material emissivities are not accurately known. As an example of a case of potential error in survey data, two surfaces, such as asphalt and aluminum, having the same temperature but different emissivities, would appear to have very different temperatures on a thermal image.

There currently exists a relatively limited body of practical information on building material emissivities. In most instances, the work that has been done in determining such data has been limited in material types and often has not considered emissivity variations with viewing angle. Data intcrpretation would be enhanced by the availability and proper application of information on material characteristics. In the case of aerial surveys, where specific roof materials are not usually known, there is the additional requirement for the develnpment of in-flight techniques which can indicate emissivity values in the surveyed scene in conjunction with the thermal scanning process.

A data base on the thermal inertia characteristics of building materials is needed. Buildings subjected to extensive sun-loading during the day may necessitate delays of four to six or more hours after sundown before infrared measurements are made if high thermal inertia materials are present. If measurements are made without sufficient delay time, exterior building survey data may be erroneously interpreted as indicating high building thermal loss due to inadequate insulation. 


\section{d. Consensus on Heat Loss Models}

A variety of heat loss models currently exist. Many however, are unverified and require validation if they are to be useful tools for supporting thermal surveys. Such models also differ in a number of respects. These differences include approximations made to reduce the complexity of analytical expressions; assumptions made as to which parameters are to be considered fixed, variable or negligible; and, in a number of instances, the range within which the model is valid. As a result, models suitable for their original purpose are not acceptable to different users. This is the situation in the relatively new area of thermal survey data interpretation. The present need is to assemble and evaluate potentially applicable models and subsequently, to develop the desired consensus.

\section{e. Inexpensive Instrumentation}

There is a general need for reduction in the cost of thermal survey instrumentation although the basis of the need varies with equipment and application. In the case of aerial survey firms, it is a matter of original equipment investment. For ground survey firms, it may still be a matter of initial investment for a small one- or two-person firm. The need for price reductions in quality spot radiometers has a different basis, i.e., the potential requirement for large quantity purchases by individual agencies and organizations conducting energy audit type programs.

The hardware used in the performance of aerial thermographic surveys is sophlsticated and costly with scanner equipment prices in the range of $\$ 100,000$ to $\$ 250,000$. However, no production level demand has been currently indicated to encourage aerial scanner cost reductions. Entrance of firms into the airborne survey market may be enhanced if investment costs in such equipments were reduced.

Ground survey firms can require an initial equipment investment of $\$ 30,000$ to $\$ 40,000$ for thermal imagers incorporating television-type displays with hardcopy outputs. Although these initial costs are substantially below that for aerial survey firms, they can be barriers to the formation of a small business. An additional problem facing ground survey firms is that of covering their labor costs. This is 
because the nature of the business is labor intensive, i.e., the major cost factors are marketing, transportation of equipment to and from each building site, and survey execution. Responses from such firms indicate that residential survey charges in excess of $\$ 100$ are often necessary to defray unit service costs. Such charges can discourage survey sales. Firms have recently indicated a trend away from residential and towards commercial and industrial building surveys because fixed cost allocations have less impact on a large scale service.

Spot radiometers are available at prices ranging from $\$ 300$ to $\$ 1,200$. The more expensive units are generally more suitable for insulation performance measurement because of the better thermal and spatial resolution they can provide. The need for inexpensive quality instrumentation in this category is not due so much to their individual purchase by firms for use as survey aids, but by the potential for large quantity purchases by gas and electric power utilities or agencies considering their use as part of larger scale energy audit or conservation service prngrams: The availability of inexpensive spot radiometers to these organizations would reduce the total cost of conducting such programs.

\section{f. Quantitative Measures - "R" Values}

There is a need for the development of techniques for obtaining quantitative measures of thermal insulation performance. Discussions conducted with members of the ASHRAE committee have indicated that currently available measurement techniques should be considered as suitable primarily for the identification of potential thermal anomalies in the case of aerial surveys, and for gross insulation measurements in the case of ground surveys. In the latter category, this corresponds to an equipment capability limited to enabling an operator (performing an interior survey) to distinguish between $R-5$ and $R-15$ levels of insulation performance, or between $\mathrm{R}-10$ and $\mathrm{R}-15$ where a larger indoor-outdoor temperature difference prevails.

The further development of analytical and procedural techniques for the performance of thermal surveys is needed if even nominal $R$-value determinations are to be made under expected conditions of measurement. An essential aspect of thermal imaging technique development is the determination of what image detail is required to provide a specified level of survey measurement accuracy. 


\section{g. Public Awareness}

The public's awareness of thermal imaging technology as an aid to conservation is still relatively limited to communities where some form of local initiative has been taken. Exceptions to this are states like Minnesota and lowa which have begun programs of aerial thermal surveys intended ultimately to include all of their communities. Such homeowner-targeted projects typically consist of performing a community aerial survey in conjunction with a planned program of information dissemination to homeowners. The intent is to develop homeowner interest in a community-wide conservation effort including follow-up energy audits of residences, installation of additional insulation, and other active contributions to National Energy Plan goals. Industrial and institutional organizations, particularly those having extensive facilities, have also begun to conduct aerial surveys and to develop their own corporate programs of thermal loss surveying. On a national scale, however, industrial awareness of the cost benefit of this technology appears uncertain.

Current needs in this area include the preparation and dissemination of information on the benefits of thermal surveys through mechanisms which include workshops, conferences and various types of publications. These would necessarily be structured to meet the potential needs of different target categories, i.e., community leaders, public utilities, state energy agencies, business and the consumer public. 


\section{5 - INFRARED PROJECTS OF THE DOE BUILDING DIAGNOSTICS PROGRAM}

\section{Objectives}

The broad objectives of the Building Diagnostics Program are to identify, develop, demonstrate and commercialize cost effective methods of evaluating the energy efficiency of buildings and their energy consuming components. Approaches and equipment capable of performing rapid onsite evaluation of a structure's performance are being identified and tested. The specific purpose of this program area is to provide consumers, equipment vendors, building inspectors, building auditors, and energy survey companies with inexpensive methods of obtaining energy data, evaluating the overall affects of energy conservation options, and making decisions based on good, reliable economic and engineering data.

The program objectives will be realized by identifying the mechanisms of thermal loss in buildings, and determining their relative importance to energy conservation; by identifying existing instrumentation for measuring these losses, or the need for either new instrumentation and methodologies or a reduction in cost and complexity of the existing ones; by developing methods for making the diagnostic hardware and software available to the public; and by demonstrating the use and benefits to be derived from using these methods on a national scale.

\section{Projects}

One technology area being investigated by DOE under the diagnostics program is the use of infrared (IR) thermal surveys for detecting heat losses/gains in buildings. This technology is presently used in a qualitative manner for detecting poor workmanship, faults in insulation, and areas of air infiltration, areas of major heat losses through windows, ventilating ducts, etc. The following projects are aimed at demonstrating the present worth of both aerial and ground IR surveys, and identifying to what extent this technology can be utilized as a quantitative diagnostic tool.

Thermal Imaging Applications: (existing project: DCS Corporation). The contractor has prepared a report entitled "Status of Thermal Imaging Technology as Applied to Conservation". This report summarizes the activities presently underway in buth ground and aerial IR data measurement programs. This compilation of work- 
done-to-date will be helpful to DOE in determining future program direction and to others interested in the conservation applications of infrared.

Aerial IR Users' Manual: (project completed: Remote Sensing Institute and the Minnesota Energy Agency). This project has produced a manual that outlines the requirements, pitfalls, limitations, and expected results from an aerial infrared survey program. The quality of heat loss data obtainable through this technique and methods of obtaining this data are discussed. The manual is a helpful tool for state and local executives in making a decision on whether an aerial IR program is appropriate in their area, and in assisting those who are attempting to initiate such a program.

Aerial Measurement of Heat Loss: (existing project: New York State Energy Research and Development Administration, and Calspan Corporation). The primary objective of this activity is to evaluate two methods of determining true surface temperature from airborne IR thermographic data of buildings. These methods include the Bi-Band Ratioing method and the Photometric Material Identification method. This work will also provide measured values of IR thermal emittance for common building materials, an assessment of the degree of accuracy required for values of surface emittance in aerial determination of true surface temperatures, and an error analysis of the parameters involved in determining true surface temperatures.

Model Heat Loss with Aerial Thermography: (existing project: Energy Measures Corporation). This effort evaluated the degree of accuracy of an algorithm developed by the Energy Measures Corporation, for estimating heat loss from buildings utilizing high resolution IR thermography and aerial photography. This quick and inexpensive method of interpreting IR data, if shown to be accurate, would offer the consumer a quantitative estimate of the heat loss from building roofs, sidewalls, and windows. This work also investigated the relationship of thermal profiles of structures obtained by aerial imaging to ground-level surveys and what electro-mechanical devices could be employed to increase the precision of IR data interpretations.

Evaluation of Handheld 'Infrared Thermometer for " $R$ " Value Measurement: (project completed: National Bureau of Standards). Various handheld IR noncontact thermometers were tested to evaluate their effectiveness in determining the $R$ value of walls. Two phases of the test were performed: first a laboratory test of a woodframe wall under controlled steady state and dynamic conditions, followed by a 
field test of a brick veneer wall. Tests were also conducted for comparative purposes utilizing thermopiles and heat flow meters. The results show substantial errors associated with predicting' actual "R" values of walls utilizing these techniques. However, the use of these spot radiometers as a qualitative measuring device is very . feasible.

Cost Effectiveness of Remote Sensing Thermal Ground Based Surveys for Housing Retrofit: (existing project: National Bureau of Standards, and the New England Innovation Group). The purpose of this effort is to establish the cost effectiveness of IR thermographic and other remote sensing thermal ground surveys for different equipment types, climate zones, and other factors. The Community Services. Administration's weatherization demonstration program is being utilized as the test bed for this effort. Various techniques for conducting IR ground surveys will be tested and analyzed. The surveys will be made by private local contractors.

ASHRAE Standard 101P: (existing project: American Society for Heating, Refrigeration, Air Conditioning Engineers). This project is in support of an ASHRAE subcommittee presently developing Standard 101P "Acceptable Procedures for Applied. Use of IR Devices for Assessment of Building Heat Loss or Heat Gain Characteristics and Interpretation of Resulting Data". This ASHRAE standard is to be distributed for comment in 1980.

Diagnostic Instrumentation Kits: (completed project: Princeton University). This project identified low cost probes and instrumentation that could be utilized in evaluating sources of energy loss in the home, simplified procedures for home energy audits including the requirements for a training program to involve the intereted homeowner. 


\section{APPENDIX}

This appendix is included to make available some new information which was obtained after the report was submitted for its review and publication cycle. 
THIS PAGE

WAS INTENTIONALLY

LEFT BLANK 
AERIAL THERMOGRAPHIC SURVEY FIRMS 
Calspan Advanced Technology Center

P.O. Box 400

Buffalo, New York 14225

(716) 632-7500

Calspan Corporation conducts aerial infrared thermal surveys to evaluate heat loss

- from residential, businesș and industrial communities. They also provide thermal survey information for use in water resource management programs. Calspan's services include planning and execution of survey flights, preparation of thermal imagery, quantitative data analysis, and dissemination of thermal dara. Tralning seminars are also available, in conjunction with data dissemination programs, to instruct users in objective thermogram interpretation employing quantitative analytical techniques. 
AERIAL SUR VEX PROGRAM DESCRIPTIONS

. 
SPONSOR: $\quad$ Syracuse University, Space and Facilities Systems

Syracuse, New York 13210

SUR VEY LOCATION: Syracuse Campus

SURVEY FLIGHTS: March 1977 and March 1979

Syracuse University contracted with Calspan. University in March 1977 to do an aerial survey of the university steam station and distribution system. The purpose of the survey was the identification of steam system leaks and/or insulation problems. In addition to the aerial photos and corresponding thermograms; the final products included a quantitative analysis of the level of heat loss frum each length of pipe and each manhole. Based on the results of the initial survey, repairs were undertaken dind a follow-up aerial scan was conducted in March 1979 to evaluate the remedial efforts. New areas of heat loss were also identified at this time. The sponsors became aware of the aerial surveys from discussions with other university personnel. 
SUR VEY LOCATION: 13 State-Owned Facilities in New York

SURVEY FLIGHTS: March, April 1979

New York State ERDA and the State Energy Office jointly contracted Calspan Corporation to conduct an aerial infrared survey of 13. State facilities to evaluate heat loss from rooftops. Quantitative analytical techniques were employed to provide sponsors with objective methods for thermogram interpretation. Data were presented in a report format with black and white photo and thermal imagery. The reports, designed to be used as training manuals, provided step-by-step instruction in the use of the analytical techniques. In addition to the reports, Calspan conducted an information seminar for facility engineers to discuss the results of the thermal survey and any problems particular to their facilities. The State sponsors became aware of the aerial surveys as a result of previous thermal research work which they had sponsored.at Calspan. 
SPONSOR: $\quad$ Sterling-Winthrop Research Institute

Albany, New York

SUR VEY LOCATION: Sterling-Winthrop Laboratories and Research Facilities, Albany SURVEY FLIGHT: February 1980

Sterling-Winthrop contracted with Calspan Corporation to conduct an aerial infrared survey of its facilities at Albany, New York. The purpose of the survey was to evaluate heat loss levels and possible insulation faults in their manufacturing and research buildings. The data were provided as thermograms in a report format, accompanied by a descriptive analysis and a quantitative method for objective interpretation of the thermal imagery. Sponsor personnel were also invited to Calspan to discilss the 'survey results and to learn the use of the quantitative techniques. The sponsors first became aware of infrared surveys from a newspaper article. 